\title{
AMBIVALENCE IN THE LEADER-FOLLOWER RELATIONSHIP: DISPOSITIONAL ANTECEDENTS AND EFFECTS ON \\ WORK-RELATED WELL-BEING
}

\author{
By \\ YU HAN
}

\begin{abstract}
A dissertation
submitted to the Faculty of Graduate and Postdoctoral Affairs in partial fulfillment of the requirements

for the degree of

Doctor of Philosophy

in

Management
\end{abstract}

Carleton University

Ottawa, Ontario

C)2020

Yu Han 


\begin{abstract}
Although ambivalence is a long-standing topic of interest in the social sciences, leadermember exchange (LMX) ambivalence and other measures of ambivalence in work settings have only recently attracted attention in the Management literature. To enhance our understanding of the nature of LMX ambivalence, this research investigated specific dispositional antecedents of LMX ambivalence, and whether and how it may influence employee work-related well-being. Using a two-wave design, survey data were collected from employees and their supervisors in a large public organization. Results revealed that specific personality traits, including both supervisor dominance- and prestige-seeking and employee hostility, were significant predictors of LMX ambivalence. Furthermore, LMX ambivalence was found to be significantly associated with two focal measures of work-related well-being: work engagement and emotional exhaustion. Moderated mediation analyses indicated that these relationships were mediated by employee psychological need fulfillment; however, these effects were contingent on two moderating factors - employee collectivism, and perceived meaning in one's work. Overall, these results suggest that supervisor and subordinate dispositional characteristics may contribute to the development of LMX ambivalence. Moreover, complementing previous work (Lee et al., 2019), these findings signal that LMX ambivalence contributes unique variance in predicting key employee work outcomes beyond traditional operationalizations of LMX. Further research is needed testing the nomological net surrounding LMX ambivalence, and when and how LMX ambivalence affects different employee attitudes and behaviors.
\end{abstract}




\section{ACKNOWLEDGEMENTS}

Firstly, I would like to thank my committee members, Dr. Irene Lu and Dr. Sefa Hayibor, for their very helpful comments. They have offered very valuable advice from the time I started writing the research proposal to the completion of this dissertation. I would also like to thank my internal examiner, Dr. Kate Dupré, for her very helpful feedback and thought-provoking suggestions for future research, and my external examiner, Dr. David Richards, for sharing his time and expertise and for his very constructive critique of the dissertation.

I would like to express my most sincere gratitude to my supervisor, Dr. Greg Sears, for his encouragement, feedback, and support throughout the course of my doctoral studies. He has been a great mentor, and I have learned a lot from him about research and academic life. I would not have started my academic career without his help and guidance. I look forward to continuing to work with him in the future. I also extend a special thanks to Dr. Eddy Ng for involving me in various research projects over the years and for also being a great source of warmth and support.

I would like to thank the professors, academic staff, and my colleagues at the Sprott School of Business, who have made it a very supportive culture in which to undertake a $\mathrm{PhD}$. I would like to thank Melissa Doric for her guidance and assistance regarding the administrative end of this project. I convey my sincere appreciation to Aareni Uruthirapathy, Dora Wang, Paul Hope, and Qi Deng for their friendship and support. I am also very grateful to Sunjeev Prakash for his help and guidance with the data collection, and I wish to thank Haydee Sears for her assistance with the design of the surveys.

Finally, I would like to thank my family - my parents, and husband - for their patience and understanding. Thank you for the enormous amount of support that you have provided. 


\section{TABLE OF CONTENTS}

ABSTRACT

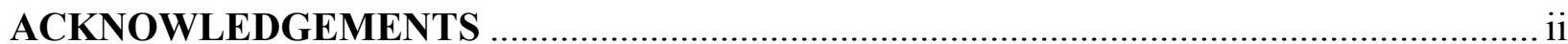

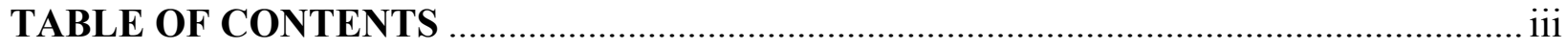

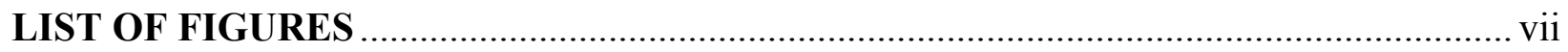

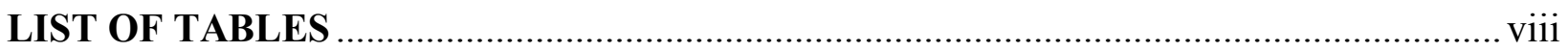

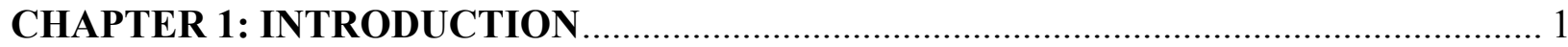

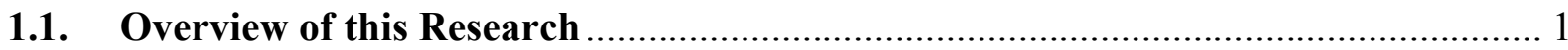

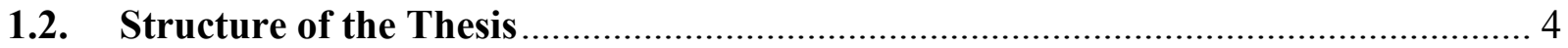

CHAPTER 2: RELATIONAL LEADERSHIP AND AMBIVALENCE: LITERATURE

REVIEW

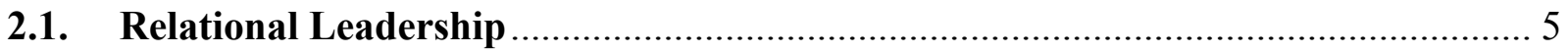

2.2. Leader-Member Exchange (LMX) Theory …..................................................... 7

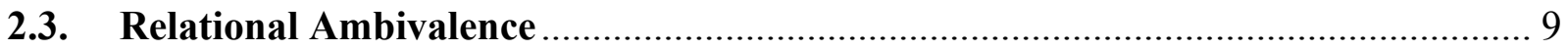

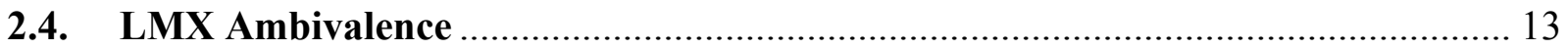

CHAPTER 3: ANTECEDENTS OF LMX AMBIVALENCE ..................................... 18

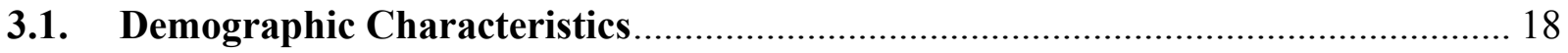

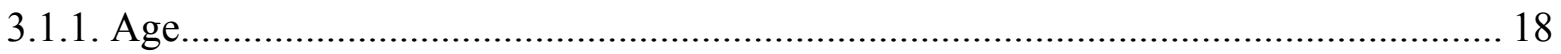

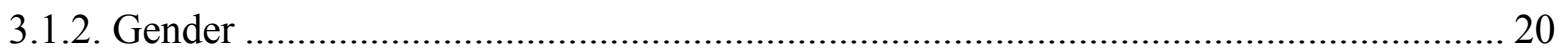

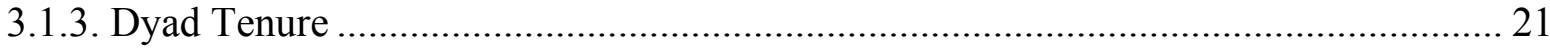

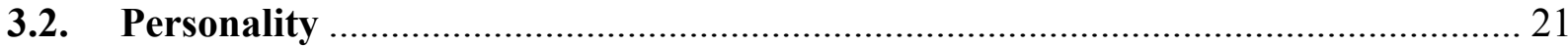


3.2.1. Emotional Stability

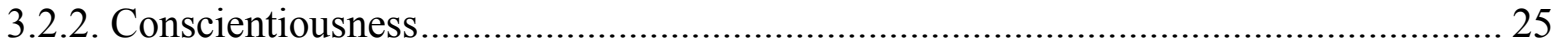

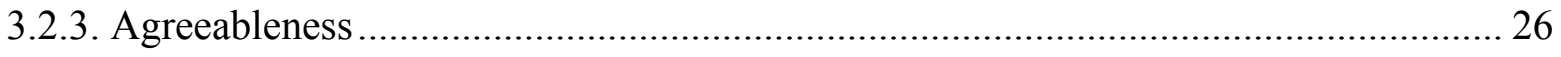

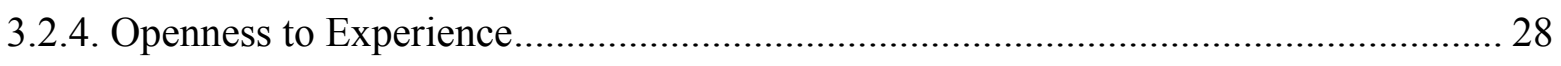

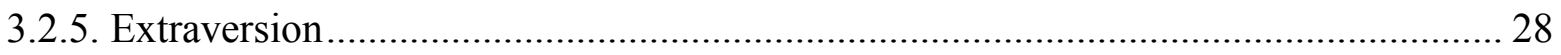

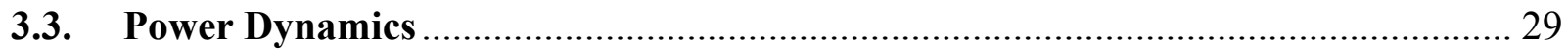

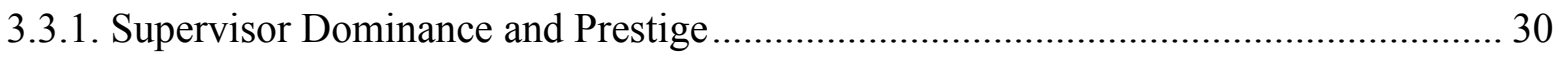

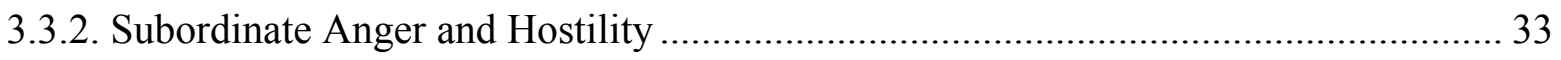

CHAPTER 4: LMX AMBIVALENCE AND WORKPLACE WELL-BEING ……............... 36

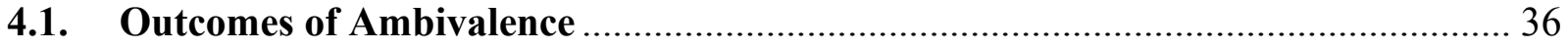

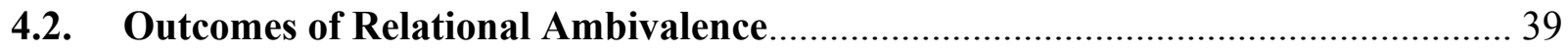

4.3. LMX Ambivalence and Work-related Well-being ................................................... 41

4.4. LMX Ambivalence, Need Fulfillment, and Work-related Well-being .................... 44

4.4.1. LMX Ambivalence and Need Fulfillment at Work ....................................................... 45

4.4.2. The Mediating Role of Need Fulfillment at Work ...................................................... 48

4.5. Moderating Effects of Collectivism and Positive Meaning in Work ....................... 51

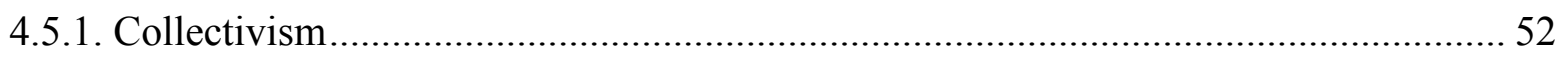

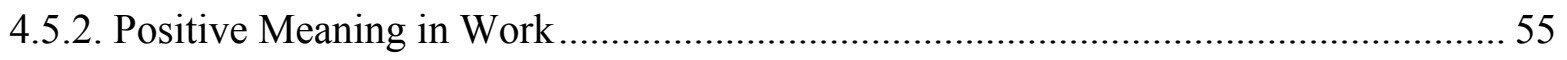

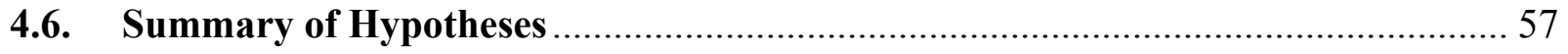

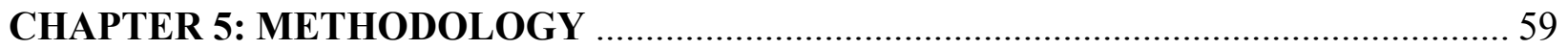




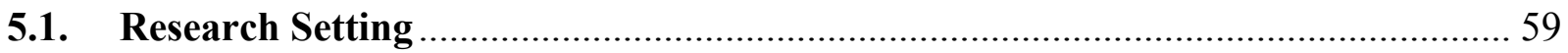

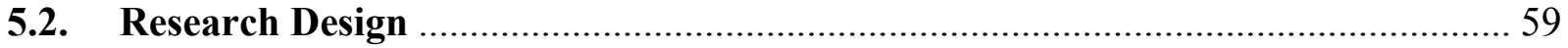

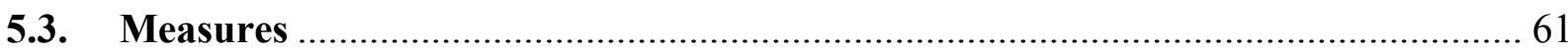

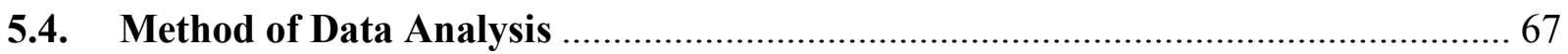

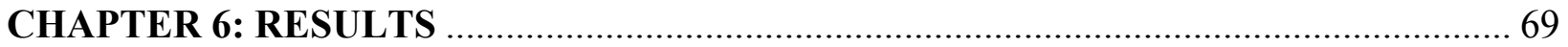

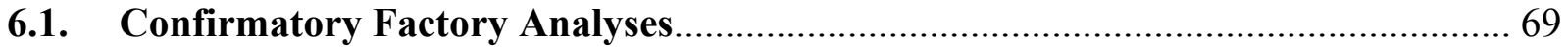

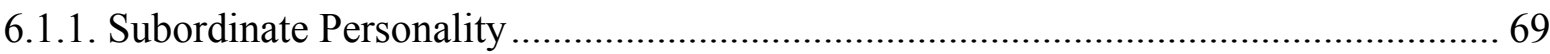

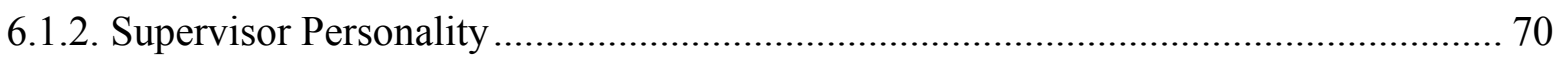

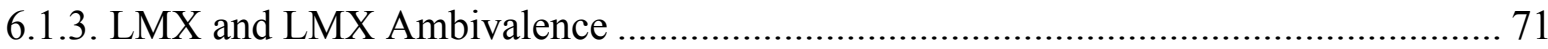

6.1.4. Perceptual Variables in Moderated Mediation Model.................................................. 71

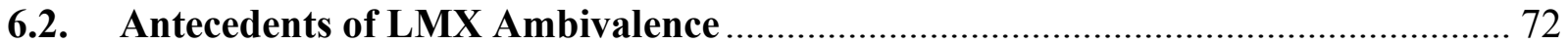

6.2.1. Descriptive Statistics and Zero-order Correlations ................................................. 72

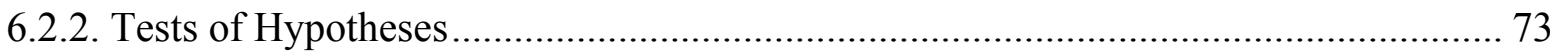

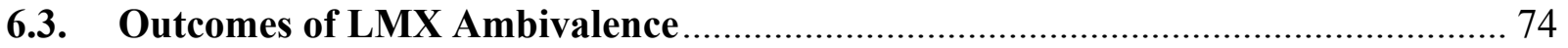

6.3.1. Descriptive Statistics and Zero-order Correlations ..................................................... 74

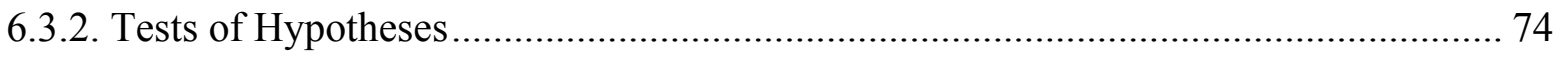

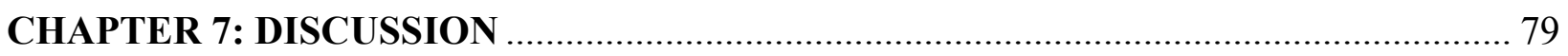

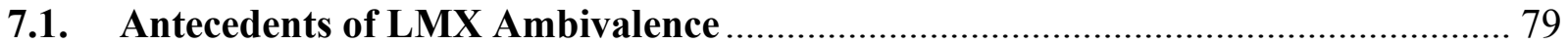

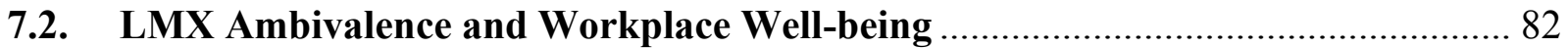

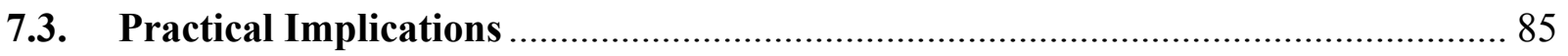




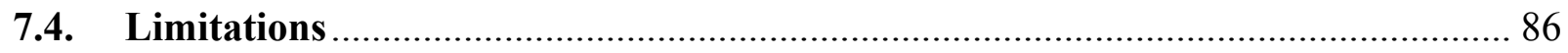

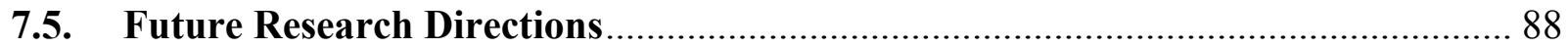

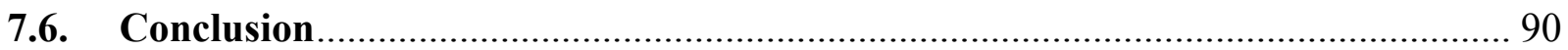

REFERENCES

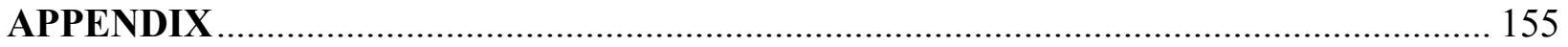




\section{LIST OF FIGURES}

Figure 1: Antecedents of LMX Ambivalence

Figure 2: Moderated Mediation Model of the LMX Ambivalence - Work-related Well-

being Relationship

Figure 3: Moderating Role of Collectivism on Relationship between LMX Ambivalence and Need Fulfillment at Work

Figure 4: Moderating Role of Positive Meaning on Relationship between LMX Ambivalence and Need Fulfillment at Work 


\section{LIST OF TABLES}

Table 1: Summary of Hypotheses

Table 2: Confirmatory Factor Analysis on Subordinate Personality Variables 143

Table 3: Confirmatory Factor Analysis on Supervisor Personality Variables 143

Table 4: Confirmatory Factor Analysis on LMX Quality and LMX Ambivalence 144

Table 5: Confirmatory Factor Analysis of Perceptual Variables in the Moderated 144

Table 6: Means, Standard Deviations and Zero-order Correlations of the Variables in Model 1F 145

Table 7: Results of Multiple Regression Analysis of Subordinate Variables on LMX

Ambivalence 146

Table 8: Results of Multiple Regression Analysis of Supervisor Variables on LMX Ambivalence

Table 9: Means, Standard Deviations and Zero-order Correlations of the Variables in Model 2

Table 10: Results of LMX Ambivalence -Work Engagement Mediation Model 149

Table 11: Results of Moderated Mediation Model: LMX Ambivalence $\times$ Collectivism and Positive Meaning on Work Engagement 150

Table 12: Results of Moderated Mediation Analyses for Work Engagement

Table 13: Results of LMX Ambivalence -Emotional Exhaustion Mediation Model....... 152

Table 14: Results of Moderated Mediation Model: LMX Ambivalence $\times$ Collectivism and Positive Meaning on Emotional Exhaustion 153

Table 15: Results of Moderated Mediation Analyses on Emotional Exhaustion 154 


\section{CHAPTER 1: INTRODUCTION}

\subsection{Overview of this Research}

The experience of ambivalence is pervasive in organizations (Ashforth, Rogers, Pratt \& Pradies, 2014). Individuals can hold coexisting positive and negative thoughts towards their relationships with their employers, coworkers, and leaders (Lee, Thomas, Martin \& Guillaume, 2019). Despite the pervasiveness of ambivalence in the workplace, feelings of ambivalence are not generally captured in measures of relational constructs in organizations. Until recently, only one study conducted by Lee et al. (2019) has attempted to evaluate ambivalence in the context of leader-follower relationships. Rooted in principles of social exchange (Blau, 1964) and role theory (Kahn, Wolfe, Quihn, Snoek, \& Rosenthal, 1964), leader-member exchange (LMX) theory has become the most prominent theory of relational leadership (Uhl-Bien, 2006). LMX theory emphasizes the reciprocal nature of the relationship between leaders and their followers. As a result of a series of dyadic transactions that occur over time, followers in high LMX relationships experience a number of benefits, including favorable treatment from their leader (i.e., more socio-emotional and instrumental support) and more career growth opportunities (Bauer \& Erdogan, 2015). However, researchers have recently suggested that LMX relationships may not just be univalent in nature (i.e., "high-quality" or "low-quality"). LMX relationships can also be bivalent, in which a dyad member may simultaneously hold positive and negative views regarding their relationships with their leader (Lee et al., 2019).

In a seminal study in this area, Lee and colleagues (2019) introduced the concept of "LMX ambivalence", providing valuable evidence of the existence of ambivalence in leaderfollower relationships. In this study, Lee and colleagues developed a measure of LMX ambivalence and demonstrated that LMX ambivalence is negatively associated with employee 
task performance. They argued and found that LMX ambivalence may negatively influence employee performance by eliciting negative affect, which may compromise task performance. This pioneering work highlights the value of the concept of LMX ambivalence and its potential to shed further light on the nature and impact of leader-follower relationships in organizations. However, additional research is needed exploring the mechanisms that contribute to the development of LMX ambivalence (Lee, 2016; Lee et al., 2019). Research has indicated that some people are more likely to experience inconsistent cognitions than others (Conner \& Sparks, 2002; Methot, Melwani \& Rothman, 2017; Rusbult \& Van Lange, 2003); however, to the best of my knowledge, there is no study explicitly examining the antecedents of LMX ambivalence. In response to this need to further elucidate the nature of LMX ambivalence and the nomological net surrounding this construct, this research explores specific individual-level antecedents of LMX. Specifically, both leader and follower demographic factors and personality characteristics are examined as potential antecedents of LMX ambivalence.

Building on Lee et al.'s (2019) study examining LMX ambivalence in relation to task performance, the second purpose of the study is to provide an empirical test of the link between LMX ambivalence and employee work-related well-being. Researchers have argued that ambivalent feelings are aversive because they breach principles of cognitive consistency, leading to feelings of dissonance and discomfort and a consequent need to divert emotional and attentional resources toward coping with this discomfort (Festinger, 1957; Nordgren, Van Harreveld \& Van der Pligt, 2006). Given the interdependent nature of leader-follower relationships and the importance of these relationships for employees (e.g., to acquire resources, to advance in their career), it is proposed that employee perceptions of LMX ambivalence may demonstrably influence their well-being in the workplace. 
Drawing on self-determination theory (SDT, Deci \& Ryan, 1985) and other key theories relating to social cognition and interpersonal interaction (e.g., role theory, cognitive dissonance theory), this research proposes and tests a moderated mediation model in which psychological need fulfillment mediates the influence of LMX ambivalence on employee work-related wellbeing. According to self-determination theory, three fundamental needs (i.e., needs for autonomy, competence, and relatedness) reflect innate psychological nutriments essential to psychological growth, integrity, and well-being (Deci \& Ryan, 1985, 2000). SDT suggests that support for autonomy in the environment enhances one's sense of self-determination and fulfillment of one's basic needs by increasing one's intrinsic motivation and internalized selfregulation (Deci et al., 2001). Leaders play an important role in encouraging and supporting their follower's autonomy. Therefore, psychological need fulfillment has been identified in relational leadership research as a central mechanism explaining how employees' perceptions of their leaders can shape and influence their work-related outcomes (e.g., Chiniara \& Bentein, 2016; Leroy, Anseel, Gardner \& Sels, 2015; Kovjanic, Schuh, \& Jonas, 2013). In this research, LMX ambivalence is expected to negatively influence psychological need fulfillment at work due to heightened cognitive dissonance and disrupted role-making in the leader-follower relationship. This reduced need fulfillment is expected to undermine employee work-related well-being. Given that employees may interpret and respond to ambivalence quite differently depending on their personal attributes (Rothman, Pratt, Rees \& Vogus, 2017), I also posit that two variables one a dispositional variable (collectivism), and the other relating to the perception of one's work (positive meaning in work) - may moderate these relationships. For example, LMX ambivalence is expected to exert a weaker influence on need fulfillment at work for collectivistic individuals as they place a stronger emphasis on their group-level identity and may, therefore, be less readily 
influenced by perceptions of ambivalence toward their leader. Likewise, for an employee who perceives positive meaning in their work, LMX ambivalence is expected to have a less pronounced negative effect on their need fulfillment at work due to the heightened work identity and autonomous motivation that they may experience related to a greater sense of meaning.

Overall, this research attempts to extend LMX theory and prior work on LMX ambivalence by elucidating the role of individual differences in the development of LMX ambivalence and delineating the process mechanisms through which LMX ambivalence influences employee well-being. In this respect, findings from this research are expected to advance our understanding of the LMX ambivalence construct and whether and how it contributes to employee outcomes beyond job performance.

\subsection{Structure of the Thesis}

This thesis consists of seven chapters. The current chapter provides an overview of the thesis and outlines the primary research objectives. Chapter 2 presents a review of key theories and previous empirical work relating to the focal constructs (i.e., relational leadership, LMX, relational ambivalence). Chapter 3 discusses the proposed individual-level antecedents of LMX ambivalence, including the theoretical underpinnings and the hypotheses relating to these antecedents. Chapter 4 presents a moderated path model that delineates the process by which LMX ambivalence influences employee work-related well-being. In this chapter, each of the hypotheses relating to this path model and their corresponding rationale are discussed. Chapter 5 provides an overview of the research methodology and data analytic techniques that are employed in this research. Chapter 6 details the results. Finally, Chapter 7 summarizes the primary research findings, highlights contributions to theory and practice, and outlines limitations and areas for future research. 


\section{CHAPTER 2: RELATIONAL LEADERSHIP AND AMBIVALENCE: LITERATURE REVIEW}

\subsection{Relational Leadership}

Although relationship-oriented workplace behavior has been studied for several decades, recent work on relational leadership has emphasized the role of interpersonal processes in effective leadership (Uhl-Bien, 2006). The concept of relational leadership asserts that both leader and follower perceptions and cognitions are important to study to fully understand how leaders and followers interact and influence the attitudes and behaviors of each other. Models of leadership such as LMX theory and servant leadership reflect examples of this relational approach (Eva, Robin, Sendjaya, Van Dierendonck \& Liden, 2019). The relational approach emphasizes the analysis of how leader and follower personalities, perceptions, behaviors, and evaluations shape the leader-follower relationship (Uhl-Bien, 2006; Werbel \& Henriques, 2009). Consequently, different perceptual and social-cognitive processes have been proposed to explain how relational models of leadership influence employee work attitudes and behaviors. For example, one of the key mechanisms that has been shown to play an important role in predicting outcomes of relational leadership is psychological need fulfillment - a fundamental component of self-determination theory.

Self-determination theory (SDT; Deci \& Ryan, 1985) is a well-established theory of human motivation that has been applied in analyzing how relational leadership may impact employee well-being and performance. SDT highlights the importance of innate psychological needs as a basis for self-motivation and behavioral self-regulation (Ryan \& Deci, 2000). SDT classifies motivation along a continuum from more controlled motivation, or experienced as external to the self, to more autonomous motivation, which is integrated within the self (DeHaan 
\& Ryan, 2014). In the SDT framework, three basic psychological needs must be satisfied in order for people to become more autonomously motivated and to experience a greater sense of self-determination (Gagné \& Deci, 2005). These needs include the need for autonomy (i.e., having choices and initiating action oneself), competence (i.e., feeling confident and capable), and relatedness (i.e., feeling connected to others, caring for and being cared for by others). According to SDT, these three needs are essential to one's development and effective functioning, and ultimately, to one's well-being (Mayer, Bardes \& Piccolo, 2008; Ryan \& Deci, 2000).

Recent work examining relational approaches to leadership has signaled that need fulfillment processes play an integral role in follower perceptions of their leader and their work motivation. Because a follower's relationship with their leader colors their perceptions of their overall work experience (Gerstner \& Day, 1997), it may play a particularly prominent role in determining one's level of need satisfaction at work (Chiniara \& Bentein, 2016). Consistent with this premise, several studies have found that adopting a relational approach to leadership may enhance followers' work outcomes by enhancing perceptions of need fulfillment (e.g., Chiniara \& Bentein, 2016; Leroy et al., 2015; Kovjanic et al., 2013). For example, servant leadership is an approach in which the leader endeavors to foster their followers' growth and development by prioritizing and satisfying their needs (Mayer, 2010; Van Dierendonck, Stam, Boersma, De Windt \& Alkema, 2014). In this respect, servant leaders convey to their followers that they are valued members of the organization and the organization will assist them in meeting their psychological needs. Empirical research has generally supported this perspective, indicating that need fulfillment mediates the influence of servant leadership on various employee outcomes, including job satisfaction, work engagement, task performance, and organizational citizenship 
behavior (Chiniara \& Bentein, 2016; Mayer et al., 2008; Van Dierendonck et al., 2014).

Likewise, LMX has been shown to predict specific work outcomes through need fulfillment processes. For example, in their study of 283 working professionals in various occupations, Graves and Luciano (2013) argued and found that LMX influences various work outcomes (i.e., vitality, job satisfaction, organizational commitment) by strengthening perceptions of need satisfaction. LMX was positively related to the satisfaction of the needs for competence, autonomy, and relatedness. Graves and Luciano (2013) maintained that satisfaction of these needs enhances autonomous motivation, which in turn, generates positive work outcomes.

To sum up, relational models of leadership emphasize the role of interpersonal processes in the development of leaders and follower perceptions of their leader. Leaders with a relational focus can enhance follower work motivation and well-being by fostering their sense of need fulfillment at work. Psychological need fulfillment can heighten work-related well-being by cultivating a stronger sense of autonomous motivation and work identity in which values embodied in one's work-activities become more internalized (Leroy et al., 2015; Olafsen, Deci \& Halvari, 2018; Van den Broeck, Vansteenkiste, De Witte \& Lens, 2008). In this respect, need fulfillment can fuel work motivation and "psychological energy" that can contribute to greater work-related well-being (Deci \& Ryan, 2000; Deci, Olafsen \& Ryan, 2017; Van den Broeck et al., 2008). Consistent with this perspective, the moderated mediation model presented in Chapter 4 situates need fulfillment at work as the key process mechanism linking perceptions of LMX ambivalence to two focal indicators of work-related well-being: work engagement, and emotional exhaustion. In the next section, we discuss LMX theory, perhaps the most prominent approach to relational leadership (Uhl-Bien, 2006).

\subsection{Leader-Member Exchange (LMX) Theory}


Role theory suggests that individuals are members of social positions and hold expectations for their behaviors and the behaviors of other people (Biddle, 1986). Social exchange theory posits that through a series of interpersonal interactions that occur over time, individuals may develop a greater sense of mutual obligation, trust, and flexibility (Cropanzano \& Mitchell, 2005; Cropanzano, Anthony, Daniels \& Hall, 2017). Derived from role theory and social exchange theory, LMX theory is a relationship-based approach to leadership that emphasizes the unique nature of the dyadic relationship that forms between a leader and their follower (Graen \& Uhl-Bien, 1995; Liden, Sparrowe \& Wayne, 1997). Unlike other leadership theories (e.g., the "average leadership style" approach - see Dansereau, Graen, \& Haga, 1975), the LMX perspective proposes that each leader-follower relationship varies in terms of the quality of treatment that is given and received (Bauer \& Erdogan, 2015). The role-making perspective on LMX argues that employees' roles in organizations are not entirely formally prescribed in the job description but develop through an informal exchange and negotiation process with one's leader (Dansereau et al., 1975; Graen \& Uhl-Bien, 1995). The process starts with the leader's communication of initial role expectations to a follower, and the follower reacts to this initial role demand (Graen \& Scandura, 1987). Through a series of interpersonal interactions, leaders and followers take actions in response to each other's behavior (Cropanzano $\&$ Mitchell, 2005) and roles evolve to the point of becoming more routinized and stable (Graen $\&$ Scandura, 1987). The role-making process results in differentiated role definitions and thus differentiated LMX relationships within workgroups (Graen, 1976). Based on followers' workrelated effort and the extent to which they satisfy their leaders' role expectations, leaders develop closer relationships with some followers relative to others and will selectively provide more individualized attention, socioemotional support, and career-related benefits to these followers 
(e.g., counselling, coaching, career growth opportunities; Graen \& Uhl-Bien, 1995; Nahrgang \& Seo, 2015; Schriesheim, Castro \& Cogliser, 1999). In return for this favourable treatment, followers reward their leaders with improved work performance and heightened commitment to both the leader and the organization (Dulebohn, Bommer, Liden, Brouer \& Ferris, 2012; Graen \& Uhl-Bien, 1995; Martin, Guillaume, Thomas, Lee \& Epitropaki, 2016). Over time, these reciprocal exchanges foster perceptions of mutual respect, loyalty, and trust, as well as a felt obligation to engage in work-related behavior that further sustains and enhances the quality of the leader-follower relationship (Liden et al., 1997; Nahrgang \& Seo, 2015).

The social exchange process between an employee and their direct supervisor is very salient and meaningful to them and may significantly affect their work engagement and wellbeing (Schriesheim et al., 1999). LMX theory postulates that leaders and followers exchange various resources, including money, services, status, information, and affiliation (Epitropaki \& Martin, 2015; Foa \& Foa, 1974; Wilson, Sin \& Conlon, 2010). By giving and receiving different resources, leaders and followers can cope with job demands and stressors more effectively. Studies have shown that LMX is positively associated with various employee work attitudes and behaviors, ranging from perceptions of job satisfaction, workplace fairness, and role clarity to improved task performance, adaptability, citizenship behavior, and creativity (Dulebohn et al., 2012; Harris, Wheeler, \& Kacmar, 2009; Martin et al., 2016; Tierney, Farmer \& Graen, 1999). LMX has also been linked to various indicators of employee well-being, including their work engagement, overall job-related well-being, and mental health (Breevaart, Bakker, Demerouti, \& Van den Heuvel, 2015; Epitropaki \& Martin, 1999; Halbesleben, 2006; Thomas \& Lankau, 2009; Tordera, González-Romá \& Peiró, 2008).

\subsection{Relational Ambivalence}


Discussion of the nature of ambivalence has a long and broad history dating back to as early as Classical Greece (Rothman et al., 2017). Ambivalence evolved from the Latin term "ambo", which means "both", and "valere" which means "to be strong" (Meyerson \& Scully, 1995). In this regard, ambivalence literally denotes the experience of two (ambi) opposing strong forces (valences) (Ashforth et al., 2014). Based on previous conceptualizations, ambivalence may be defined as coexisting positive and negative affective or cognitive orientations toward a person, situation, object, or idea (Rothman et al., 2017).

Scholars have identified and analyzed different forms of ambivalence, including attitudinal ambivalence, emotional ambivalence, trait ambivalence, expressed ambivalence, and relational ambivalence (Rothman et al., 2017). Attitudinal ambivalence has been defined as equivalently strong positive or negative evaluations given to an attitude object (Thompson, Zanna \& Griffin, 1995). Emotional ambivalence relates to the co-occurrence of positive and negative emotions about the same target (Fong, 2006; Larsen, McGraw, \& Cacioppo, 2001). Trait ambivalence has been defined as overlapping approach-avoidance tendencies directed toward a given person or experience (Sincoff, 1990). Expressed ambivalence reflects the expression of tension and conflict, such as conflicted facial, vocal, and body expressions (Rothman \& Northcraft, 2015). Finally, the concept of relational ambivalence refers to the perception of a network member as a source of ambivalence (Uchino, Holt-Lunstad, Uno \& Flinders, 2001). Although these definitions of ambivalence are directed toward different targets, they share an emphasis on a simultaneous presence of strong, contradictory thoughts or feelings toward a given entity. The current study mainly focuses on the literature and theory relating to both relational and attitudinal ambivalence as these forms of ambivalence are most relevant to studying positive and negative cognitions relating to leader-follower relationships (Lee et al., 
2019). Specifically, this study focuses on the cognitive experience of attitudinal ambivalence, which refers to an individual's conflicting beliefs or thoughts toward the attitude target (Eagly, Mladinic, \& Otto, 1994).

The current study also focuses more on a subjective conceptualization of ambivalence. Objective ambivalence deals with the existence of incongruent associations about a target (e.g., the results of two separate scales measuring positive and negative feelings concerning $\mathrm{X}$ are high), while subjective ambivalence refers to perceptions relating to the experience of this conflict (e.g., "I find myself 'torn' between two sides of the issue of X"; Thompson et al., 1995; Van Harreveld, Nohlen \& Schneider, 2015). Although the coexistence of conflicting associations is a prerequisite for subjectively experienced ambivalence, subjective ambivalence is more consequential for people (Van Harreveld et al., 2015). Subjective ambivalence is, by definition, perceived by individuals, making it a more salient and intense form of ambivalence (Ashforth et al., 2014). Indeed, researchers argue that the consequences of objective ambivalence tend to be driven by subjective ambivalence (DeMarree, Wheeler, Brinol, \& Petty, 2014). Thus, the present research focuses on subjective ambivalence as it is more closely related to defining ambivalence as simultaneously evaluating an object negatively and positively, and it tends to exert a stronger influence on an individual's perceptions and behaviors (Thompson et al., 1995; Van Harreveld et al., 2015).

A good deal of research has studied ambivalence in relation to different social relationships. In their study of different types of relationships, Campo, Uchino, Holt-Lunstad, Vaughn, Reblin, and Smith (2009) reported that individuals viewed about 50\% of their social relationships in an ambivalent manner. Indeed, a mix of both positive and negative perceptions can exist within most types of social relationships. For example, ambivalent perceptions are quite 
frequently reported in spousal relationships (e.g., Uchino, Smith \& Berg, 2014) and in friendships (e.g., Holt-Lunstad, Uchino, Smith, \& Hicks, 2007). Ambivalence is also found in intergenerational relations. For instance, it is often evidenced in the relationship between children and their parents, as well as their in-laws (e.g., Willson, Shuey \& Elder, 2003). Ambivalence has also been studied in same-generation familial relationships, such as among siblings (Smelser, 1998).

Although ambivalence is a long-standing topic of interest in disciplines, such as sociology, political psychology, and social psychology (e.g., Baek, 2010; Rudolph, 2011; Van Harreveld et al., 2015), research exploring ambivalence in organizational settings has been limited. Given that organizational members are often facing changing circumstances relating to various factors in the work environment, including policies and practices, their work activities, and interactions with different individuals (Rothman et al., 2017), one might expect that ambivalence will be prevalent in organizational settings. Ambivalent attitudes toward specific policies and practices (e.g., firm marketing practices), events (e.g., organizational change), and stakeholders (e.g., coworkers) have been linked to different employee work attitudes and behaviors, ranging from perceptions of organizational identification and organizational commitment (e.g., Pratt, 2000; Pratt \& Rosa, 2003) to employee creativity (e.g., Vadera \& Pratt, 2013), deviant behavior (e.g., Fong, 2006), job performance, and turnover (e.g., Zou \& Ingram, 2013). However, there has been an absence of research exploring how ambivalence toward one's leader may impact one's work experiences and behaviors.

Extant conceptualizations and measures of the quality of work relationships in organizations assume that perceptions of relationship quality are univalent and can be arranged along a bipolar continuum from negative to positive (Methot et al., 2017). However, workplace 
relationships are complex and multifaceted. Employees must constantly balance mixed expectations, demands, and goals within their work relationships (Ashforth et al., 2014; Rothman et al., 2017). Relationships with coworkers, for example, often require balancing conflicting demands for friendship and competition (Ingram \& Zou, 2008). Likewise, leader-follower relationships can contain a mixture of both positive and negative elements. For example, police officers often report ambivalent feelings towards their managers as they are expected to demonstrate both authoritative and caring behaviors toward their employees simultaneously (Duffy, Ganster, \& Pagon, 2002). Similarly, in their study of call centre employees, Pratt and Doucet (2000) documented how employees often have love-hate relationships with their supervisor due to the need for managers to provide directive, task-focused behaviors while also offering emotional support. Given the importance of leader-follower relationships in organizations, coupled with our limited understanding of the role of ambivalence in these relationships, the current study focuses on employee perceptions of LMX ambivalence and factors that both contribute to, and result from, these perceptions (Lee et al., 2019).

\subsection{LMX Ambivalence}

Current conceptualizations of LMX examine it as unidimensional, presupposing that perceptions of LMX can be placed on a continuum from low to high quality. Followers experiencing higher levels of LMX are more likely to have developed a robust social exchange relationship with their leader characterized by higher levels of mutual respect, affect, and loyalty

(Bauer, Erdogan, Liden \& Wayne, 2006; Liden et al., 1997). In contrast, followers in low-quality LMX relationships are only involved in contractual exchanges with their leaders (Graen \& UhlBien, 1995). Hence, they often receive limited emotional support from their immediate leaders and few benefits outside the employment contract (Gerstner \& Day, 1997). While extant research 
has assumed that LMX is univalent in nature, recently Lee and colleagues (2019) have introduced a novel construct: LMX ambivalence. They define LMX ambivalence as "a leaderfollower relationship that is subjectively evaluated as being made up of both positive and negative cognitions" (Lee, 2016, pp. 71). As LMX reflects perceptions of the quality of the relationship between a leader and a follower, it may also involve ambivalent cognitions which have been shown to exist in different types of interpersonal relationships (e.g., Campo et al, 2009; Uchino et al., 2014; Willson et al., 2006).

Perceptions of ambivalence in LMX relationships are important to assess and study for several reasons. First, LMX is conceptualized as reflecting employees' attitudes towards their relationship with their leaders. As noted previously, LMX is generally measured as a cognitive attitude in bipolar terms; that is, it is assessed as either positive or negative (i.e., high- or lowquality LMX) (Lee, Martin, Thomas, Guillaume \& Maio, 2015). However, in reality, ambivalent attitudes are fairly common, and people can simultaneously hold a positive and a negative evaluation of a given target (Thompson et al., 1995). For example, people can evaluate smoking as both positive and negative because they believe that smoking can help them to make more friends; however, they may also be afraid of the negative health consequences (Hohman, Crano \& Niedbala, 2016). Attitudinal ambivalence can also exist within all types of social relationships (e.g., relationships with family members, coworkers, friends, social acquittance, e.g., Campo et al., 2009). Given previous work suggesting that both attitudinal and relational forms of ambivalence can significantly impact an individual's decision-making and behavior (e.g., Costarelli \& Colloca, 2004; Olsen, Wilcox \& Olsson, 2005; Pratt, 2000; Van Harreveld et al., 2015), research examining ambivalence in the context of leader-follower relationships may shed additional light on individual work perceptions and behavior in the workplace. 
Second, leader-follower relationships may be particularly prone to eliciting ambivalent perceptions. LMX relationships can be paradoxical because leaders and followers desire to form close interpersonal bonds while simultaneously seeking to maintain hierarchical distance (Lee et al., 2019; Zhang, Waldman, Han \& Li, 2015). Furthermore, the leader-follower relationship may encompass different roles and corresponding expectations that can breed ambivalence (Ashforth et al., 2014; Rothman et al., 2017). From the perspective of role theory, leaders and followers need to adopt different roles such as supervisor, mentor, subordinate, coworker and friend (Lee et al., 2019). As a result, conflicts may arise because of the various demands that leaders may face in fulfilling multiple roles. The role-making process may unfold smoothly for some roles, but leaders and followers may have disagreements in carrying out other roles. For some roles, employees may have very clearly defined role perceptions and hold similar role expectations to their leader (Thomas \& Lankau, 2009). However, for other roles, employees may experience an absence of information or incongruent role expectations compared to their leader. For example, a follower might perceive their leader as being friendly and having strong interpersonal skills. As a result, they may be satisfied with the exchange relationship because of the indispensable socioemotional support provided by the leader. However, the follower might also feel that they are being treated unfairly because the leader does not actively monitor work demands and may overload them with work (Pratt, 2000). Therefore, the follower might experience ambivalence toward their exchange relationship because of their incongruent evaluations toward their leader's performance relative to different roles (Pratt \& Doucet, 2000).

Third, ambivalence may be quite prevalent in LMX relationships due to the power differences that exist between a leader and a follower (Fingerman, Pitzer, Lefkowitz, Birditt \& Mroczek, 2008). Leaders and followers can exchange several different types of resources (e.g., 
goods, expertise, money, status, affiliation; Wilson et al., 2010); however, compared to followers, leaders hold more power and control over the use of these resources. For example, while leaders can often influence or decide followers' pay (e.g., salaries/bonuses), followers can only influence a leader's pay indirectly (e.g., through their performance), if at all (Wilson et al., 2010). Leaders also assign job tasks, offer career development opportunities, and provide feedback and support to followers. These resources are critical in shaping followers' work experiences and perceptions, including their sense of need fulfillment. As leaders hold more power and control over resources in the relationship, this imbalance and dependence on one's leader may conflict with certain needs of their follower, including their need for autonomy. Followers may accept this power imbalance and dependence to achieve their ultimate goal of becoming more independent over time; however, this duality may result in ambivalent thoughts toward one's LMX relationship (Ashforth et al., 2014; Fingerman, 2001; Lee et al., 2019).

Finally, leader-follower relationships include both external and internal barriers to exiting the relationship. These external (e.g., difficulty in finding alternatives; financial burdens) and internal barriers (e.g., a sense of commitment or investment in the relationship) restrict a follower's ability to leave relationships that are dysfunctional or in which the follower has an ambivalent view of the leader (Bushman \& Holt-Lunstad, 2009). As a result, perceptions of ambivalence will persist and potentially grow over time (Bushman \& Holt-Lunstad, 2009).

Based on the preceding arguments, I submit that research on LMX should extend beyond a strictly univalent view of LMX relationships and assess the presence of coexisting positive and negative attitudes towards the leader-follower relationship. Building on initial work in this area (i.e., Lee et al., 2019), the present research explores the role of leader and follower dispositional characteristics in shaping perceptions of LMX ambivalence. Furthermore, I examine whether and 
how LMX ambivalence may contribute to employee perceptions of well-being at work. Next, I will discuss potential dispositional antecedents of LMX ambivalence and outline why I anticipate that these characteristics are associated with follower perceptions of ambivalence. 


\section{CHAPTER 3: ANTECEDENTS OF LMX AMBIVALENCE}

Although studies have shown that perceptions of ambivalence in organizations are quite common (Methot et al., 2017), research on LMX ambivalence is just emerging. Scholars have called for research exploring predictors of ambivalence to enhance our understanding of the factors that contribute to the formation of ambivalence perceptions (Conner \& Sparks, 2002). To date, however, antecedents of LMX ambivalence have not been investigated. Thus, the first question explored in this research is "what are some of the individual difference variables that predict LMX ambivalence?” In this respect, both supervisor (leader) and subordinate (follower) individual differences (i.e., demographics and personality traits) are tested as potential antecedents of employee perceptions of LMX ambivalence.

\subsection{Demographic Characteristics}

Preliminary evidence suggests that various demographic variables can be drivers of followers' perception of ambivalence in workplace relationships (Methot et al., 2017). Three demographic variables are investigated in this research: supervisor and subordinate age and gender, and the length of the leader-follower relationship (i.e., dyad tenure).

\subsubsection{Age}

Subordinate Age. An individual's age has been found to be associated with greater emotional complexity. Older adults have accumulated more experience in different social situations and coping with various emotions (Blanchard-Fields \& Coats, 2008). As a result, they tend to experience less intense discrete emotions (e.g., anger), and they are more capable of regulating their emotions (Blanchard-Fields \& Coats, 2008; Lawton, 2001). Given these differences in the experience of emotions, older individuals may also be more tolerant of the cooccurrence of positive and negative emotions (Chipperfield, Perry, \& Weiner, 2003). Consistent 
with this perspective, previous empirical work has suggested that older individuals are more likely to experience emotional complexity (Ong \& Bergeman, 2004). Based on this evidence, I propose that subordinate's age will be positively associated with their reports of LMX ambivalence.

Supervisor Age. A supervisor's age might also influence subordinates' perceptions of ambivalence in their relationship. Meta-analytic evidence has indicated that older workers exhibit more citizenship and safety-related behavior, and less workplace aggression, on-the-job substance use, tardiness, and absence (Ng \& Feldman, 2008). In this regard, older workers appear to demonstrate higher levels of reliability and less counterproductive behavior in the workplace. However, older workers have also been perceived by others as lower on autonomy and in their physical capability and effectiveness relative to younger workers (Kite, Stockdale, Whitley, Johnson, 2005). Some studies have also suggested that older workers may be more resistant to change, less creative, and more cautious (Chiu, Chan, Snape \& Redman, 2001; Posthuma \& Campion, 2009; Weiss \& Maurer, 2004; Wrenn \& Maurer, 2004). Research findings regarding the role of supervisor age in the display of relational leader behaviors are mixed (Walter \& Scheibe, 2013). Some studies demonstrate older leaders are more likely to display consultative, participative, and courteous leaders behaviors (Oshagbemi, 2004; Pinder \& Pinto, 1974); while other studies found that younger leaders were perceived as displaying more friendly and considerate behaviors than older leaders (Gilbert, Collins \& Brenner, 1990; Vecchio, 1993). Given these mixed views of the leader behaviors and overall capability exhibited by older workers, it is possible that followers may report more uncertain and mixed views regarding the quality of their relationships with their leader when the leader is older. I, therefore, hypothesize the following: 


\section{Hypothesis 1a: Subordinates' age is positively associated with their experience of}

\section{LMX ambivalence.}

\section{Hypothesis 1b: Supervisors' age is positively associated with subordinates' experience of LMX ambivalence.}

\subsubsection{Gender}

Subordinate Gender. Gender differences relating to different types of ambivalence have been reported in previous research. Studies have suggested that females may exhibit more advanced social cognitive development with respect to their belief systems (Kramer \& Melchior, 1990). For example, they develop more relativistic and dialectical paradigm beliefs, which allow one to see and hold contradictory beliefs (Kramer, 1989). In a study of ambivalence in adult children's relationships with their parents and in-laws, researchers found that dyads consisting only of women indicated higher ambivalence compared with dyads including only men (Willson et al., 2003). It is possible that because female subordinates more readily perceive contradictions and inconsistencies in social relationships, they may perceive more ambivalence toward their relationship with their leader.

Supervisor Gender. It is expected that employees with a female leader may report higher levels of LMX ambivalence. Role congruity theory suggests that inconsistency can arise when perceivers hold a stereotype about a social group (e.g., women) that is incongruent with the attributes that are thought to be required for success in certain social roles (e.g., a leader) (Eagly \& Karau, 2002). Compared with men, women tend to be described as friendly, pleasant, interested in other people, expressive, and socially sensitive (Eagly, 1987; Hall \& Friedman, 1999). Female leaders may be subjected to incompatible expectations regarding their managerial role and their gender role (e.g., Eagly, Wood \& Diekman, 2000; Kruse \& Wintermantel, 1986). 
The inconsistency between the predominantly communal qualities associated with women and the predominantly agentic qualities exhibited by a leader (Eagly \& Karau, 2002) suggests that subordinates may perceive greater ambivalence toward their LMX relationship with a female leader than a male leader.

Hypothesis 2a: Subordinates' gender is associated with the experience of LMX ambivalence, such that female subordinates will report more LMX ambivalence than men.

Hypothesis 2b: Supervisors' gender is associated with the experience of LMX ambivalence, such that subordinates will report more LMX ambivalence when they have a female supervisor.

\subsubsection{Dyad Tenure}

Ambivalence in relationships can form over time because familiarity may breed ambivalence (Brooks \& Highhouse, 2006). Indeed, when an individual becomes more familiar with an object, he/she is more likely to encounter the object's multiple facets and imperfections (Ashforth et al., 2014). In her qualitative study of mentorship, Oglensky (2008) observed that ambivalence increased as the mentor-protégé relationship evolved over time (Oglensky, 2008). Similarly, I argue that employee perceptions of LMX ambivalence should increase with greater exposure to and familiarity with one's supervisor. A longer length of time spent in the relationship may cause both positive and negative views about the exchange relationship to rise to the surface.

Hypothesis 3: Leader-follower dyad tenure is positively associated with subordinates' experience of LMX ambivalence.

\subsection{Personality}


Personality traits are stable individual difference constructs that reflect habits, consistencies, or patterns in an individual's thoughts, feelings, and behaviors over time and across situations (Oswald, Hough \& Ock, 2013). Personality traits influence how people interpret and react to their work and other life experiences (Wayne, Musisca \& Fleeson, 2004). Personality traits may predispose employees to form ambivalent attitudes toward their relationship with their leader as individuals with certain personality traits might be more (or less) likely to resolve conflicts between positive and negative evaluations of their leader (Conner \& Sparks, 2002; Methot et al., 2017). For example, individual differences such as need for cognition, need for closure, and fear of invalidity, have been examined as dispositional characteristics that can influence the development and expression of ambivalent attitudes (Conner \& Sparks, 2002; Sparks, Conner, James, Shepherd, \& Povey, 1995; Thompson \& Zanna, 1995). Need for cognition refers to the stable tendency to engage in cognitive endeavors and effortful thought (Cacioppo, Petty, Kao, \& Rodriquez, 1986). Individuals high in need for cognition dislike ambiguity, and they may spontaneously search for information and bring coherence to issues (Thompson \& Zanna, 1995). Fear of invalidity is a tendency to be concerned about committing errors or the consequences of a decision (Kruglanski, 1980). Fear of invalidity is associated with a prolonged evaluation of information and hesitation in making decisions (Thompson, Naccarato, Parker \& Moskowitz, 2001). People high in fear of invalidity tend to put equal weight on contradictory opinions and maintain ambivalent attitudes (Thompson \& Zanna, 1995).

In addition to employee personality traits influencing perceptions of ambivalence, the personality traits of one's leader may likewise foster ambivalence regarding the LMX relationship. Leader personality characteristics have been shown to affect followers' perceptions 
of their leader and their LMX relationship (Bernerth, Armenakis, Feild, Giles, \& Walker, 2007; Dulebohn et al., 2012; Judge, Piccolo \& Kosalka, 2009; Nahrgang, Morgeson \& Ilies, 2009; Zhang, Wang \& Shi, 2012). In a meta-analysis of 73 samples, researchers found that four of the Big Five traits had non-trivial correlations with leadership emergence and effectiveness (Judge, Bono, Ilies, \& Gerhardt, 2002). For example, agreeable leaders are more likely to be perceived as empathetic, cooperative and trustworthy (Costa \& McCrae, 1992). By influencing a leaders' motivation and behavior, and in turn, followers' perceptions of their leader, leader personality characteristics may shape follower perceptions of LMX ambivalence. For example, leader personality traits might relate not only to different behavioral tendencies, but also different personal strivings such as striving for communion and striving for status (Barrick, Mount \& $\mathrm{Li}$, 2013; Traupman, Smith, Uchino, Berg, Trobst \& Costa, 2009). As discussed previously, LMX ambivalence partly stems from the conflict between followers' desires for interpersonal closeness and hierarchical distance. In this manner, different behavioral tendencies and personal strivings of both the leader and follower might further influence the intensity of this conflict. In this respect, both the leader and the follower's personality may contribute to ambivalent reactions. In their study of ambivalence in the parent and offspring relationship, Fingerman, Chen, Hay, Cichy and Lefkowitz (2006) found that the child's personality (i.e., neuroticism) and perceived importance of the relationship significantly predicted their parents' ambivalence toward the relationship. Consistent with this dyadic view of how personality may impact perceptions of ambivalence, this research explores the influence of both leader and follower personality traits on LMX ambivalence.

In personality research, the five-factor model is generally recognized as the most comprehensive and fundamental organizing structure of personality (Hough, Oswald \& Ock, 
2015; Ones, 2005; Oswald et al., 2013). The five-factor model was uncovered and validated through factor analyses assessing the relationships among all of the adjectives used to describe individuals and is generally accepted as capturing the most salient aspects of personality (Goldberg, 1990; Oswald et al., 2013). The five-factor model is comprised of five broad traits (i.e., the "Big Five"): emotional stability (neuroticism), conscientiousness, agreeableness, openness to experience, and extraversion (Oswald et al., 2013). A sizeable body of research indicates the Big Five personality constructs are quite stable over time and generalize across cultural groups (McCrae \& Costa, 2008). Given that this might be the first study testing personality traits as predictors of LMX ambivalence, I use the Big Five model as a means of organizing and investigating whether leader and follower personality traits are associated with LMX ambivalence.

\subsubsection{Emotional Stability}

Emotionally stable individuals are those who are in control of their emotions and demonstrate higher levels of emotional adjustment (Mount \& Barrick, 1995). Emotionally stable individuals are less emotionally anxious and tend to maintain more cognitive clarity to assess and interpret situations (Piedmont, 1998). The inverse of emotional stability is neuroticism, which reflects a tendency to be more anxious, hostile, depressed, self-conscious, impulsive, and vulnerable (Costa \& McCrae, 1992; Mount \& Barrick, 1995). Subordinate emotional stability is expected to be negatively related to LMX ambivalence. Indeed, previous studies have suggested that neuroticism may predispose people to view their workplace relationships as ambivalent because they are more attuned to internal and interpersonal contradictions (Fingerman et al., 2006; Methot et al., 2017). Kokkonen and Pulkkinen (2001) tested and found that neuroticism can evoke ambivalent feelings because ambivalence involves dysregulation of emotion. 
Emotional dysregulation involves directing emotions toward inappropriate goals, leading to maladaptive emotional, cognitive, and behavioral outcomes (Cicchetti, Ackerman \& Izard, 1995). Likewise, Fingerman and colleagues (2006) found that people high in neuroticism are likely to view their relationship with parents or offspring as ambivalent. They argued that people high in neuroticism might experience ambivalence because they have difficulty regulating their reactions to different social situations (Fingerman et al., 2006). Based on this evidence, I anticipate that subordinates higher in emotional stability should report lower LMX ambivalence.

Supervisor emotional stability can also influence subordinates' perception of LMX ambivalence. Individuals low in emotional stability are more prone to experiencing feelings of insecurity, worry, and anxiousness (Costa \& McCrae, 1992). Emotional stability is associated with effective emotional regulation skills and emotional regulation (Elliot, Herrick, MacNair \& Harkins, 1994). Due to their higher levels of emotional regulation and control, emotionally stable supervisors may be less likely to engage in behaviors that engender more negative or ambivalent feelings, such as losing their temper when dealing with subordinates (Smith \& Canger, 2004). Because emotionally stable leaders are calmer and more consistent in their emotional expressions and behavior (Judge \& LePine, 2007), their subordinates may have more consistent attitudes towards them.

\section{Hypothesis 4a: Subordinates' emotional stability is negatively associated with their experience of LMX ambivalence.}

\section{Hypothesis 4b: Supervisors' emotional stability is negatively associated with subordinates' experience of LMX ambivalence.}

\subsubsection{Conscientiousness}

Individuals high in conscientiousness tend to be careful, diligent, thoughtful, organized 
and mindful of details (McCrae \& Costa, 1987). They are dutiful, achievement striving, selfdisciplined, and deliberate in their actions (Costa \& McCrae, 1992). Conscientiousness is a characteristic of a mature personality (Hogan \& Roberts, 2004). Conscientious individuals tend to be more deliberate in their actions and inclined to engage in goal-directed activity that allows them to exert greater control over themselves and their environment (Bipp, Steinmayr \& Spinath, 2008).

Subordinates higher in conscientiousness might experience lower LMX ambivalence partly due to their tendency to be more systematic and deliberate in their thoughts and actions. Conscientiousness is positively related to need for cognition (Sadowski \& Cogburn, 1997) and desire for predictability (Berenbaum, Bredemeier \& Thompson, 2008), which are both negatively related to perceptions of ambivalence (Thompson \& Zanna, 1995). Individuals high in need for cognition are task-oriented and willing to engage in intellectual thought but also more likely to seek cognitive closure (Furnham \& Throne, 2013). Likewise, supervisors who are conscientious tend to be diligent, dependable, achievement-oriented and planful (Costa \& McCrae, 1992; Mount \& Barrick, 1995). The higher level of predictability and reliability of supervisors should result in less ambivalent attitudes from their subordinates regarding their LMX relationship.

\section{Hypothesis 5a: Subordinates' conscientiousness is negatively associated with their experience of LMX ambivalence.}

\section{Hypothesis 5b: Supervisors' conscientiousness is negatively associated with subordinates' experience of LMX ambivalence.}

\subsubsection{Agreeableness}

Agreeable individuals tend to be helpful, tender-minded, considerate, compliant, cooperative, and modest (Costa \& McCrae, 1992; Goldberg, 1992). Low scores on this construct 
are associated with being less trusting of others, more argumentative, and selfish (Costa \& McCrae, 1992). Agreeableness is associated with a stronger need for closure (Neuberg, Judice \& West, 1997), which reflects a desire for a more definitive answer on a given topic, as opposed to one that is ambiguous (Webster \& Kruglanski, 1994). In this respect, agreeable individuals may be less likely to experience ambivalent thoughts. Moreover, Laghai and Joseph (2000) found that agreeable individuals may experience lower levels of emotional ambivalence due to the more compliant and less argumentative disposition of these individuals. Based on this evidence, it is expected that higher levels of subordinate agreeableness may be associated with lower perceptions of LMX ambivalence.

Likewise, agreeable supervisors should also be less likely to elicit ambivalent feelings from their followers. Agreeable individuals are motivated to achieve interpersonal intimacy (Graziano \& Eisenberg, 1997; Judge \& Ilies, 2002). As leaders, agreeable individuals are perceived as more nurturing, caring, emotionally supportive and trustworthy (Barrick \& Mount, 1991; Costa \& McCrae, 1992; Digman, 1990; Judge et al., 2009). In this respect, agreeableness is an important factor in the ability to form reciprocal social alliances (Buss, 1991; Kamdar \& Van Dyne, 2007), which is the foundation of social exchange (Schriesheim et al., 1999; Uhl-Bien \& Maslyn, 2003). Indeed, agreeableness is positively related to the display of reciprocity behavior (Perugini, Gallucci, Presaghi, \& Ercolani, 2003). As high levels of agreeableness contribute to a stable exchange relationship, the agreeableness of supervisors and subordinates should be negatively related to employee perceptions of LMX ambivalence.

\section{Hypothesis 6a: Subordinates' agreeableness is negatively associated with their experience of LMX ambivalence.}




\section{Hypothesis 6b: Supervisors' agreeableness is negatively associated with subordinates' experience of LMX ambivalence.}

\subsubsection{Openness to Experience}

Individuals who are high in openness to experience are open-minded, curious, intelligent, and imaginative (Goldberg, 1993; Mount \& Barrick, 1995). Openness is negatively related to need for closure (Neuberg et al., 1997). High levels of openness are associated with being nonjudgmental, tolerant, and being willing to generate and embrace creative and divergent ideas (McCrae \& Costa, 1997). For example, openness is related to flexibility towards uncertain beliefs (Berenbaum et al., 2008).

Because subordinates who are higher in openness tend to be more imaginative and embrace divergent ideas, they may be more likely to possess coexisting positive and negative attitudes toward their LMX relationship. Likewise, supervisors high in openness to experience will be more likely to possess more divergent, unconventional, and flexible patterns of thoughts (Digman, 1990; McCrae, 1987). Because their thoughts and actions may be less predictable (Cable \& Judge, 2003), this may evoke more uncertain and ambivalent attitudes toward supervisors who report higher openness to experience.

Hypothesis 7a: Subordinates' openness to experience is positively associated with their experience of LMX ambivalence.

Hypothesis 7b: Supervisors' openness to experience is positively associated with subordinates' experience of LMX ambivalence.

\subsubsection{Extraversion}

Extraverted individuals are active, energetic, talkative and expressive (Costa \& McCrae, 1992). Extraverts are more flexible towards ambiguity and cognitive inconsistency (Berenbaum 
et al., 2008; Norman \& Watson, 1976) and are less likely to seek cognitive closure on a given topic (Heaton \& Kruglanski, 1991; Berenbaum et al., 2008). Given this tendency to be more accepting of cognitive inconsistency, I posit that extraverts may be more likely to report ambivalence regarding their relationship with their leader.

Extraverted people are sociable and outgoing, and they enjoy interacting with others (Costa \& McCrae, 1992). Because extraverted leaders are more likely to be talkative and communicate more frequently with their followers (Phillips \& Bedeian, 1994; Piedmont, 1998), this greater frequency of interaction might elicit higher levels of ambivalence because followers will have more opportunities to learn about different aspects of their leader and their relationship with their leader. I, therefore, propose the following:

\section{Hypothesis 8a: Subordinates' extraversion is positively associated with their experience of $L M X$ ambivalence.}

\section{Hypothesis 8b: Supervisors' extraversion is positively associated with subordinates' experience of LMX ambivalence.}

\subsection{Power Dynamics}

In the recent handbook of LMX, Schyns (2015) argued that the next frontier in LMX research involves developing a greater understanding of the complex associations of leader and follower personality in the LMX relationships, and in particular, examining personality characteristics that extend beyond the Big Five. Issues of power and influence play an important role in organizations and how leaders interact with their followers (Emerson, 1962; Elias, 2008). According to LMX theory, a follower's perception of their leader's power can strongly impact their initial interaction and the subsequent development of their LMX relationship (Cogliser \& Schriesheim, 2000). Moreover, McClane (1991) reported that leaders tend to accord more 
negotiating latitude to followers if they share a similar level of need for power. Guided by the premise that power dynamics can significantly influence leader-follower relationships, I examine the effects of four dispositional characteristics relating to power on perceptions of LMX ambivalence: dominance and prestige-seeking (assessed in supervisors) and trait anger and hostility (assessed in subordinates).

Individual differences in power can significantly impact perceptions of ambivalence in the workplace. For example, Fong and Tiedens (2002) found that female leaders in high-status positions experience both emotional ambivalence (i.e., the coexistence of positive and negative affect) and motivational ambivalence (i.e., simultaneous desires to build relationships and display power) because they simultaneously pursue both power-oriented and relationshiporiented goals. Power dynamics are especially important in determining relational ambivalence. Power derives from the notion of resource dependence, such that the power of one person over another is determined by the extent to which the latter person is dependent on the first person for resources (Emerson, 1962; Martinez, Kane, Ferris \& Brooks, 2012). Followers are traditionally assumed to be dependent on their leaders for resources; however, followers also possess resources that are valuable to their leader, including their work capability and performance. In this regard, the manner in which leaders and followers seek power and distribute resources can influence perceptions of leader-follower relationships. As discussed previously, relational ambivalence partly stems from followers' need for autonomy and their dependence on leaders. I, therefore, propose that individual differences relating to how one uses and responds to displays of power in the leader-follower relationship can impact perceptions of LMX ambivalence.

\subsubsection{Supervisor Dominance and Prestige}

Social psychologists have identified two distinct strategies that individuals can use to 
navigate social hierarchies in society: dominance and prestige (Anicich, Fast, Halevy, \& Galinsky, 2016; Hays \& Bendersky, 2015; Henrich \& Gil-White, 2001). The differentiation between dominance and prestige is consistent with the theoretical distinction between power and status (Cheng, Tracy, Foulsham, Kingstone \& Henrich, 2013). Dominance strategies relate to seizing and maintaining social power through the use of tactics such as intimidation and coercion (De Waal-Andrews, Gregg, \& Lammers, 2015). Prestige strategies aim to achieve greater social status (e.g., recognition and respect from others) through displaying and sharing one's valued knowledge and skills (Cheng, Tracy \& Henrich, 2010; Maner, 2017). These two strategies can be expected to have different implications for leader-member relationships and follower perceptions of LMX ambivalence.

Dominance strategies induce fear in others as a result of the use of intimidation and coercion (Cheng et al., 2013; Cheng \& Tracy, 2014). Dominant leaders are concerned primarily with gaining authority and increasing one's capacity for influence, even if it means sacrificing the well-being of the group (Maner, 2017; Maner \& Case, 2016). Leaders high in dominanceseeking possess a strong desire for power (Magee \& Galinsky, 2008), which enables them to coerce followers through their distribution of resources (Maner \& Case, 2016). For example, leaders using a dominance strategy may unpredictably threaten to remove or withhold resources (Cheng et al., 2013). As dominant leaders are more likely to use access to resources as a way to gain power and control over others, this may strengthen the follower's dependence on their leader and compromise fulfillment of some of their needs, including their need for autonomy. Followers of leaders who display dominance strategies often comply with the leader's demands or provide social resources to their leader (e.g., deference, attention) due to the fear of losing other more valuable resources (e.g., their physical health, livelihoods; Cheng et al., 2010). 
Despite the coercive behavioral tendencies of dominant leaders, they also can be decisive and exhibit other behaviors that may be viewed favorably by some subordinates. For example, dominant leaders are more likely to form political coalitions to obtain resources, and in this respect, can be effective in securing more resources for their workgroup (Kakkar \& Sivanathana, 2017). They are also assertive and tend to take less time to make decisions (Kakkar \& Sivanathana, 2017; Maner \& Case, 2016). Some followers might prefer a self-assured and decisive leader who serves the interest of group members even at the expense of non-group members (Halevy, Chou, Cohen, \& Livingston, 2012). Therefore, followers may feel controlled and threatened; but at the same time, they may benefit from working with a dominant leader as long as they are compliant and adhere to their leader's requests (Cheng et al., 2013; Van Vugt, 2006). Because of these inconsistent beliefs, I propose that followers who have dominant leaders may be more likely to report ambivalent feelings toward their leader.

In contrast to leaders who are dominance-seeking, leaders who are prestige-seeking are more likely to be viewed with respect and admiration due to their tendency to display kindness and generosity and their desire to be viewed favorably by others (Cheng et al., 2013; Maner \& Case, 2016). Leaders adopting prestige strategies tend to consider the well-being of the group and its members, even if their power is at risk (Henrich, Chudek, \& Boyd, 2015; Maner, 2017). Because prestige-oriented leaders are more concerned with how they are perceived by members of the group and tend to maintain more positive relationships with others (Maner, 2017; Maner \& Case, 2016), they may behave more consistently in their interactions with others to manage their prestige and reputation. These higher levels of behavioral consistency and predictability might reduce their followers' perceptions of ambivalence. Furthermore, the stronger relational behavior of status-striving leaders may facilitate the role-making process in LMX, resulting in more 
clearly defined roles in the leader-follower relationship. Prestige-motivated leaders might also foster a sense of empowerment in their followers and decrease asymmetric control over valued resources (Magee \& Galinsky, 2008; Maner \& Case, 2016), which may reduce contradictory perceptions of their leader and further consolidate their perceptions of the leader-follower relationship.

According, the following hypotheses are proposed:

Hypothesis 9a: Supervisors' dominance is positively associated with subordinate's experience of LMX ambivalence.

\section{Hypothesis 9b: Supervisors' prestige-seeking is negatively associated with} subordinates' experience of LMX ambivalence.

\subsubsection{Subordinate Anger and Hostility}

According to state-trait anger theory (Deffenbacher, Oetting, Lynch, \& Morris, 1996; Spielberger, Jacobs, Russell \& Crane, 1983), both trait anger and hostility are associated with individual displays of aggression. Trait anger, which involves physiological arousal and preparation for aggression; and hostility, which consists of feelings of ill will and injustice, represent the affective and cognitive components of aggression behavior, respectively (Forgays, Forgays \& Spielberger, 1997; Sanz, García-Vera \& Magán, 2010). Although trait anger and hostility have been found to play a significant role in influencing the quality of interpersonal relationships in different settings (e.g., Parrott \& Zeichner, 2003; Smith, Furlong \& Boman, 2006), there has been a paucity of research exploring the effects of trait anger and hostility in leader-follower relationships. Anger can be understood as a momentary state or a trait (Spielberger et al., 1983; Spielberger, 1999). In this study, anger is assessed as a trait reflecting anger proneness and the tendency to experience state anger (Deffenbacher et al., 1996; 
Spielberger, 1999). Trait anger reflects the general disposition of an individual who experiences more frequent, intense and persistent anger triggered by a broader range of situations/things (Sanz et al., 2010). Hostility is conceptualized as a relatively stable pattern of unfavorable and destructive attitudes and beliefs towards others (Buss, 1961; Sanz et al., 2010). Hostility is a cognitive trait that indicates "a relational view of being in opposition toward others, and a desire to inflict harm or see others harmed" (Smith, 1994, p.26). Although correlated, trait anger and hostility reflect conceptually and empirically distinct constructs (Sanz et al., 2010; Smith, Glazer, Ruiz \& Gallo, 2004).

Followers' trait anger and hostility may lead to perceptions of LMX ambivalence due to the increased emotional instability and distrust associated with these traits. Previous studies have indicated that trait anger and hostility are negatively associated with emotional stability and agreeableness (Gallo \& Smith, 1997; Ruiz, Smith \& Rhodewalt, 2001; Sanz et al., 2010; Sharpe \& Desai, 2001; Whiteman, Bedford, Grant, Fowkes \& Deary, 2001). People high in trait anger and hostility tend to be less emotionally secure, more skeptical of others' intentions, and are more likely to report confrontational attitudes (Sanz et al., 2010). For example, people high in trait anger and hostility may doubt the motives underlying a leader's acts of kindness and may experience more uncertainty in terms of reciprocating or meeting a leader's needs and expectations. They also experience more dysfunctional anger suppression and express their anger in less controlled ways (Deffenbacher et al., 1996; Tafrate, Kassinove \& Dundin, 2002). Due to these lower levels of self-control, followers who report higher trait anger and hostility may be more likely to express both positive and negative views of their leader.

Previous research has also suggested that individuals with anxious attachment styles are more likely to experience and report ambivalent attitudes. Trait anger and hostility can be a 
manifestation of an anxious attachment style (Mikulincer \& Shaver, 2005). Specifically, individuals high on attachment-anxiety are more likely to report feelings of insecurity and to express anger and hostility as a means of satisfying their needs for power, dominance, and security (Lemerise \& Dodge, 2008; Zians, 2007). Individuals with an anxious attachment style report stronger perceptions of relational ambivalence (Mikulincer \& Shaver, 2007; Mikulincer, Shaver, Bar-On \& Ein-Dor, 2010) as these individuals desire intimacy, but they also fear separation and abandonment (Mikulincer \& Shaver, 2005). Thus, they seek a close relationship with others while they hold negative expectations regarding the other's responses. Similarly, people high on trait anger and hostility may be more likely to report ambivalence toward their leader due to a desire to develop a close relationship with them, but also a concomitant tendency to distrust their leader and express negative views toward them. These cognitions and behavioral tendencies may increase perceptions of ambivalence toward their LMX relationship.

Hypothesis 10a: Subordinates' trait anger is positively associated with their experience of $L M X$ ambivalence.

Hypothesis 10b: Subordinates' hostility is positively associated with their experience of LMX ambivalence.

Please see Figure 1 for a summary of the hypotheses outlined in this chapter. 


\section{CHAPTER 4: LMX AMBIVALENCE AND WORKPLACE WELL-BEING}

While the preceding chapter explores the antecedents of LMX ambivalence, we now turn to the question of whether and how LMX ambivalence may influence employee well-being. Lee et al.'s (2019) pioneering study has introduced the concept of LMX ambivalence and has demonstrated that this construct has critical implications for employee task performance. However, due to the nascent nature of research in this area, LMX ambivalence has not yet been explored in relation to other work outcomes. This study extends prior research by examining the relationship between LMX ambivalence and employee work-related well-being. Employee perceptions of well-being at work reflect the quality of one's work life and can be a key determinant of various employee and organizational outcomes (e.g., health, productivity, product quality; Schulte \& Vainio, 2010). Drawing on self-determination theory and role theory, this study examines the idea that LMX ambivalence is negatively associated with two indicators of employee well-being at work: work engagement and emotional exhaustion.

Accordingly, this chapter presents a conceptual model outlining how LMX ambivalence unfolds and operates to affect employee work engagement and emotional exhaustion. In this chapter, I first provide a review of the literature regarding both ambivalence and relational ambivalence, and their respective consequences. The theoretical linkage between LMX ambivalence and work-related well-being is then be explained, followed by a discussion of the main mechanisms that are proposed to underlie these relationships. Individual differences that are hypothesized to moderate these relationships are then presented.

\subsection{Outcomes of Ambivalence}

Psychological theories such as balance theory (Heider, 1946) and cognitive dissonance theory (Festinger, 1957) have long posited that people prefer cognitive consistency and are 
motivated to reduce inconsistency. Cognitive dissonance theory suggests that when individuals hold two contradictory cognitions, an unpleasant state - dissonance - will arise (Hinojosa, Gardner, Walker, Cogliser \& Gullifor, 2017). Ambivalence involves experiencing a mix of positive and negative thoughts, thereby breaching principles of cognitive consistency and violating an individual's preference for consistency in their thoughts and perceptions (Festinger, 1957; Heider, 1946). In this respect, while ambivalence involves coexisting positive and negative perceptions, it can cause the state of dissonance, which is aversive and can lead to various negative outcomes (Cooper, 2012; Hinojosa et al., 2017).

Several experimental studies indicate that the attitudinal ambivalence can be aversive, unpleasant, and can lead to emotional discrepancies. In their experimental study, Van Harreveld, Rutjens, Schneider, Nohlen and Keskinis, (2014) asked participants in the ambivalent condition to think of a topic they have mixed thoughts or feelings about. These participants reported more negative emotions (e.g., uncertainty, anxious, irritated, doubtful, nervous) than their counterparts in the univalent condition in which participants were asked to think of something they were either positive or negative about. In another study examining the nature of ambivalent attitudes, Nordgren, Van Harreveld and Van der Pilgt (2006) assigned participants into tense or relaxed conditions (using a tense/relaxed pill manipulation). Participants then read an article designed to induce ambivalence toward an attitude object (genetically modified food). Participants in the tense-pill condition reported less intense negative emotions (i.e., tense, fearful, anxious, and angry) toward the attitude object than participants in the relaxed condition, indicating that their discomfort over the attitude object was amplified by the aversive nature of ambivalence and their expectation to feel relaxed (Nordgren et al., 2006). In a study examining the consequences of conflicted racial attitudes, Hass, Katz, Rizzo, Bailey and Moore (1992) found that racial 
ambivalence led to negative mood change while the positive or negative racial attitudes alone were not associated with negative moods. Racial ambivalence was also found to induce more negative affect when respondents were aware of holding incompatible cognitions (Hass et al., 1992). Finally, Van Harreveld, Rutjens, Rotteveel, Nordgren, and Van der Pligt (2009) examined people's reactions when they were ambivalent and needed to make a choice. Participants were given a univalent (negative) or an ambivalent text about an attitude object (i.e., the potential introduction of a new labor law) and asked to write an essay on the attitudinal topic. Results of the study showed that ambivalent attitudes were associated with greater physiological arousal (skin conductance level) when one had to make a choice (writing an essay in favor or against the issue), even before the decision was made (Van Harreveld et al., 2009).

Ambivalence has also been linked to different facets of well-being (Van Harreveld et al., 2015). In a study assessing the relationship between personal striving and subjective well-being among university students, King, Richards and Stemmerich (1998) found that ambivalence over daily goals negatively influenced goal progress. Ambivalence over goals was also related to lower life satisfaction and higher levels of depression (King et al., 1998). Similarly, using a student sample, Emmons and King (1988) assessed ambivalence in relation to 15 different personal strivings (desires to achieve or not achieve specific personal goals). Stronger perceptions of ambivalence were associated with higher levels of negative affect, depression, and physical illness. A one-year follow-up study showed that ambivalence was stable and predicted psychosomatic complaints over time (Emmons \& King, 1988).

In addition to ambivalence relating to one's goals, ambivalence relating to one's emotional expression has also been linked to measures of personal well-being. For example, Emmons and Colby (1995) found that ambivalence over emotional expression was related to a 
lower level of self-reported well-being. This relationship was mediated by perceived social support. Ambivalence regarding emotional expression has also been shown to be related to pain symptoms, and lower psychological well-being in arthritis and cancer patients (Porter, Keefe, Lipkus, \& Hurwitz, 2005; Tucker, Winkelman, Katz, \& Berman, 2006).

Taken together, these findings indicate that different forms of ambivalence may influence one's physical and psychological well-being. In line with cognitive dissonance theory, this appears to be partly a function of ambivalence reflecting a violation of consistency motives (Van Harreveld et al., 2014).

\subsection{Outcomes of Relational Ambivalence}

In addition to ambivalence relating to specific attitude objects discussed above (e.g., personal striving, emotional expression, race), ambivalence within interpersonal relationships has recently attracted increased attention in social psychological research. For example, in a study of 158 family triads (parents and adult daughters/sons), Fingerman et al. (2006) found that both parents and offspring experienced ambivalence regarding their perceptions of the parentoffspring relationship.

Compared to ambivalence toward ideas, ambivalence towards relationships may be particularly damaging to one's well-being (Methot et al., 2017; Pratt \& Pradies, 2011). Interpersonal relationships require a considerable investment of personal resources - thus, ambivalent relationships capture emotion-laden cognition (i.e., hot cognition) that may result in more dysfunctional outcomes (e.g., a perpetual state of approaching and avoiding others; unable to form close positive relationships, obsessive-compulsive disorders, schizophrenia; Pratt, \& Doucet, 2000). Consistent with this perspective, Uchino and colleagues (2014) found that more ambivalent assessments of one's spouse were associated with lower levels of cardiovascular 
health. Likewise, Uchino et al. (2001) reported that a higher number of ambivalent relationships in one's social network are related to increased levels of depression and heart rate reactivity. In a subsequent study, Uchino, Holt-Lunstad, Uno, Campo and Reblin (2007) observed that individuals experienced higher levels of stress when responding to others with whom they have an ambivalent relationship. Finally, Reblin, Uchino and Smith (2010) examined friendship quality and its influence on the effectiveness of receiving support and cardiovascular reactivity. Participants in the experiment were asked to discuss a stressful event with a friend perceived as either supportive or ambivalent. Results indicated that participants received fewer emotionally supportive and more negative behaviors from ambivalent friends. Furthermore, receiving support from an ambivalent friend was associated with higher systolic blood pressure reactivity (a consistent predictor of cardiovascular risk) compared to receiving support from a supportive friend. On the whole, findings from this research suggest that ambivalent social ties may be harmful to one's well-being because they are unpredictable and elicit increased perceptions of stress (Uchino et al., 2007).

Several studies have suggested that ambivalent relationships can be even more destructive than negative relationships (Rothman et al., 2017). In their study examining the effect of social ties on psychological outcomes, Uchino, Holt-Lunstad, Smith and Bloor's (2004) found that the number of ambivalent ties in social networks was an independent predictor of psychological distress even controlling for the number of aversive ties. Likewise, in a three-day diary study, Holt-Lunstad, Uchino, Smith, Olson-Cerny, and Nealey-Moore (2003) examined cardiovascular functioning among participants during social interactions. Healthy normotensive participants underwent blood pressure assessment after five minutes of each social interaction. After each interaction, participants also completed a diary entry about the relationship type (i.e., 
familial, romantic, spousal and work) and the quality of the interaction (i.e., positive, negative, indifferent, and ambivalence). Results demonstrated that compared to interactions with positive, negative and indifferent network ties, interactions with ambivalent network members were associated with the highest blood pressure readings (Holt-Lunstad, Uchino, Smith, Olson-Cerny \& Nealey-Moore, 2003). Later, a similar study conducted by Holt-Lunstad, Uchino, Smith, and Hicks (2007) found that individuals interacting with an ambivalent friend exhibited greater blood pressure reactivity, especially while discussing an adverse personal event.

Overall, the literature on relational ambivalence suggests that this form of ambivalence is prevalent and potentially harmful. Moreover, ambivalent views toward a social relationship can compromise certain indicators of an individual's physical and psychological well-being beyond the effects of only experiencing negative perceptions of a relationship. Given that research on ambivalence has primarily been conducted in non-work settings, this raises the question of whether this phenomenon may also be evidenced in leader-follower relationships in the workplace.

\subsection{LMX Ambivalence and Work-related Well-being}

Both balance theory (Heider, 1946) and cognitive dissonance theory (Festinger, 1957) suggest that holding two contradictory cognitions is unpleasant and aversive (Hinojosa et al., 2017). Building on this work and applying relevant models of social cognition and work motivation (e.g., self-determination theory, role theory), the current study proposes a negative relationship between LMX ambivalence and employees' well-being in the workplace.

Emotional exhaustion and work engagement have been operationalized as key indicators of work-related well-being in the literature (Bakker \& Demerouti, 2008; Bakker \& Schaufeli, 2008; Rothmann, 2003). Emotional exhaustion is the core component of workplace burnout 
(Maslach, Schaufeli \& Leiter, 2001). It refers to the feelings of being drained and depleted of emotional resources by one's work (Maslach \& Jackson 1981; Schaufeli, Maslach \& Marek, 1993). Although related to emotional exhaustion, work engagement deals with the positive aspect of employee work-related well-being. Schaufeli, Salanova, González-Romá, and Bakker (2002) define work engagement as "a positive, fulfilling, work-related state of mind that is characterized by vigor, dedication, and absorption" (p. 74). This study focuses on these two indicators of well-being as this enables a more nuanced assessment of one's well-being at work by including both positive and negative components (González-Roma, Schaufeli, Bakker, \& Lloret, 2006; Schaufeli et al., 2002).

Our arguments about the effects of LMX ambivalence on employee work-related wellbeing are consistent with self-determination theory, role theory and the role-making process in LMX (Deci et al., 2017; Kahn, 1990; Örtqvist \& Wincent, 2006). Self-determination theory provides a framework for understanding human motivation and innate psychological needs for competence, relatedness, and autonomy (Deci \& Ryan, 2001). The needs for competence, relatedness, and autonomy are essential for psychological health and well-being (Deci et al., 2017; Ryan, 1995). These three basic psychological needs must be satisfied in order for people to become more autonomously motivated and to experience a greater sense of self-determination (Gagné \& Deci, 2005). SDT asserts that when the environment provides people with autonomy support, their basic needs are more likely to be satisfied, and this can in turn, translate into enhanced perceptions of well-being in the workplace (Deci \& Ryan, 2000; Deci et al., 2017). Applied in work organizations, SDT has largely focused on the links between various workplace factors, need fulfillment (or thwarting), and employee wellness or performance in organizations (Deci et al., 2017). In particular, research testing SDT in work organizations highlights the 
important role of leadership, suggesting that the dyadic relationship between the leader and follower plays a critical role in supporting follower autonomy and influencing follower basic need satisfaction (Deci, Connell \& Ryan, 1989, Deci \& Ryan, 2000; Leroy et al., 2015).

In concert with self-determination processes, the role-making process in LMX development may also assist in explaining how LMX ambivalence influences employee need fulfillment and well-being at work. Role definition processes are fundamental to LMX development (Graen \& Scandura, 1987; Graen \& Uhl-Bien, 1995) and may play a central role in the formation of perceptions of LMX ambivalence. Ambiguous and inconsistent role expectations may elicit perceptions of ambivalence, which may hinder psychological need fulfillment. Instead of providing autonomy support to employees, LMX ambivalence may produce a stronger sense of internal conflict about the relationship, and as a result, one's sense of self in the workplace may be undermined. Consistent with role theory, work engagement involves identifying with and fully investing one's self in their work role (Kahn, 1990; 1992). Unclear and inconsistent role expectations may lower one's attachment and commitment to their work role, including how the individual relates to their leader and their specific work activities. In this respect, ambivalent attitudes toward one's LMX relationship can divert attention, create uncertainty and indecision, and consume resources, preventing employees from feeling connected and integrated into their work role (Lee et al., 2019). This reduced sense of connection and integration with one's role can, in turn, undermine employee work engagement (Bakker \& Leiter, 2010; Matta, Scott, Koopman, \& Conlon, 2015).

Both self-determination theory and role theory also suggest that discrepancies in role definitions produce need thwarting, role stress, tension, confusion and anxiety, which can lead to emotional exhaustion (Deci et al., 2017; Kahn et al., 1964; Örtqvist \& Wincent, 2006). Lower 
need fulfillment has an energy-depleting effect on individuals (e.g., Deci \& Ryan, 2000; Van den Broeck et al., 2008) and can heighten perceptions of burnout (Kovjanic et al., 2013; Trépanier, Fernet, \& Austin, 2013). Moreover, because feeling conflicted is accompanied with unpleasant feelings of being torn and a sense of contradiction, individuals need to invest their attentional resources in reducing the feelings of tension and discomfort associated with these emotionally complex states (Rothman \& Melwani, 2017). The depletion of coping resources makes individuals more likely to suffer from poor psychological well-being and adjustment (Koval \& Kuppens, 2012). Based on the preceding, I propose the following general hypotheses:

\section{Hypothesis 11a: LMX ambivalence is negatively related to subordinates' work engagement.}

\section{Hypothesis 11b: LMX ambivalence is positively related to subordinates' emotional exhaustion.}

\subsection{LMX Ambivalence, Need Fulfillment, and Work-related Well-being}

Although a handful of studies have shown that relational ambivalence can have deleterious effects on different outcomes, ranging from relational disengagement (Bushman \& Holt-Lunstad, 2009) to reduced job performance (Lee et al., 2019), research has yet to explore the specific psychological processes underlying some of these relationships. In a recent review of the ambivalence literature, Rothman et al. (2017) suggest that research must focus on the mechanisms that explain when and why ambivalence can lead to positive or negative consequences. In response to this call, this study aims to shed light on an important question that has yet to be addressed: how does ambivalence in perceptions of the LMX relationship influence well-being at the workplace? In Chapter 2, a central mechanism linking relational leadership to outcomes was discussed: basic psychological need fulfillment. In this section, I further elaborate 
on the mediating influence of psychological need fulfillment on the relationship between LMX ambivalence and workplace well-being. Specifically, drawing on self-determination theory (Deci \& Ryan, 1985, 2000; Ryan \& Deci, 2000), I discuss the proposed influence of LMX ambivalence on need fulfillment at work and explain why this process mechanism mediates the influence of LMX ambivalence on the two focal well-being outcomes: work engagement and emotional exhaustion.

\subsubsection{LMX Ambivalence and Need Fulfillment at Work}

Broadly defined, human needs refer to specific motivating forces found within individuals, including desires, wants, goals, or values (McClelland, Koestner, \&Weinberger, 1992; Ryan, 1995). According to self-determination theory (SDT), three fundamental needs, including the needs for autonomy, competence, and relatedness, reflect innate psychological nutriments essential to psychological growth, integrity, and well-being (Deci \& Ryan, 1985, 2000). These needs refer to core tendencies that can facilitate achieving effectiveness, connectedness, and coherence in different domains of one's life (Deci \& Ryan, 2000). The satisfaction of the need for autonomy is considered the most salient need (Ryan \& Deci, 2006). It refers to one's sense of volition and psychological freedom, and one's need to act in accordance with their integrated sense of self (Deci \& Ryan, 1985; Deci \& Ryan, 2000). Deci and Ryan (2008) emphasize that autonomy in SDT involves acting with the experience of choice and an absence of salient external controls (Ryan, 1995). The satisfaction of the need for competence involves feeling capable of mastering the environment, succeeding at challenging tasks, and attaining desired outcomes (Gagné \& Vansteenkiste, 2013; Deci et al., 2001). The satisfaction of the need for relatedness involves feeling a sense of belongingness and communion, and a meaningful sense of connectedness to others in one's social environment (Ryan \& Deci, 2001, 
2002).

Consistent with SDT, empirical studies have supported the notion that basic need satisfaction is a crucial condition related to thriving in different life domains, including one's school and family lives, and even in one's recreational activities (e.g., sport and exercise; Deci \& Ryan, 2008). SDT concepts have also been applied to the workplace (Van den Broeck, Ferris, Chang, \& Rosen, 2016). Need satisfaction at work is built on early research on basic psychological needs and assesses need satisfaction in the work domain (Deci et al., 2001; La Guardia, Ryan, Couchman, \& Deci, 2000). In their meta-analysis focusing on need satisfaction at work, Van den Broeck, Ferris, Chang and Rosen (2016) examined various work outcomes associated with employee perceptions of need satisfaction at work. They found that need satisfaction relating to each of the basic needs is positively associated with various indicators of well-being as well as one's work attitudes and behaviors. With respect to well-being outcomes, each of the basic needs was found to be positively related to positive affect, work engagement, and life satisfaction and negatively related to negative affect, work strain, and burnout. With respect to work attitudes and behavior, each of the basic needs was positively related to job satisfaction, affective commitment, and different measures of job performance measures (e.g., task performance, proactive performance, organizational citizenship behavior directed at both individuals and organizations) while being negatively related to turnover intentions (Van den Broeck et al., 2016).

In this research, I posit that if a follower has ambivalent cognitions regarding their relationship with this leader, this may negatively impact their perceptions of need fulfillment at work. SDT posits that support for autonomy in the environment enhances one's sense of selfdetermination and fulfillment of one's basic needs by increasing one's intrinsic motivation and 
internalized self-regulation (Deci et al., 2001). Moreover, leaders play an important role in encouraging and supporting their follower's autonomy. When leaders acknowledge and understand their followers' perspectives, provide meaningful information and feedback, offer opportunities for choice, and encourage self-initiation (Deci, Eghrari, Patrick, \& Leone, 1994), followers are more likely to perceive that their basic needs are being satisfied (Baard, Deci \& Ryan, 2004; Leroy et al., 2015). Consistent with this perspective, social support from one's manager and immediate supervisor has been found to be positively associated with overall levels of psychological need satisfaction (Baard et al., 2004; Leroy et al., 2015).

In this study, I propose that LMX ambivalence is negatively associated with need fulfillment at work for several reasons. First, perceptions of ambivalence may jeopardize the predictability of an individual's relational partner, which is essential in forming intimacy and meaningful connectedness with other human beings (Pratt \& Pradise, 2011). In this respect, LMX ambivalence may negatively influence one's sense of need fulfillment by disrupting the role-making process in LMX, leading to unclear role definitions and ambiguity in how to interact with one's leader (Hinojosa et al., 2017; Rothman et al., 2017). Second, previous research has demonstrated how ambivalence can compromise one's ability to make decisions (Rothman et al., 2017). Similarly, individuals with conflicting thoughts toward the quality of their relationship with their leader may not be able to form a consistent opinion toward that relationship, and by extension, toward their role in that relationship. Thus, LMX ambivalence may precipitate more rumination about the relationship and an inability to make important work-related decisions (e.g., whether they should take the initiative and assume greater work-related responsibilities), which may impede one's ability to take action (Rothman et al., 2017). Finally, feelings of dissonance and discomfort caused by ambivalence may divert emotional and attentional resources toward 
coping with this discomfort (Nordgren et al., 2006). In this respect, LMX ambivalence may produce a stronger sense of internal conflict about the relationship; and as a result, one's sense of self in the workplace may be undermined. Thus, the enactment of behaviors that achieve work goals and that build a meaningful relationship with their leader might be inhibited (Pratt \& Pradise, 2011; Rothman et al., 2017), thwarting one's fulfillment of their needs for autonomy, competence, and relatedness at work. Based on the reasoning above, I hypothesize the following:

\section{Hypothesis 12: LMX ambivalence is negatively associated with basic psychological} need fulfillment at work.

\subsubsection{The Mediating Role of Need Fulfillment at Work}

In addition to LMX ambivalence negatively influencing perceptions of need satisfaction at work, I propose that an employee's psychological need fulfillment at work will act as a key mediator of the effects of LMX ambivalence on employee well-being. SDT postulates that psychological needs embody nutriments essential to optimal functioning, psychological growth and wellness (Deci \& Ryan, 2000). Empirical studies have generally supported this assertion, indicating that psychological need fulfillment is positively associated with measures of wellness across various domains, ranging from one's educational outcomes to their recreational involvement, and their overall health (Deci \& Ryan, 2000; DeHaan \& Ryan, 2014; Milyavskaya \& Koestner, 2011; Ng et al., 2012). These effects are also evidenced across different cultures. For example, Chirkov, Ryan, Kim, and Kaplan (2003) demonstrated that fulfillment of one's need for autonomy predicted overall well-being (happiness and self-fulfillment) across four countries (i.e., South Korea, Russia, Turkey, and the United States). Likewise, Deci and colleagues (2001) found that basic psychological need satisfaction predicted perceptions of wellbeing both in collectivistic and individualistic cultures (i.e., Bulgaria and the United States). 
According to the SDT perspective, one of the main reasons that need satisfaction at work promotes employee well-being is that need satisfaction facilitates autonomous motivation (Deci et al., 2017; Gagné \& Deci, 2005). Autonomous motivation exists when an individual is engaged in an activity with a sense of willingness, volition, and choice (Deci et al., 2017). People who are autonomously motivated experience improved well-being because they pursue what is intrinsically valuable to them and act in line with their sense of self (DeHaan \& Ryan, 2014). In this regard, individuals who are autonomously motivated tend to experience a stronger sense of work engagement as they genuinely enjoy and want to do their work (Deci \& Ryan, 2000). In line with this premise, empirical studies have linked need fulfillment to both employee autonomous motivation and well-being in the workplace. In a study on workaholism, Andreassen, Hetland, and Pallesen (2010) found that satisfaction of employees' basic psychological needs at work led to greater enjoyment of their job but also a weaker sense of obligation to perform their job (a component of workaholism). Likewise, De Cooman, Stynen, Van den Broeck, Sels, and De Witte (2013) examined the basic need satisfaction and autonomous motivation of 689 Belgian employees and found that employees who felt greater need satisfaction on the job also displayed greater autonomous motivation and work-related effort.

The satisfaction of the three needs in the workplace has also been shown to be positively related to employee well-being. A highly cited study conducted by Baard, Deci, and Ryan (2004) found that basic need satisfaction on the job was positively related to employees' feelings of vitality, vigor, and dedication, and was negatively related to indicators of ill-being (e.g., anxiety, somatization symptoms, depression). Applying SDT to the Job Demands-Resources model, Van den Broeck, Vansteenkiste, De Witte and Lens (2008) argued and found that basic need 
satisfaction at work was associated with lower levels of emotional exhaustion and higher work engagement. Likewise, Fernet, Austin, Trépanier, and Dussault (2013) found that psychological need satisfaction mediated the relationship between job demands, job resources, and three components of employee burnout (i.e., emotional exhaustion, depersonalization, and personal accomplishment). Conversely, Vander Elst, Van den Broeck, De Witte and De Cuyper (2012) showed that frustration of basic needs might result in reduced employee work-related well-being, as evidenced by increased emotional exhaustion.

Perceptions of one's leader have also been linked to employee well-being through need fulfillment. For instance, Gillet, Fouquereau, Forest, Brunault, and Colombat (2012) found that workers' perceptions of supervisor controlling behaviors (e.g., motivating workers by making them feel guilty for not doing enough) were associated with employees' psychological need thwarting, which in turn, negatively influenced employee eudaemonic well-being (levels of selfrealization), happiness and work satisfaction. Likewise, Kovjanic, Schuh, and Jonas (2013) reported that need satisfaction mediated the path between perceptions of supervisor transformational leadership style and employee work engagement, highlighting the role that transformational leader behavior may play in fostering need satisfaction and the enjoyment of one's work. Similarly, Williams et al. (2014) found that managers' support for their employees' basic psychological needs prompted fewer psychosomatic symptoms and less emotional exhaustion. They deduced from these findings that managers' adoption of an employee-focused leadership style promoted employees' autonomous self-regulation at work (Williams et al., 2014). Taken together, these studies demonstrate that a supportive approach to leadership can enhance an employee's sense of need satisfaction at work, which in turn, can act as a catalyst for positive employee well-being outcomes, including higher levels of engagement and lower levels 
of burnout.

It is also likely that the negative impact of LMX ambivalence on emotional exhaustion and work engagement can be explained by the frustration of basic psychological needs. Perceptions of ambivalence produce dissonance and discomfort that can drain one's emotional and attentional resources at work. Moreover, by hindering the role-making process in the leaderfollower relationship, perceptions of ambivalence may further undermine one's sense of need fulfillment at work. Because lower need fulfillment has an energy-depleting effect on individuals (e.g., Deci \& Ryan, 2000; Van den Broeck et al., 2008) and can, therefore, lower work engagement and heighten perceptions of burnout (Kovjanic et al., 2013; Trépanier et al., 2013), I posit that psychological need fulfillment will mediate the influence of LMX ambivalence on both work engagement and exhaustion. Therefore, the following hypotheses are proposed:

Hypothesis 13a: Need fulfillment at work mediates the relationship between LMX ambivalence and work engagement.

Hypothesis 13b: Need fulfillment at work mediates the relationship between LMX ambivalence and emotional exhaustion.

\subsection{Moderating Effects of Collectivism and Positive Meaning in Work}

In their recent review of ambivalence in workplace relationships, Methot and colleagues (2017) call for research exploring boundary conditions that might influence the relationship between perceptions of ambivalence and work outcomes. Consistent with this call to probe potential boundary conditions, the present study investigates two key moderating variables of the proposed relationships - collectivism and positive meaning in work. As suggested by role theory and previous work on LMX formation (Dienesch \& Liden, 1986; Graen \& Scandura, 1987), 
clear role identities play a central role in LMX development. Likewise, social identification processes can be instrumental in shaping how one perceives and responds to their leader (Jackson \& Johnson, 2012; Smith \& Semin, 2007; Van Knippenberg, Van Knippenberg, De Cremer, \& Hogg, 2004). In this respect, factors related to one's self-concept and the meaningfulness of their work may influence how employees respond to LMX ambivalence. Collectivism reflects the degree to which group membership is central to one's self-concept (Oyserman, Coon \& Kemmelmeier, 2002). As I discuss below, if an employee strongly values and identifies with their workgroup or other group entities (the organization) rather than their own self- interests, this should mitigate the detrimental effects of LMX ambivalence on need fulfillment and work-related well-being. Likewise, if an employee experiences a sense of positive meaning in their work, they will perceive that their job is more aligned with their values, and this may buffer the potentially damaging influence of LMX ambivalence on need fulfillment and well-being at work. Below, I further explain these proposed moderating effects.

\subsubsection{Collectivism}

Collectivism has been treated as a national-level cultural construct (Hofstede, 1980) as well as an individual-level personal value reflecting one's conceptualization of the self (Hui, 1988; Triandis, Leung, Villareal \& Clack, 1985; Markus \& Kitayama, 1991). In this study, the individual-level perspective on collectivism is adopted. The individual-level conceptualization of collectivism takes a within-culture, individual differences perspective (Wagner \& Moch, 1986). This perspective has been adopted widely in the literature and has indicated that individual-level collectivism is positively associated with a number of employee attitudes and behaviors, ranging from job satisfaction and organizational commitment to task and citizenship performance, and cooperation in groups (e.g., Kirkman \& Shapiro, 2001; Moorman \& Blakely, 1995; Wagner, 
1995; Van Dyne, Vandewalle, Kostova, Latham \& Cummings, 2000).

High levels of collectivism indicate that group membership is a central aspect of one's self-concept (Hofstede, 1980; Kim, 1994; Markus \& Kitayama, 1991; Oyserman et al., 2002). People high in collectivism value group membership and emphasize group goals and cohesiveness (Van Dyne et al., 2000; Wagner, 1995). They tend to define themselves in relation to the group, attribute success to cooperation, and value and seek a sense of social belonging (Triandis et al., 1985). People high in collectivism value and recognize the importance of social interdependence and tend to put aside their self-interests and personal desires when they conflict with group goals (Triandis, 1995). They care about whether they belong to organizations and whether they "fit in" with respect to their relationships with others (Triandis, 1990). It is important for them to follow norms and rules prescribed by social groups and to maintain harmonious relationships with others in these groups (Fischer et al., 2009; Oyserman et al., 2002; Triandis, 1995). Collectivistic individuals are also more likely to retrieve collective selfcognitions and use more collective and interdependent descriptors to define themselves (Trafimow, Triandis, \& Goto, 1991).

As a result of collectivistic individuals' higher emphasis placed on group-level identity, I propose that employee collectivism may weaken the role of need fulfillment in mediating the effects of LMX ambivalence (i.e., Stage 1 moderated mediation, Edwards \& Lambert, 2007). Having contradictory opinions towards their role in the relationship with the leader, collectivists may still have a clear sense of self as a member of the group (e.g., work team; organization). They may also shift their attention to factors such as group-level collective outcomes (e.g., team performance, group benefits) to define their roles. Their ability to act in accordance with one's sense of self in the workplace will therefore be less likely to be inhibited by ambivalent 
perceptions of their LMX relationship. In contrast, employees low in collectivism possess a sense of identity that is distinct from their group membership. In this respect, their self-concept may be more strongly negatively impacted by their experience of LMX ambivalence. Because LMX quality is associated with the attainment of important individual career outcomes for the employee (e.g., promotions, career-enhancing assignments; Kraimer, Seibert \& Astrove, 2015), ambivalent perceptions of the LMX relationship for employees low on collectivism may have a more pronounced negative effect on their sense of need fulfillment.

Furthermore, in contrast to individuals lower on collectivism, individuals higher on collectivism may also maintain a generally more positive view of their leader even when experiencing feelings of ambivalence. One essential element of collectivism is the premise that groups bind and create a sense of mutual obligation among individuals (Oyserman et al., 2002). As a result, collectivists tend to rely more on their ingroups and their relationships at work as a social capital resource (Warren, Dunfee, \& Li, 2004; Yang et al., 2012). Accordingly, when facing stressful circumstances at work, collectivistic employees may be more likely to seek and garner the support of others in the workplace, such as their work colleagues (Triandis, Bontempo, Villareal, Asai \& Lucca, 1988; Yang et al., 2012). In this respect, social support from their colleagues may buffer the negative effect of LMX ambivalence on one's sense of need fulfillment for collectivistic individuals.

Finally, collectivists tend to maintain relationships even when negative factors impacting the quality of their relationship with others exist. Because collectivists have a strong desire to be attached to a collective group (Brewer \& Chen, 2007; Earley, 1993) and protecting harmonious relationships is valuable for them (Erdogan \& Liden, 2006), high levels of LMX ambivalence may less readily impact this sense of need satisfaction at work. Erdogan and Liden (2006), for 
example, found collectivists were less likely to engage in behaviors that would lower the quality of their relationship with their leader when they perceived injustice (i.e., they are not fairly treated and rewarded). Building on this work, I propose that collectivism may enable followers to maintain higher levels of need satisfaction at work even when facing contradictory thoughts about their relationship with their leader. Thus, as outlined above (Hypotheses 13a and 13b), LMX ambivalence is expected to influence work engagement and emotional exhaustion via need fulfillment processes; however, these relationships will be stronger for followers lower in collectivism. The following hypotheses will therefore be tested:

Hypothesis 14: Collectivism moderates the indirect effect of LMX ambivalence on work engagement through need fulfillment at work such that the mediated effect will be stronger for subordinates with low rather than high collectivism.

Hypothesis 15: Collectivism moderates the indirect effect of LMX ambivalence on emotional exhaustion through need fulfillment at work such that the mediated effect will be stronger for subordinates with low rather than high collectivism.

\subsubsection{Positive Meaning in Work}

As illustrated in Figure 2, employee perceptions of positive meaning in their work are positioned as a second moderator of the mediating effect of need fulfillment at work on the LMX ambivalence - well-being relationship. Positive meaning in work refers to one's judgement of whether they view their work as having personal significance and meaningfulness, and as being worth doing (Steger, Dik \& Duffy, 2012). These perceptions reflect whether one's work is aligned with their values, goals, and beliefs (Harpaz \& Fu, 2002; Kinjerski \& Skrypnek, 2004). Perceptions of work meaningfulness are socially and individually constructed and play a significant role in shaping one's sense of work identity (Rosso, Dekas \& Wrzesniewski, 2010; 
Pratt \& Ashforth, 2003). Perceptions of positive meaning in one's work can be differentiated from one's sense of need fulfillment as the former focuses more specifically on individuals' interpretations of the significance of their work activities and work experiences based partly on societal and cultural forces (Rosso et al., 2010; Wrzesniewski, Dutton, \& Debebe, 2003). For example, scholars have proposed that work is likely to be perceived as meaningful when the social norms and cultural systems ascribe value to people's work activities (Rosso et al., 2010; Ros, Schwartz \& Surkis, 1999). Meaningful work is related to a number of important workrelated variables, such as being able to use one's strengths at work and greater intrinsic work motivation (Arnold, Turner, Barling, Kelloway, \& McKee, 2007; Duffy \& Dik, 2013; LittmanOvadia \& Steger, 2010; Steger et al., 2012). Indeed, Arnold et al (2007) suggest that finding positive meaning in one's work is a critical intrinsic reason for working (Arnold et al., 2007). Likewise, Spreitzer, Kizilos and Nason (1997) stated that meaning serves as the "engine of empowerment" (p. 681). Indeed, several authors have described finding meaning in events as a "fundamental human motive" (Britt, Adler, \& Bartone, 2001, p. 54).

Finding one's work meaningful implies that there is congruence between one's selfconcept and their work behavior (Rosso et al., 2010). Because meaningful work is positively related to higher levels of intrinsic motivation and internal regulation, it can also facilitate psychological need fulfillment at work. In this respect, I propose that positive meaning may buffer the negative influence of ambivalence on need fulfillment and well-being. Although employees experiencing LMX ambivalence have inconsistent opinions towards their role in the relationship with the leader, if they have a positive sense of meaning in their work, they should still maintain a positive sense of work identity and pay more attention to the value and outcomes of their work (Quintanilla, 1991). In this respect, individuals who perceive positive meaning in 
their work will still behave autonomously and take responsibility for their decisions and actions (Clark, 1995; Lee, 2015). These employees should therefore still feel more confident and willing to invest effort toward realizing their potential in the workplace even when experiencing ambivalence toward their leader (Lee, 2015; Morrison, Burke \& Greene, 2007). Employees experiencing positive meaning may also convey passion to their colleagues which may help them to forge stronger relationships that offset the negative effects of LMX ambivalence on need fulfillment and well-being. In contrast, employees who do not perceive higher levels of meaning in their work, may be more vulnerable to experiencing the negative effects of LMX ambivalence. Indeed, previous work has found that stronger perceptions of meaning at work can protect employees from work-related stress and elevate perceptions of meaning in life (Allan, Douglass, Duffy \& McCarty, 2016). Based on the preceding, I propose the following hypotheses:

Hypothesis 16: Positive meaning in work moderates the indirect effect of LMX ambivalence on work engagement through need fulfillment at work such that the mediated effect will be stronger for subordinates with less positive meaning in their work.

Hypothesis 17: Positive meaning in work moderates the indirect effect of LMX ambivalence on emotional exhaustion through need fulfillment at work such that the mediated effect will be stronger for subordinates with less positive meaning in their work.

\subsection{Summary of Hypotheses}

In this chapter, I presented a moderated mediation model (Figure 2) in which need fulfillment at work is hypothesized to mediate the relationship between follower perceptions of LMX ambivalence and both work engagement and emotional exhaustion. Guided by self- 
determination theory and research suggesting that one's self-concept and perceptions on one's work may moderate the effect of LMX ambivalence, I further propose that two variables collectivism and positive meaning in work - may buffer the proposed negative effects of LMX ambivalence on need fulfillment and the two indicators of well-being: work engagement and emotional exhaustion. Each of the hypotheses presented in this chapter and Chapter 3 is summarized in Table 1. 


\section{CHAPTER 5: METHODOLOGY}

This chapter details the research methodology employed. I begin with an introduction to the research setting and sample. This is followed by a description of the research design, including the specific procedures and measures used.

\subsection{Research Setting}

To test the proposed antecedents of LMX ambivalence (Figure 1) and the moderated mediation model of LMX ambivalence and work-related well-being (see Figure 2), I conducted a field study with a large police organization. Participants included police officers and their respective supervisors. This research involved administering two separate surveys to employees to assess their focal dispositional characteristics (Figure 1) as well as their perceptions of LMX ambivalence and each of the variables outlined in the proposed moderated mediation model (Figure 2). Supervisors of the employees were also asked to complete a survey assessing their dispositional characteristics. The final sample consisted of subordinates who completed both employee surveys, and supervisors who responded to the supervisor survey. In total, 281 subordinates responded to both the first and second employee survey, and 130 responses were received for the supervisor survey ${ }^{1}$.

\subsection{Research Design}

A time-separated design was employed in which data were collected via surveys administered at two different points in time. Adopting this design can reduce problems associated with common method variance (CMV) and allow stronger inferences regarding the direction of the proposed relationships compared to a cross-sectional design in which data is

\footnotetext{
${ }^{1}$ With one exception, employees who responded to the survey did not share the same supervisor. As a result, nonindependence in the data was not an issue in this study.
} 
collected at one point in time (Podsakoff, MacKenzie, \& Podsakoff, 2012; Taris \& Kompier, 2014).

Staff members were invited to participate in the study via the weekly newsletter e-mailed to all police officers in the organization. The newsletter provided a brief description of the research project, the investigators, how long the survey will take to complete, and assurances of confidentiality. The newsletter informed officers that the purpose of the study is to examine how various individual differences and perceptions of the work environment affect employee well-being and performance. A link to the first employee survey was included in the newsletter's invitation to participate in the research. Employees who agreed to participate in the research were able to click the link and were directed to the survey website to respond to the first online survey. The surveys were administered through Carleton University's Qualtrics survey system. Qualtrics employs multiple layers of security to make sure that data remains private and secure.

At Time 1, employees responded to the first employee survey. This survey asked general demographic/background questions (e.g., gender, age, job tenure, tenure of relationship with direct supervisor) as well as questions regarding their personality and LMX ambivalence (see specific "Measures" below). At the end of the first online survey, participants were asked to fill in their email address if they were willing to participate in the follow-up survey. They were also asked to invite their direct supervisor to participate in the survey by providing the email address of their supervisor. Employees were informed that inviting their supervisor to participate was completely voluntary and under no circumstance would individual response data be released to anyone at their organization. Supervisors whose email addresses were provided were sent an invitation to participate in the study and were asked to respond to a survey containing measures 
assessing their personality and basic demographic background (e.g., gender, age, organizational tenure).

Three months later, those employees who previously agreed to be contacted to participate in the follow-up survey were invited via email to complete the second online survey (Time 2). The three-month duration between surveys is consistent with previous time-separated studies assessing LMX relationships (e.g., Bauer et al., 2006; Lee et al., 2019; Lin \& Leung, 2010; Stinglhamber \& Vandenberghe, 2003). This time period is deemed to be sufficiently long to allow change to occur, but is not long enough that radical changes in the work environment may take place that may bias results of the study (e.g., relocation, organizational restructuring) (Demerouti, Bakker \& Bulters, 2004; Mitchell \& James, 2001). In the second survey (Time 2), employees were asked to complete measures assessing their LMX ambivalence and each of the variables included in the proposed moderated mediation model (Figure 2), including need fulfilment at work, work engagement, and emotional exhaustion. Collectivism and positive meaning in work were also assessed at Time 2 . Each employee survey took approximately 15-20 minutes to complete. Responses from the two employee surveys and the supervisor survey were matched by requesting respondents' employee identification (HRIS) number. All responses were kept strictly confidential.

\subsection{Measures}

The following measures were used in the study (please see the Appendix for a list of all of the items for each scale). For each of the measures, scale items were averaged to create a composite mean score. Cronbach's alpha coefficients were calculated to gauge whether the measures used in the study have acceptable levels of internal consistency.

LMX. Subordinates reported their LMX by responding to the LMX-6 scale (Schriesheim, 
Neider, Scandura \& Tepper, 1992) at Time 1. Sample items include: “The way my supervisor sees it, the importance of my job to his/her performance is: $5=$ very great-it critically affects his/her performance, $4=$ great, $3=$ moderate, $2=$ somewhat, $1=$ slight-it has little effect on his $/$ her performance". Cronbach's alpha for this scale was 0.83 .

LMX ambivalence. Lee's (2016) seven-item measure of LMX ambivalence was used to assess followers' LMX ambivalence at both times 1 and 2. Lee (2016) adapted this scale's items from the LMX-7 (Graen \& Uhl-Bien, 1995) and Jamieson's (1993) ambivalence scale, and reported evidence supporting its reliability and validity, including its discriminant validity in relation to measures of LMX quality and LMX attitude importance. In completing the scale, participants were asked to indicate if they have conflicting thoughts relating to each item. Sample items include: "I have conflicting thoughts: sometimes I think my supervisor would use his/her power to help to solve problems in my work, while at other times I don't." and "I have conflicting thoughts: sometimes I think my supervisor recognizes my potential, while at other times I don't." With each statement, participants indicated their level of agreement using a seven-point Likert scale ( $1=$ strongly disagree to $7=$ strongly agree). Cronbach's alphas for LMX Ambivalence were 0.92 and 0.93 for Time 1 and Time 2 measurements, respectively.

"Big Five" personality constructs. The Ten Item Personality Inventory (TIPI; Gosling, Rentfrow, \& Swann, 2003) was used to assess supervisor and subordinate scores on each of the Big Five Constructs at Time 1. The TIPI uses descriptive traits from other widely used instruments such as Goldberg's Big Five measure (Goldberg, 1992), the Big Five Inventory (John, Donahue \& Kentle, 1991) and Adjective Checklist markers (John \& Srivastava, 1999) to maximize content validity. Each of the five personality dimensions is measured by two opposite items, each consisting of a pair of descriptive traits. Participants were asked to indicate the extent 
to which they agree or disagree with each statement. All items were assessed on a five-point scale ranging from 1 (strongly disagree) to 5 (strongly agree). Although this scale is short (10 items), it demonstrates adequate test-retest reliability and convergent validity in relation to other Big Five measures such as Goldberg's (1992) 100-item Big Five measure, Costa and McCrae's (1992) NEO Five-Factor Inventory, John and Srivastava's 44-item Big Five Inventory (BFI), and Goldberg, Johnson, Eber, Hogan, Ashton, Cloninger, and Gough's (2006) 50-item International Personality Item Pool (IPIP) FFM measure (Ehrhart et al., 2009; Gosling et al., 2003). Moreover, the reliability and validity of TIPI have been supported across different samples of respondents, including respondents from the U.S., Germany, Holland, Iran, Japan and Spain (Atari, Barbaro, Sela, Shackelford \& Chegeni, 2017; Ehrhart et al., 2009; Hofmans, Kuppens \& Allik, 2008; Oshio, Shingo \& Cutrone, 2012; Herzberg \& Brähler, 2006; Romero, Villar, Gómez-Fraguela \& López-Romero, 2012). Sample items include: "Reserved, quiet" (reverse-scored; Extraversion); “Anxious, easily upset" (reverse-scored; Emotional Stability); "Sympathetic, warm" (Agreeableness); "Open to new experiences, complex" (Openness to Experience), and "Dependable, self-disciplined" (Conscientiousness). In the subordinate sample, Cronbach's alphas for the TIPI scales were: Extraversion $=0.76$, Agreeableness $=0.48$, Conscientiousness $=$ 0.45 , Openness $=0.32$, and Emotional Stability $=0.65$. In the supervisor sample, Cronbach's alphas for the TIPI scales were: Extraversion $=0.73$, Agreeableness $=0.34$, Conscientiousness $=$ 0.68 , Openness $=0.53$, and Emotional stability $=0.62$. Alphas were relatively low due to the concise nature of this measure (Gosling et al., 2003); however, these alpha coefficients were consistent with those reported in previous studies using the TIPI scale (e.g., Atari et al., 2017; Jonason, Teicher, \& Schmitt, 2011).

Dominance and prestige orientations of supervisor. Subordinates' perceptions of their 
supervisor's use of dominance and prestige strategies were assessed using the eight-item version of Cheng, Tracy, and Henrich's (2010) Dominance-Prestige scales. This measure was developed by selecting the highest loading items in Cheng et al.'s (2010) 17-item other-report DominancePrestige Scales and has been used in several recent studies (e.g., Redhead, Cheng, Driver, Foulsham \& O'Gorman, 2019; Witkower, Tracy, Cheng \& Henrich, 2019). The measurement of these two strategies as trait-like dispositions has been supported in prior studies (Cheng et al., 2013). Cheng et al.'s (2010) Dominance-Prestige Scales have demonstrated discriminant validity, and validity in predicting various outcomes, including social influence and social rank (Cheng et al., 2010; Cheng et al., 2013). Participants were asked to indicate the extent to which each statement describes their direct supervisor by using a seven-point Likert scale $(1=$ not at all; $7=$ very much). Sample statements for the Dominance scale include: "My supervisor enjoys having control over other members of the group" and "My supervisor often tries to get his/her way regardless of what others in the group may want". Sample items for the Prestige scale include: "Members of my group respect and admire my supervisor" and "Members of my group do not value my supervisor's opinion" (reverse-scored). Cronbach's alphas for these scales were: dominance of supervisor: 0.91 ; prestige of supervisor: 0.87 .

Trait anger and hostility. The three-item trait anger and three-item hostility scales from the Brief Aggression Questionnaire (Webster et al., 2014) were used to measure subordinates' trait anger and hostility at Time 1 . Webster and colleagues $(2014,2015)$ have provided evidence supporting the test-retest reliabilities of these scales as well as their validity in predicting behavioral aggression over time. They also supported the convergent validity of the 3 -item trait anger scale in relation to the 15 -item trait anger scale from the State-Trait Anger Scale (Spielberger et al., 1983), Revenge Planning and Displaced Aggression scales in the Displaced 
Aggression Questionnaire (Denson, Pedersen, \& Miller, 2006) and Irritability subscale in the Buss-Durkee Hostility Inventory (BDHI; Buss \& Durkee, 1957). The three-item hostility scale has been shown to display convergent validity with hostility subscales in the Displaced Aggression Questionnaire (Denson et al., 2006) and Buss-Durkee Hostility Inventory (BDHI; Buss \& Durkee, 1957). In both the trait anger and the hostility scales, respondents were asked to record their level of agreement with each item using a five-point Likert scale ranging from $1=$ "strongly disagree" to $5=$ "strongly agree". Sample items for the trait anger scale include: "I am an even-tempered person" (reverse-scored) and "Sometimes I fly off the handle for no good reason". Sample items for hostility are: "I sometimes feel that people are laughing at me behind my back" and "When people are especially nice, I wonder what they want". Cronbach's alphas for the trait anger scale and hostility scales were 0.80 and 0.66 , respectively.

Need fulfillment at work. A six-item version of the Basic Psychological Needs at Work Scale (La Guardia et al., 2000; Van der Cammen, Hofmans, \& Theuns, 2014) was used to measure the satisfaction of the basic psychological needs at work (Time 2). Participants were asked to indicate the extent to which they agree with each of the statements related to their experiences on the job. Sample items include: "People at work tell me I am good at what I do", "I feel like I can provide a lot of input into deciding how my job gets done", and "I get along with people at work". All items were answered on a seven-point Likert scale ( $1=$ strongly disagree, $7=$ strongly agree). According to SDT, the fulfillment of one need is closely associated with the fulfillment of the two other needs (Gagné, 2003; Van den Broeck et al., 2008), while the frustration of any need leads to similar negative outcomes (Deci \& Ryan, 2000; Lian, Ferris \& Brown, 2012). Indeed, empirical studies have indicated that the three needs overlap considerably and load on a single factor in various settings (e.g., Baard et al., 2004; Sheldon \& Niemiec, 2006; 
Uysal, Lin, \& Knee, 2010; Van den Broeck et al., 2008). Thus, based on theoretical assumptions of SDT and in line with earlier research (e.g., Baard et al., 2004; Deci et al., 2001; De Cooman et al., 2013; Gillet et al., 2012; Hetland et al., 2015; Lian et al., 2012; Rosen, Ferris, Brown, Chen \& Yan, 2013; Van den Broeck et al., 2008; Vansteenkiste et al., 2007), the composite scores for the three facets of need satisfaction were aggregated and applied as an overall index of the satisfaction of basic psychological needs. Cronbach's alpha for this scale was 0.64 .

Collectivism. Erez and Earley's (1987) four-item scale was administered at Time 2 to measure individual differences in collectivism. This scale has been widely used to assess collectivism in different cultural settings and has garnered support for its construct validity (e.g., Earley, 1989; Earley, 1993; Rong, Secchi \& Shou, 2018; Song \& Kim, 2009; Wagner, 1995). Sample items include: "Only those who depend on themselves get ahead in life (reversescored)", and "Working with a group is better than working alone". Participants record responses on a five-point Likert scale ( $1=$ strongly disagree; $5=$ strongly agree). Cronbach's alpha was 0.63 for this scale.

Positive meaning in work. Steger and colleagues' (2012) four-item scale was used to measure subordinate' perceived positive meaning in work at Time 2. Sample items include: "I have found a meaningful career" and "I have a good sense of what makes my job meaningful". Participants recorded responses on a five-point Likert scale ( $1=$ strongly disagree; $5=$ strongly agree). Cronbach's alpha for this scale was 0.92 .

Work engagement. The three-item version of the Utrecht Work Engagement Scale (UWES-3; Schaufeli, Shimazu, Hakanen, Salanova \& De Witte, 2017) was used to measure subordinates' work engagement at Time 2. Since its development, this scale has been used in many empirical studies (e.g., Fiorilli, Schneider, Buonomo \& Romano; 2019; Gillet, Caesens, 
Morin \& Stinglhamber, 2019; Nikolova, Schaufeli \& Notelaers, 2019) and has been shown to perform in a similar manner to the longer nine-item Utrecht Work Engagement scale (i.e., UWES-9) with respect its internal consistency, construct validity, and correlations with job demands and job resources (Schaufeli et al., 2017). Sample items include: “At my work, I feel bursting with energy" and "I am enthusiastic about my job". Responses are recorded using a seven-point Likert-type scale $(1=$ never to $7=$ always $)$. Cronbach's alpha was 0.84 for this scale.

Emotional exhaustion. The three-item version of the emotional exhaustion scale from the Maslach Burnout Inventory (MBI) was used to assess subordinates' emotional exhaustion (Time 2; Leiter \& Shaughnessy, 2006). The MBI-General Survey (Schaufeli, Leiter, Maslach \& Jackson, 1996) is the most widely used instrument for assessing burnout (Schaufeli, Bakker, Hoogduin, Schaap \& Kladler, 2001). The three-item version of the scale was developed by assessing item loadings and error correlations of the original items (Leiter \& Shaughnessy, 2006). Sample items include: "I feel burned out from my work" and "I feel tired when I get up in the morning and have to face another day on the job". Responses are recorded on a seven-point frequency scale ranging from 1 "never" to 7 "always". The alpha coefficient for this scale was 0.84 .

Demographic variables. Both supervisors and subordinates were asked to respond to a number of questions assessing various demographic factors, including their gender $(1=$ male; $2=$ female), age (i.e., year of birth), education level, job tenure (i.e., number of years and months), and the length of time the subordinates have worked with their supervisor (i.e., "dyad tenure").

\subsection{Method of Data Analysis}

As outlined in Chapter 3 and Chapter 4, this study examines two models. The first model (Figure 1) is designed to test various demographic and dispositional antecedents of LMX 
ambivalence. The second model (Figure 2) tests a more complex set of relationships in which LMX ambivalence is hypothesized to influence two components of work-related well-being (i.e., work engagement, and emotional exhaustion) via moderated mediating mechanisms.

In the first stage of data analysis, four sets of confirmatory factor analyses (CFA) were conducted to verify the distinctiveness of the scales used in the study. Also, for both models, basic descriptive statistics (i.e., means, standard deviations) and zero-order correlation coefficients were calculated to provide a basic understanding of the variables in each model and the correlations between variables.

In the second stage of data analysis, hierarchical regression analyses were conducted using SPSS to test the hypotheses delineated in model 1. Two separate hierarchical regression analyses were conducted - one focusing on dispositional antecedents of the subordinate, and the other dispositional antecedents of the supervisor ${ }^{2}$. To test the more complex moderated mediation model illustrated in model 2, conditional process analysis was conducted using the latest PROCESS macro (Hayes, 2018). PROCESS was designed to enable simultaneous testing of models that include both mediation and moderation (Hayes, 2018). A bootstrapping approach with 10,000 repetitions was employed to obtain accurate parameter estimates for the hypothesized direct and indirect effects (Hayes, 2018). Because the proposed model (Figure 2) specifies a mediator qualified by two moderating effects at Stage 1, model specification 9 was employed (Hayes 2018). The specific data analysis process and corresponding results are described in more detail in the next chapter.

\footnotetext{
${ }^{2}$ Before conducting these analyses, data were inspected for normality. Most variables displayed distributions that were close to normal, however, there were a couple of exceptions with respect to some of the control/predictor variables (e.g., dyad tenure; supervisor and subordinate gender). Because these distributions reflect true variance (not error variance) related to the nature of the sample, these data were retained and not adjusted/transformed (Aguinis, Gottfredson, \& Joo, 2013).
} 


\section{CHAPTER 6: RESULTS}

This chapter reports results from data analyses testing the proposed models. The chapter begins with results from the confirmatory factory analyses testing the factor structure and distinctiveness of the measures used in the study. This is followed by results from the analyses used to test the proposed antecedents of LMX ambivalence, and the estimation of the hypothesized moderated mediation model.

\subsection{Confirmatory Factory Analyses}

Confirmatory factor analyses (CFA) were conducted using AMOS software to assess the distinctiveness of each of the perceptual variables assessed in the study. CFAs were conducted on four sets of constructs: 1. follower personality attributes (i.e., the Big Five personality traits, subordinate trait anger, subordinate hostility), 2. supervisor personality attributes (i.e., the Big Five personality traits, supervisor dominance, supervisor prestige-seeking), 3. LMX and LMX ambivalence, and 4. the remaining perceptual variables proposed in the moderated path model (i.e., collectivism, positive meaning in work, need fulfillment at work, emotional exhaustion, work engagement).

\subsubsection{Subordinate Personality}

To test the discriminant validity of the personality scales of the follower, CFAs were conducted comparing the hypothesized seven-factor model and four competing models: a sixfactor model, a three-factor model, a one-factor model, and the null (independence) model. The hypothesized seven-factor model specified the Big Five personality constructs, trait anger, and hostility as distinct but correlated factors. The six-factor model tested the same model but combined trait anger and hostility into one factor. The three-factor model tested trait anger and hostility as separate factors but combined the Big Five personality constructs into one factor. The 
one-factor model specified that all personality items load onto one overall latent factor. The null (independence) model assumed that each of the seven sets of personality items was unrelated. Model fit indices for these CFAs are reported in Table 2. Results indicated that the hypothesized seven-factor model $\left(\chi^{2}=189.24, \mathrm{~d} f=83, \mathrm{CFI}=.89, \mathrm{TLI}=.82, \mathrm{RMSEA}=.07\right)$ provided a good fit to the data. The seven-factor model produced better comparative fit indices (AIC=327.24, RMSEA=.07) than the six-factor model (AIC=396.13, RMSEA=.09), the three-factor model $(\mathrm{AIC}=544.15, \mathrm{RMSEA}=.11)$, the one-factor model $(\mathrm{AIC}=677.13$, $\mathrm{RMSEA}=.13)$, and the independence model (AIC=1150.22, RMSEA=.16).

\subsubsection{Supervisor Personality}

To examine the distinctiveness of the seven personality measures relating to the supervisor, CFAs were conducted comparing the hypothesized seven-factor model and four competing models: a six-factor model, a three-factor model, a one-factor model, and the null (independence) model. The hypothesized seven-factor model specified supervisor Big Five personality constructs, dominance, and prestige as distinct but correlated factors. The six-factor model was similar but combined dominance and prestige into one factor. The three-factor model tested dominance and prestige as separate factors but merged the Big Five personality constructs into one factor. Finally, the one-factor model specified that all personality items load on one overall latent factor, and the null (independence) model assumed that each of the seven personality scales was unrelated. Results of model fit indices are reported in Table 3. Results indicated that the hypothesized seven-factor model $\left(\chi^{2}=213.67, \mathrm{~d} f=114, \mathrm{CFI}=.95, \mathrm{TLI}=.92\right.$, RMSEA $=.06$ ) provided an acceptable fit to the data. The seven-factor model produced better comparative fit indices $(\mathrm{AIC}=363.67, \mathrm{RMSEA}=.06)$ than the six-factor model $(\mathrm{AIC}=634.46$, RMSEA=.11), three-factor model (AIC=446.97, RMSEA=.07), one-factor model (AIC=853.36, 
RMSEA=.13), and the independence model $(\mathrm{AIC}=2168.69, \mathrm{RMSEA}=.20)$.

\subsubsection{LMX and LMX Ambivalence}

To determine the distinctiveness of LMX quality and LMX ambivalence measured at Time 1, CFAs were conducted comparing the hypothesized two-factor model and two competing models: a one-factor model and the null (independence) model. The hypothesized two-factor model specified LMX quality and LMX ambivalence as distinct but correlated factors. The onefactor model specified that all LMX and LMX ambivalence items load on one overall latent factor while the null (independence) model assumed that the items for each scale are unrelated. Model fit indices from the CFAs are reported in Table 4. Results indicated that the hypothesized two-factor model $\left(\chi^{2}=132.72, \mathrm{~d} f=50, \mathrm{CFI}=.96, \mathrm{TLI}=.94, \mathrm{RMSEA}=.08\right)$ provided a good fit to the data. The two-factor model produced better comparative fit indices (AIC=212.72, RMSEA $=.08)$ than the alternative one-factor $(\mathrm{AIC}=981.82, \mathrm{RMSEA}=.21)$ model or the independence model $(\mathrm{AIC}=2075.14, \mathrm{RMSEA}=.33)$.

\subsubsection{Perceptual Variables in Moderated Mediation Model}

To examine the distinctiveness of each of the hypothesized perceptual variables proposed in the moderated mediation model, a CFA was conducted on five constructs: collectivism, positive meaning in work, need fulfillment at work, emotional exhaustion, and work engagement. As shown in Table 5, the proposed five-factor model generated the best fit statistics $\left(\chi^{2}=357.86, \mathrm{~d} f=158, \mathrm{CFI}=.91, \mathrm{TLI}=.89, \mathrm{RMSEA}=.08\right)$. The baseline five-factor model provided a significantly better representation of the data than an alternative four-factor model which combined emotional exhaustion and work engagement into one factor $\left(\chi^{2}=555.67, \mathrm{~d} f=\right.$ $163, \mathrm{CFI}=.82, \mathrm{TLI}=.79, \mathrm{RMSEA}=.10)$ and an alternative one-factor model, in which all items measuring the variables were loaded on one overall factor $\left(\chi^{2}=1060.65, \mathrm{~d} f=170, \mathrm{CFI}=.58\right.$, 
$\mathrm{TLI}=.48, \mathrm{RMSEA}=.15)$. Taken together, results from these CFAs supported the distinctiveness of the scales used to measure each construct included in this research.

\subsection{Antecedents of LMX Ambivalence}

As outlined in Chapter 3 and Chapter 4, there are two primary objectives of the present research: 1. to explore the antecedents of LMX ambivalence (see Figure 1); and 2. to elucidate the mechanisms through which LMX ambivalence influences employee work-related well-being (see Figure 2). In this section, I report results regarding the antecedents of LMX ambivalence. In the next section, I will report results from tests of the proposed moderated mediation model.

\subsubsection{Descriptive Statistics and Zero-order Correlations}

Means, standard deviations, and zero-order correlations for all variables are reported in Table 6. As shown in Table 6, mean ratings on LMX ambivalence (T2) were in the moderate range $($ mean $=3.08$ on 5 -point scale $)$ with significant variation $(\mathrm{SD}=1.45)$ evidenced. $\mathrm{LMX}$ ambivalence was significantly positively correlated with the gender of one's supervisor $(r=.14, p$ $<.05$ ), indicating that respondents with a female supervisor are more likely to report LMX ambivalence. As hypothesized, subordinate emotional stability $(r=-.16, p<.05)$ was found to be negatively associated with LMX ambivalence while supervisor openness to experience $(r=.19, p$ $<.05$ ) was positively associated with LMX ambivalence. Correlations between supervisor dominance and LMX ambivalence $(r=.35, p<.01)$, and between supervisor prestige-seeking and LMX ambivalence $(r=-.34, p<.01)$ were also significant and in the expected direction. Finally, both subordinate trait anger $(r=.17, p<.05)$ and hostility $(r=.21, p<.01)$ were found to be positively associated with LMX ambivalence. Taken together, these results indicate that participants reported appreciable levels of LMX ambivalence and variation was observed on this variable. Moreover, LMX ambivalence appears to be associated with some of the hypothesized 
antecedents; however, more detailed analyses are needed controlling for extraneous variables.

\subsubsection{Tests of Hypotheses}

In order to conduct a more comprehensive and robust test of each of the hypotheses relating to antecedents of LMX ambivalence (Hypotheses 1-10), two separate hierarchical regression analyses were conducted - one focusing on dispositional antecedents of the subordinate, and the other focusing on dispositional antecedents of the supervisor. In the regression analyses, missing values were dealt with using pairwise deletion. In the first regression examining subordinate antecedents of LMX ambivalence, subordinate demographic variables, including age, gender, and dyad tenure, were entered in the first block followed by the Big Five personality constructs in the second block, and trait anger and hostility in the final block. Likewise, in the second regression focusing on supervisor antecedents, demographic variables (e.g., age, gender, dyad tenure) were entered in the first block, followed by supervisor Big Five traits, and finally, supervisor dominance and prestige-seeking. For both regression analyses, LMX ambivalence (assessed at time 2) was the focal dependent variable. Before conducting the hypothesis tests, I checked for multicollinearity among the predictor variables, which, if present, may distort the magnitude of some relationships. The results of collinearity diagnostic analyses showed that all tolerance indices were larger than 0.5 , and the Variance Inflation Factors (VIF) were smaller than 2, suggesting that multicollinearity is not present.

Results for the two hierarchical regression analyses are reported in Table 7 and Table 8. As shown in Table 7 , subordinate hostility $(\beta=.16, p<.05)$ was found to be significantly positively related to LMX ambivalence, providing support for hypothesis 9(a). Furthermore, supervisor dominance $(\beta=.19, p<.01)$ was also significantly positively related to LMX ambivalence, while prestige-seeking was negatively related to LMX ambivalence $(\beta=-.17, p$ 
$<.05$ ), providing support for Hypotheses 10a and 10b, respectively. Somewhat surprisingly, none of the demographic variables (i.e., subordinate and supervisor age, gender, dyad tenure) or other dispositional characteristics (i.e., supervisor or subordinate Big Five, subordinate trait anger) were found be significantly related to LMX ambivalence, failing to support Hypotheses 18 , and $9 b$.

\subsection{Outcomes of LMX Ambivalence}

The second model (Figure 2) examined in this research tests a more complex set of relationships in which LMX ambivalence (measured at time 1) is hypothesized to influence the two focal components of work-related well-being (work engagement and emotional exhaustion) through need fulfillment. Furthermore, two variables - collectivism and positive meaning in work - are tested as potential moderators of this indirect effect.

\subsubsection{Descriptive Statistics and Zero-order Correlations}

Means, standard deviations, and zero-order correlations for all variables in this model (Figure 2) are reported in Table 9. Mean ratings were just above the midpoint on the LMX ambivalence $(\mathrm{T} 1)$ measure $($ mean $=3.26$ on 5 -point scale) with significant variation $(\mathrm{SD}=1.37)$ observed. LMX ambivalence was negatively associated with $\operatorname{LMX}(r=-.39, p<.01)$ and negatively related to psychological need fulfillment $(r=-.36, p<.01)$. LMX ambivalence was also found to be negatively related to subordinate's work engagement $(r=-.22, p<.01)$ and positively related to subordinate's emotional exhaustion $(r=.17, p<.05)$, providing initial support for the relationship between LMX ambivalence and our two focal well-being outcomes (hypotheses 11a and 11b).

\subsubsection{Tests of Hypotheses}

Conditional process analyses were conducted using the PROCESS macro (version 3, Hayes, 
2018) to test each of the hypotheses delineated in the proposed moderated mediation model

(Figure 2). Conditional process analysis enables simultaneous testing of models that include both mediation and moderation, which can reduce estimation bias (Hayes, 2018). Missing values were dealt with using listwise deletion, resulting in a sample size of 205 for this analysis. Below, I report results for the conditional process analysis examining work engagement first, followed by results relating to emotional exhaustion.

\subsubsection{Moderated Mediation Analysis: Work Engagement}

A moderated mediation analysis (model $=9$; Hayes, 2018) was conducted specifying need fulfillment as the focal mediator (M) of the relationship between LMX ambivalence (X) and work engagement $(\mathrm{Y})$. In this model, both collectivism and positive meaning in work were positioned as moderating these relationships at stage 1 in the model. Several control variables were also included in this analysis (i.e., age, gender, education, job tenure, and LMX).

As shown in Table 10, LMX ambivalence was significantly negatively related to need fulfillment at work $(b=-.11, p<.01)$, providing support for hypothesis 12 . Need fulfillment at work was, in turn, positively related to work engagement $(b=.55, p<.001)$. In order to test the significance of the mediation pathway, $95 \%$ confidence intervals were calculated by means of bootstrapping with 10,000 repetitions. Consistent with hypothesis 13a, a significant indirect effect was uncovered (indirect effect $=-.06$; lower limit $(\mathrm{LL})=-.12$, upper limit $(\mathrm{UL})=-.02)$ indicating that need fulfillment mediates the relationship between LMX ambivalence and work engagement.

With respect to the moderating role of collectivism, as can be seen in Table 11, the interaction between LMX ambivalence and collectivism on need fulfillment was statistically significant $(b=.10, p<.05)$, providing preliminary support for the moderated mediation 
hypothesis (hypothesis 14). In order to examine the precise nature of this interaction, conditional effects at three levels of collectivism were reviewed. As indicated in Table 12, need fulfillment mediated the effect of LMX ambivalence on work engagement only when collectivism was low $(-1 \mathrm{SD})$ but not when collectivism was high $(+1 \mathrm{SD})$ or at the mean. In particular, the coefficient of the conditional indirect effect of LMX ambivalence at -1 SD collectivism was $-.10(\mathrm{LL}=-.18$ and $\mathrm{UL}=-.04)$. The coefficient of the conditional indirect effect at the mean level of collectivism was smaller ( $b=-.05)$, and the confidence interval contained zero ( $\mathrm{LL}=$ -.11 and $\mathrm{UL}=.00)$. The coefficient of the conditional indirect effect at $+1 \mathrm{SD}$ collectivism was close to zero $(b=-.01)$, and the confidence interval contained zero $(\mathrm{LL}=-.10$ and $\mathrm{UL}=.06)$. Taken together, these results support hypothesis 14 and signal that LMX ambivalence is only significantly related to work engagement via need fulfillment at lower levels of collectivism.

Similarly, results indicate that positive meaning in work moderates the indirect effect of LMX ambivalence on work engagement via need fulfillment. A significant interaction between LMX ambivalence and positive meaning on need fulfillment was observed $(b=.08, p<.05)$. As displayed in Table 12, this mediating effect was only significant when positive meaning was low $(-1 \mathrm{SD})$, but not when positive meaning was high (+1 SD). The coefficient of the conditional indirect effect of LMX ambivalence at low positive meaning $(-1 \mathrm{SD})$ was $-.08(\mathrm{LL}=-.16$ and $\mathrm{UL}=-.02)$, and at the mean it was $-.05(\mathrm{LL}=-.11$ and $\mathrm{UL}=.00)$. Conversely, the conditional indirect effect at $+1 \mathrm{SD}$ was low $(b=-.01)$ and the confidence interval contained zero $(\mathrm{LL}=$ -.09 and $\mathrm{UL}=.05$ ). Overall, these results are in line with hypothesis 16 and suggest that LMX ambivalence is more strongly associated with work engagement via its effects on need fulfillment at moderate or lower levels of positive meaning in work.

\subsubsection{Moderated Mediation Analysis: Emotional Exhaustion}


The same analytic approach as that for work engagement was used for testing hypotheses relating to emotional exhaustion. Specifically, need fulfillment was tested as mediating the relationship between LMX and emotional exhaustion, with both collectivism and positive meaning positioned as moderating variables at stage 1 .

Results revealed that LMX ambivalence was negatively associated with need fulfillment at work ( $b=-.11, p<.01$ ), providing support for hypothesis 12 . Furthermore, need fulfillment at work was negatively related to emotional exhaustion $(b=-.76, p<.001)$. A significant indirect effect was also found (indirect effect $=.09$; lower limit $(L L)=.03$, upper limit $(U L)=.16$ ), indicating that need fulfillment mediates the relationship between LMX ambivalence and emotional exhaustion (hypothesis 13b).

In terms of the hypothesized moderating effects, evidence of a significant interaction between LMX ambivalence and collectivism on need fulfillment was found $(b=.10, p<.05)$. As shown in Table 15, need fulfillment mediated the effect of LMX ambivalence on emotional exhaustion only when collectivism was low (-1 SD) but not when collectivism was at the mean or high (+ $1 \mathrm{SD})$. The coefficient of the conditional indirect effect of LMX ambivalence at -1 $\mathrm{SD}$ was $.13(\mathrm{LL}=.05$ and $\mathrm{UL}=.22)$. Conversely, the conditional indirect effect at the mean was smaller $(b=.06)$, and the confidence interval contained zero $(\mathrm{LL}=-.00$ and $\mathrm{UL}=.13)$. Likewise, the conditional indirect effect at +1 SD was close to zero $(b=.01)$, and the confidence interval contained zero $(\mathrm{LL}=-.08$ and $\mathrm{UL}=.11)$. This pattern of results supported hypothesis 15 and indicates that the indirect effect of LMX ambivalence on emotional exhaustion via need fulfillment is only evident at lower levels of collectivism.

Hypothesis 17 proposed that positive meaning moderates the indirect effect of LMX ambivalence via need fulfillment on emotional exhaustion. Consistent with this prediction, the 
interaction of LMX ambivalence and positive meaning on need fulfillment was significant $(b=.08, p<.05)$. As shown in Table 15, the indirect effect of LMX ambivalence on emotional exhaustion via need fulfillment was only significant when positive meaning in work was low $(-1$ $\mathrm{SD})$, and not when positive meaning was at the mean or higher (+ $1 \mathrm{SD})$. The coefficient of the conditional indirect effect at low perceived positive meaning $(-1 \mathrm{SD})$ was $.10(\mathrm{LL}=.03$ and $\mathrm{UL}$ $=.19)$. The conditional indirect effect at the mean was $.06(\mathrm{LL}=-.00$ and $\mathrm{UL}=.13)$, and at +1 $\mathrm{SD}$ it was .01 , with the confidence interval containing zero $(\mathrm{LL}=-.07$ and $\mathrm{UL}=.11)$. Overall, these results furnish support for the moderated mediation effect presented in hypothesis 17 .

To provide a graphical illustration of the moderating effects of collectivism and positive meaning in work, simple slopes are plotted at $+/-1$ SD respectively, in Figures 3 and 4 . As can be seen in Figure 3, collectivism moderated the relationship between LMX ambivalence and need fulfillment at work, with higher levels of collectivism buffering the negative influence of LMX ambivalence on need fulfillment. Likewise, as illustrated in Figure 4, positive meaning in work moderated the relationship between LMX ambivalence and need fulfillment at work, with higher levels of positive meaning neutralizing this effect. 


\section{CHAPTER 7: DISCUSSION}

This chapter provides a discussion of the main findings from this dissertation. Results relating to the antecedents of LMX ambivalence will be discussed, followed by findings regarding the proposed moderated mediation model. Next, practical implications and limitations will be outlined, and potential avenues for future research will be highlighted.

\subsection{Antecedents of LMX Ambivalence}

Perhaps somewhat surprisingly, the Big Five constructs were not found to significantly associated with LMX ambivalence; however, traits relating to power dynamics in the leaderfollower relationship did emerge as key predictors. Followers with more dominant leaders were more likely to report ambivalent feelings toward their exchange relationship while leaders who were more prestige-oriented were less likely be viewed in an ambivalent manner. Followers with a dominant leader may feel controlled and threatened in the relationship, while at the same time, they may feel they have benefitted as an in-group member if they have complied with their leader's requests and have forged a strong exchange relationship with their leader (Cheng et al., 2013; Van Vugt, 2006). Furthermore, followers' attitudes towards dominant leaders may change depending on the situation (Lausten \& Petersen, 2017). For example, although dominant leaders are perceived as less competent in situations requiring cooperation, followers may prefer dominant leaders when intergroup conflict exists (Merolla \& Zechmeister, 2009; Spisak, Homan, Aramovich \& Morgan, 2012). In this respect, dominant leaders may elicit stronger perceptions of ambivalence due to these inconsistent beliefs and variation in the desirability of their behavior across situations. Conversely, subordinates reported lower levels of LMX ambivalence when their leader displayed more prestige-seeking behaviors. Prestige-oriented leaders seek to gain status by engaging in social modelling and maintaining positive relations with their staff (Case, 
Bae \& Maner, 2018; Maner \& Case, 2016). Because prestige-oriented leaders are more concerned with how they are perceived by members of the group they tend to behave more consistently in interacting with others to manage their reputation and maintain positive relationships with group members (Maner, 2017; Maner \& Case, 2016). To accumulate respect and admiration, these leaders are more likely to help group members by sharing their knowledge and skills, and may be more inclined to match subordinates' skills to their roles than dominant leaders (Case \& Maner, 2016; Maner \& Case, 2016). Due to their more consistent and predictable behavior, and the improved role definition they provide to their followers, this may lower subordinates' perceptions of LMX ambivalence.

In addition to the use of dominance- and prestige-seeking strategies by leaders, subordinates' hostility was also found to be associated with LMX ambivalence. People high in hostility tend to be more emotionally insecure, more skeptical of others' intentions, and are more likely to report confrontational attitudes (Sanz et al., 2010). In this respect, higher levels of distrust and cynicism in hostile employees may generate ambivalence toward one's LMX relationship. Interestingly, although a somewhat similar concept, trait anger was not significant in predicting LMX ambivalence. This may be due to the fact that although trait anger can be maladaptive, this trait is more affective rather than cognitive in nature (Sanz et al., 2010; Smith, et al., 2004). Hostility more specifically reflects a cognitive pattern of cynicism, mistrust, and suspicion, which may have a more direct relationship with relational ambivalence (i.e., the coexistence of a desire to have a close relationship but also to distrust of other people).

Unlike the antecedents associated with power dynamics in the leader-follower relationship, other personality characteristics (e.g., the Big Five) and demographic factors were not found to be significant unique predictors of LMX ambivalence. Some of the zero-order 
correlations suggested that characteristics, such as supervisor gender and openness to experience, and subordinate emotional stability, may be associated with LMX ambivalence; however, these effects were not significant when controlling for other factors. There are a couple of possible explanations for these null effects. For example, it is notable that previous research demonstrating links between global personality traits (e.g., the Big Five) and ambivalence examined other specific types of ambivalence in different contexts. For instance, previous work has found that agreeableness is associated with lower levels of ambivalence relating to emotional expression (Laghai \& Joseph, 2000). Likewise, studies suggest that personality traits may be linked to attitudinal ambivalence relating to social policy issues and food choice (Sparks et al., 1995; Thompson \& Zanna, 1995). However, these results relating to attitudinal ambivalence toward specific objects/issue may not generalize to relationships in the workplace. Indeed, there has been very limited study of whether the Big Five may influence relational ambivalence. Furthermore, there was significant variation in the length of leader-follower relationships (dyad tenure) in the study, which may have attenuated personality - LMX ambivalence relationships. Although the average dyad tenure was 16.78 months, more than $90 \%$ of employees reported a dyad-tenure of less than 30 months. Because it may take time for LMX and LMX ambivalence to develop (Ashforth et al., 2014; Gerstner \& Day, 1997; Nahrgang et al., 2009), and likewise, personality characteristics tend to exert more pronounced effects on the quality of interpersonal relationships over longer periods of time (e.g., Asendorpf \& Wilpers, 1998; O’Meara \& South, 2019), this may have constrained the effects of personality on LMX ambivalence.

Taken together, these results highlight the role that specific personality traits, including leader dominance and prestige-seeking and subordinate hostility, may play in contributing to LMX ambivalence. Additional work is needed exploring the role of the Big Five constructs and 
other dispositional characteristics in the development of LMX ambivalence. For example, although supervisor openness to experience was not found to be directly associated with LMX ambivalence when controlling for other factors, it was significantly associated with LMX ambivalence when examined separately. Previous studies have suggested that leaders high in openness to experience might have divergent, unconventional, and flexible patterns of thought (Digman, 1990; McCrae, 1987). Because their thoughts and actions may be less predictable (Cable \& Judge, 2003), this may produce more uncertain and ambivalent attitudes toward leaders. Further research is needed examining the effects of these characteristics, including specific facets of the Big Five, on LMX ambivalence. For example, it may be that facets of openness to experience in leaders, such as active imagination (fantasy) and preference for variety, may be more strongly associated with LMX ambivalence compared to other facets of this construct (e.g., attentiveness to inner feelings, intellectual curiosity).

\subsection{LMX Ambivalence and Workplace Well-being}

In addition to exploring potential antecedents of LMX ambivalence, this research also examined whether and how LMX ambivalence may influence levels of employee work relatedwell-being. Researchers have previously reported a negative relationship between LMX ambivalence and employee task performance (Lee et al., 2019). However, the influence of LMX ambivalence on employee well-being has not been studied.

In line with SDT and the role-making model of LMX, LMX ambivalence was found to influence both work engagement and emotional exhaustion through psychological need fulfillment. This finding complements previous work suggesting that the use of relational leadership styles, and the quality of the LMX relationship, enhance employee need fulfillment (Graves \& Luciano, 2013; Kovjanic et al., 2013; Leroy et al., 2015) by indicating that LMX 
ambivalence may also contribute to employee need fulfillment beyond the effects of LMX alone. For example, Graves and Luciano (2013) found that LMX cultivates stronger perceptions of need fulfillment and autonomous motivation, which in turn, engender positive attitudinal outcomes (e.g., job satisfaction, affective commitment, vitality). Results from this study extend this work by indicating LMX ambivalence may undermine work-related well-being (work engagement and emotional exhaustion) by decreasing one's sense of need fulfillment. Followers with conflicting thoughts toward the quality of their relationship with their leader may not be able to form a consistent opinion toward that relationship and their role in that relationship. As a result, one's sense of need fulfillment and autonomous motivation in the workplace may be undermined. Ambivalent feelings toward relationships may be damaging to one's well-being because unclear and inconsistent role expectations associated with LMX ambivalence may thwart one's fulfillment of their needs for autonomy, competence, and relatedness at work. The frustration of basic psychological needs has an energy-depleting effect on individuals (e.g., Deci \& Ryan, 2000; Van den Broeck et al., 2008) and can, therefore, lower work engagement and heighten perceptions of burnout (Kovjanic et al., 2013; Trépanier et al., 2013). Taken together, these findings provide support for the idea that LMX ambivalence can impede work-related well-being (i.e., lower work engagement and higher emotional exhaustion) by reducing a follower's satisfaction of their basic needs.

I also found, however, that two moderating variables - collectivism and positive meaning in work - may buffer the negative influence of LMX ambivalence on work-related well-being. According to SDT, when individuals more strongly value and identify with their workgroup and also understand the purpose of their jobs, they are likely to become more autonomously motivated (Deci et al., 2017). In this respect, collectivism and perceptions of meaning in one's 
work may attenuate the relationship between LMX ambivalence and need fulfillment. Consistent with this premise, moderated mediation analyses revealed that subordinates high in collectivism may be less likely to experience negative effects of LMX ambivalence on their levels of need fulfillment and well-being. Collectivistic individuals place a higher emphasis on group-level identity. When they have contradictory opinions towards their role in the relationship with the leader, employees higher in collectivism may be more likely to shift their attention to factors such as group-level collective outcomes in defining their roles and their contributions to the organization. Moreover, collectivists rely more on their ingroups and their relationships at work as a coping resource (Warren et al., 2004; Yang et al., 2012). Thus, because they view themselves as interdependent with other individuals in their group (Oyserman et al., 2002; Triandis, 1995), collectivistic employees may be more inclined to seek and garner the support of others in the workplace. In this respect, collectivism may compensate for the effects of the inconsistent beliefs and unclear role definitions associated with LMX ambivalence. In their meta-analytic review of the LMX literature, Rockstuhl, Dulebohn, Ang and Shore (2012) reported that the effects of LMX on various work outcomes (e.g., organizational citizenship behavior, leader trust, job satisfaction, turnover intentions) may be more pronounced in cultures that are horizontal-individualistic (i.e., lower in power distance and collectivism) compared to those that are vertical-collectivistic (i.e., higher in power distance and collectivism). Due to the tendency to value collective interests over personal goals and respect for authority, employees in vertical-collectivistic cultures are less likely to base their attitudes and behaviors solely on leader treatment (Chen, Friedman, Yu, Fang, \& Lu, 2009; Rockstuhl et al., 2012). Similarly, Dulebohn et al. (2012) found that both collectivism and power distance moderate the effects of LMX on various work outcomes. Findings from the present study suggest that these values may also play 
a key role at the individual level in moderating the effects of LMX ambivalence.

Finally, results also indicated that positive meaning in work moderates the influence of LMX ambivalence on need fulfillment and well-being. Employees with high positive meaning may be better equipped to cope with LMX ambivalence because they strongly identify with their work and may already experience high levels of autonomous motivation. If an employee is internally motivated and regulated, it is more likely they will perceive that their psychological needs at work are being met (Ryan \& Deci, 2002). These findings are consistent with previous research indicating that work meaningfulness can buffer the deleterious effects of workplace stressors on employee well-being. For example, meaningful work has been found to moderate the relationship between work stress and the presence of meaning in life (Allan et al., 2016). Likewise, Harris, Kacmar, and Zivnuska (2007) found that abusive supervision is less likely to negatively impact performance for employees who derive greater value and meaning from their

job. Taken together, the moderating effects observed in the present research highlight the role of employee personal values and perceptions of their work in contributing to employee well-being. Because perceptions of ambivalence are highly individualized and dynamic (Schneider et al., 2015), future studies should continue to examine whether the effects of LMX ambivalence may vary for employees with different personal values and who are exposed to different working conditions.

\subsection{Practical Implications}

In this research, LMX ambivalence was found to significantly associated with workrelated well-being beyond the effects of LMX. This finding signals that organizations should provide guidance and training to leaders on the importance of demonstrating behaviors that minimize LMX ambivalence. Indeed, previous studies suggest that perceptions of ambivalence 
are malleable and subject to changing over time (e.g., Harmon-Jones \& Harmon-Jones, 2007;

Jonas, Diehl, \& Bromer, 1997). Furthermore, specific leader behaviors, including dominanceand prestige-seeking, were found to be associated with LMX ambivalence. These results suggest that leader training that educates leaders on the nature of LMX ambivalence, and encourages behavioral consistency and the display of stronger self-management and interpersonal skills (e.g., two-way communication, sharing one's knowledge and skills, empathy) may reduce LMX ambivalence and the negative effects of LMX ambivalence in the organization.

In addition to these efforts, organizations may also benefit from interventions that seek to optimize work design and enhance employee perceptions of work meaningfulness. Research relating to the job characteristics model has shown that jobs with higher levels of skill variety, task identity, and task significance are perceived as more meaningful to employees (Fried \& Ferris, 1987; Hackman \& Oldham, 1976; Rosso et al., 2010). Furthermore, Grant (2008) highlighted that sharing specific stories and narratives about the benefits and the importance of one's job to others can enhance employee perceptions of task significance and meaningfulness by reframing and reconstructing employees' experiences. Managers should also make an effort to learn about their employees' specific aspirations and passions, and match or build these into their work roles (May, Gilson \& Harter, 2004). Through these initiatives that aim to enhance leader training and perceived meaning in one's work, perceptions of LMX ambivalence may be mitigated as well as its negative effects on work-related well-being.

\subsection{Limitations}

One of the primary strengths of this research was the use of a time-separated design and data collection from two rating sources (both leaders and followers), which minimized problems associated with common method variance. A further strength was that various controls (e.g., 
demographic factors, LMX) were included in the research design, enabling an assessment of the unique effects of LMX ambivalence beyond these factors.

Despite these strengths, certain limitations should be noted. The first limitation relates to the nature of the sample. The participants were mostly male (74.4\%) police officers working in a large police organization in Canada. As previously discussed, it is possible that the nature of the sample may have attenuated the effects of personality on LMX ambivalence as dyad tenure varied significantly. Moreover, previous research has suggested that the effects of certain personality traits, such as openness to experience, on work outcomes may be less evident in specific types of organizations with more formalized and hierarchical structures, including law enforcement, government, and military organizations (Aamodt, 2010; Griffin \& Hesketh, 2004; Judge et al., 2002). At the same time, however, it is also possible that LMX ambivalence may have exerted a stronger influence on well-being in this sample due to the resource dependency of subordinates and the key role that leaders may play in supporting employee's work and career development in organizations that use a more hierarchical organizational structure (Detert \& Treviño, 2010; Emerson, 1962; Gabris \& Ihrke, 2007). Likewise, given the challenging nature of police work and its importance to society, it is possible that perceived meaning may exert a stronger moderating influence in this sample. Additional studies drawing on different occupations, organizations, and employing demographically diverse samples are needed to establish the generalizability of these findings.

Secondly, it is important to note that the sample size, particularly with regard to the number of supervisor respondents, may have limited statistical power in some analyses. While the sample size for the moderated mediation analyses (Model 2) was sufficient ( $\mathrm{N}=205)$, analyses examining the relations between supervisor personality traits and LMX ambivalence 
(Model 1) were based on smaller sample sizes $(\mathrm{N}=128)$ and should be considered exploratory.

Finally, due to constraints on survey length, relatively short measures were used to assess some constructs. The concise nature of these measures (e.g., the Big Five traits) resulted in lower Cronbach's alpha coefficients in some cases. For example, although the TIPI is a wellestablished measure of the Big Five and has demonstrated convergent validity in relation to other Big Five instruments, future studies would benefit from using longer measures that also assess facets of each of the Big Five (e.g., the Big Five Inventory (BFI), John \& Srivastava, 1999; International Personality Item Pool-Five Factor Model (IPIP-FFM), Goldberg et al., 2006; the NEO Five-Factor Inventory, McCrae \& Costa, 2004). Likewise, although we used Lee et al's (2019) measure of LMX ambivalence, a multidimensional measure would enable a more nuanced assessment of the construct.

\subsection{Future Research Directions}

The present research included only a limited number of demographic and dispositional predictors, focusing mostly on more global traits (e.g., the Big Five). Among the Big Five constructs, subordinate emotional stability and leader openness to experience demonstrated significant zero-order correlations with LMX ambivalence, but these effects dissipated when controlling for other factors. Future research should continue to examine facets of these constructs, as well as other traits that may be more proximal predictors of ambivalence. For example, more proximal predictors relating to one's cognitive style, including need for cognition, need for closure, tolerance of ambiguity, and fear of invalidity, may shed additional light on the dispositional characteristics that contribute to the development of LMX ambivalence. These individual differences have been examined as important factors in the development and expression of ambivalent attitudes (Conner \& Sparks, 2002; Sparks et al., 1995; Thompson \& 
Zanna, 1995). For instance, individuals with high fear of invalidity tend to be concerned with the error or the consequences of a decision, and therefore, they continually collect and evaluate relevant information (Thompson, Naccarato, Parker \& Moskowitz, 2001). Thus, people high in fear of invalidity may see many aspects of their relationship with others, but due to putting equal weight on contradictory evidence, they would be less able to make sense of the relationship as a whole (Thompson et al., 2001; Thompson \& Zanna, 1995). Future studies should examine the role of fear of invalidity and other cognitive traits in the development of ambivalence in work relationships.

Previous research has suggested that ambivalence is a dynamic process that declines over time because of people's tendency to seek to reduce cognitive dissonance (Connidis \& McMullin, 2002; Festinger, 1957). Interestingly, the current study showed that LMX ambivalence was relatively stable over a three-month time period (i.e., the correlation between T1 and T2 LMX ambivalence was 0.60), which corresponds with Lee's (2016) previous finding (i.e., the correlation between T1 and T2 LMX ambivalence was 0.44). Additional research is needed exploring the temporal nature of LMX ambivalence through the use of research designs that employ longer time intervals or other research methods (e.g., experience sampling that captures changes in LMX ambivalence within individuals). Efforts to better assess and capture the temporal nature of LMX ambivalence can help us to better understand the conditions that trigger its development and how it may shape employee work experiences and behaviors over time.

Finally, results from this research indicate that both collectivism and perceived meaning may temper the negative effects of LMX ambivalence on work-related well-being. Additional research is needed exploring boundary conditions surrounding the effects of LMX ambivalence. 
For example, other cultural values beyond collectivism (e.g., power distance, uncertainty avoidance) may moderate the influence of LMX ambivalence on work outcomes. Moreover, other components of one's self concept (e.g., self-identity, relational identity) may assist in explaining differences in how employees respond to LMX ambivalence. Previous studies have suggested that a follower's self-identity and relational identity may play a crucial role in how they view their leader and in shaping the tenor of their relationship (Flynn, 2005; Jackson \& Johnson, 2012; Van Knippenberg, Van Knippenberg, De Cremer, \& Hogg, 2005). People with strong relational identities pay particular attention to fulfilling their relational partner's role expectations and enhancing their welfare (Jackson \& Johnson, 2012). Consistent with this focus on the well-being of others, relational identity has been found to be positively related to perceptions of LMX (Johnson \& Saboe, 2011). Examining one's self, relational, and collective identities in relation to LMX ambivalence may provide a more in-depth understanding of how one's self-concept contributes to the development of ambivalence, and whether the effects of LMX may vary as function of on one's self-concept.

\subsection{Conclusion}

Although a rich body of research on ambivalence has accumulated in the social and cognitive psychology literature, LMX ambivalence and other measures of ambivalence in work settings have only recently attracted attention in the research literature. The purpose of this research was to enhance our understanding of the LMX ambivalence construct by investigating factors that contribute to its development and to explore whether and how it may influence employee well-being.

Results indicated that dispositional characteristics relating to power dynamics were particularly prominent predictors of LMX ambivalence. Employees with leaders who 
demonstrated dominance-seeking strategies reported more ambivalent feelings toward their LMX relationship; whereas employees with prestige-seeking leaders reported lower levels of LMX ambivalence. Employees higher in hostility also reported increased levels of LMX ambivalence likely as a function of greater distrust, cynicism, and emotional insecurity associated with this trait. With respect to the influence of LMX ambivalence on work-related well-being, LMX ambivalence was found to be significantly associated with both emotional exhaustion and work engagement. Moreover, psychological need fulfillment played a central role in mediating these relationships, highlighting the role that LMX ambivalence may play in contributing to well-being by shaping one's perceptions of their work experience and fostering a sense of need fulfillment from their work. Results also indicated, however, that collectivism and perceived meaning in one's work may buffer the negative effects of LMX ambivalence on need fulfillment and work-related well-being.

Overall, results from this research complement recent evidence suggesting that LMX ambivalence may contribute unique variance in predicting work outcomes beyond univalent measures of LMX. Further research is needed testing the nomological net surrounding LMX ambivalence, including its relationship to different work attitudes and employee work behaviors (e.g., citizenship behavior, voice, creativity). Although its conceptual origins lie in LMX theory, this research also underscores that investigating the effects of LMX ambivalence through a complementary lens of self-determination theory may assist in elucidating the process through which LMX ambivalence influences work outcomes. Additional research is needed integrating LMX ambivalence with other theoretical perspectives (e.g., social identity theory, organizational trust) to further illuminate the factors that elicit LMX ambivalence and when and how it affects different workplace perceptions and behaviors. 


\section{REFERENCES}

Aamodt, M. G. (2010). Predicting Law Enforcement Officer Performance with Personality Inventories. In Weiss, P. A. (Eds.), Personality assessment in police psycholog: A 21st century perspectivey (pp. 229-249). Illinois: Charles C Thomas.

Aguinis, H., Gottfredson, R. K., \& Joo, H. (2013). Best-practice recommendations for defining, identifying, and handling outliers. Organizational Research Methods, 16(2), 270-301.

Allan, B. A., Douglass, R. P., Duffy, R. D., \& McCarty, R. J. (2016). Meaningful work as a moderator of the relation between work stress and meaning in life. Journal of Career Assessment, 24(3), 429-440.

Andreassen, C. S., Hetland, J., \& Pallesen, S. (2010). The relationship between 'workaholism’, basic needs satisfaction at work and personality. European Journal of Personality, 24(1), 317.

Anicich, E. M., Fast, N. J., Halevy, N., \& Galinsky, A. D. (2016). When the bases of social hierarchy collide: Power without status drives interpersonal conflict. Organization Science, $27,123-140$.

Arnold, K. A., Turner, N., Barling, J., Kelloway, E. K., \& McKee, M. C. (2007). Transformational leadership and psychological well-being: the mediating role of meaningful work. Journal of Occupational Health Psychology, 12(3), 193-203.

Ashforth, B. (2001) Role Transitions in Organizational Life: An Identity-Based Perspective, Lawrence Erlbaum Associates, Mahwah, NJ.

Ashforth, B. E., Rogers, K. M., Pratt, M. G., \& Pradies, C. (2014). Ambivalence in organizations: A multilevel approach. Organization Science, 25(5), 1453-1478. 
Asendorpf, J. B. \& Wilpers, S. (1998). Personality effects on social relationships. Journal of Personality and Social Psychology, 74(6), 1531-1544.

Atari, M., Barbaro, N., Sela, Y., Shackelford, T. K., \& Chegeni, R. (2017). The Big Five personality dimensions and mate retention behaviors in Iran. Personality and Individual Differences, 104, 286-290.

Baard, P. P., Deci, E. L., \& Ryan, R. M. (2004). Intrinsic Need Satisfaction: A Motivational Basis of Performance and Weil - Being in Two Work Settings. Journal of Applied Social Psychology, 34(10), 2045-2068.

Baek, Y. M. (2010). An integrative model of ambivalence. The Social Science Journal, 47(3), 609-629.

Bakker, A. B., \& Demerouti, E. (2008). Towards a model of work engagement. Career Development International, 13(3), 209-223.

Bakker, A. B., \& Leiter, M. P. (2010). Work engagement: A handbook of essential theory and research. New York: Psychology Press.

Bakker, A. B., \& Schaufeli, W. B. (2008). Positive organizational behavior: Engaged employees in flourishing organizations. Journal of Organizational Behavior, 29(2), 147-154.

Barrick, M. R., \& Mount, M. K. (1991). The Big Five personality dimensions and job performance: A meta-analysis. Personnel Psychology, 44, 1- 27.

Barrick, M. R., Mount, M. K., \& Li, N. (2013). The theory of purposeful work behavior: The role of personality, higher-order goals, and job characteristics. Academy of Management Review, 38(1), 132-153. 
Bauer, T. N. \& Erdogan, B. (2015). Leader-member exchange (LMX) theory: An introduction and overview. In Bauer, T. N. \& Erdogan, B. (Eds.), Oxford handbook of leader-member exchange (pp. 3-9). New York, NY: Oxford University Press.

Bauer, T. N., Erdogan, B., Liden, R. C., \& Wayne, S. J. (2006). A longitudinal study of the moderating role of extraversion: leader-member exchange, performance, and turnover during new executive development. Journal of Applied Psychology, 91, 298-310.

Berenbaum, H., Bredemeier, K., \& Thompson, R. J. (2008). Intolerance of uncertainty: Exploring its dimensionality and associations with need for cognitive closure, psychopathology, and personality. Journal of Anxiety Disorders, 22(1), 117-125.

Bernerth, J. B., Armenakis, A. A., Feild, H. S., Giles, W. F., \& Walker, H. J. (2007). Is personality associated with perceptions of LMX? An empirical study. Leadership \& Organization Development Journal, 28(7), 613-631.

Biddle, B. J. (1986). Recent developments in role theory. Annual Review of Sociology, 12(1), 6792.

Blanchard-Fields, F., \& Coats, A. H. (2008). The experience of anger and sadness in everyday problems impacts age differences in emotion regulation. Developmental Psychology, 44(6), 1547.

Blau, P. M. (1964). Justice in social exchange. Sociological Inquiry, 34(2), 193-206.

Bipp, T., Steinmayr, R., \& Spinath, B. (2008). Personality and achievement motivation: Relationship among big five domain and facet scales, achievement goals, and intelligence. Personality and Individual Differences, 44(7), 1454-1464. 
Breevaart, K., Bakker, A. B., Demerouti, E., \& Van den Heuvel, M. (2015). Leader-member exchange, work engagement, and job performance. Journal of Managerial Psychology, 30(7), 754-770.

Brewer, M. B., \& Chen, Y. R. (2007). Where (who) are collectives in collectivism? Toward conceptual clarification of individualism and collectivism. Psychological Review, 114(1), $133-151$.

Britt, T. W., Adler, A. B., \& Bartone, P. T. (2001). Deriving benefits from stressful events: The role of engagement in meaningful work and hardiness. Journal of Occupational Health Psychology, 6(1), 53-63.

Brooks, M. E., \& Highhouse, S. (2006). Familiarity breeds ambivalence. Corporate Reputation Review, 9(2), 105-113.

Bushman, B. B., \& Holt-Lunstad, J. (2009). Understanding social relationship maintenance among friends: Why we don't end those frustrating friendships. Journal of Social and Clinical Psychology, 28(6), 749-778.

Buss, A. H. (1961). The psychology of aggression. New York: Wiley.

Buss, D. M. (1991). Evolutionary personality psychology. Annual Review of Psychology, 42(1), 459-491.

Buss, A. H., \& Durkee, A. (1957). An inventory for assessing different kinds of hostility. Journal of Consulting Psychology, 21(4), 343-349.

Cable, D. M., \& Judge, T. A. (2003). Managers' upward influence tactic strategies: The role of manager personality and supervisor leadership style. Journal of Organizational Behavior, 24(2), 197-214. 
Cacioppo, J. T., Petty, R. E., Kao, C. F., \& Rodriguez, R. (1986). Central and peripheral routes to persuasion: An individual difference perspective. Journal of Personality and Social Psychology, 51(5), 1032-1043.

Campo, R. A., Uchino, B. N., Holt-Lunstad, J., Vaughn, A., Reblin, M., \& Smith, T. W. (2009). The assessment of positivity and negativity in social networks: The reliability and validity of the social relationships index. Journal of Community Psychology, 37(4), 471-486.

Case, C. R., Bae, K. K., \& Maner, J. K. (2018). To lead or to be liked: When prestige-oriented leaders prioritize popularity over performance. Journal of Personality and Social Psychology, 115(4), 657-676.

Case, C. R., \& Maner, J. K. (2016). When expertise is squandered: The misalignment of skills and roles within groups. Kellogg School of Management (manuscript under review).

Chen, Y., Friedman, R., Yu, E., Fang, W., \& Lu, X. (2009). Supervisor-subordinate guanxi: Developing a three-dimensional model and scale. Management and Organization Review, $5,375-399$.

Cheng, J. T., \& Tracy, J. L. (2014). Toward a unified science of hierarchy: Dominance and prestige are two fundamental pathways to human social rank. In J. T. Cheng, J. L. Tracy \& C. Anderson (Eds.), The psychology of social status (pp. 3-27). New York, NY: Springer.

Cheng, J. T., Tracy, J. L., Foulsham, T., Kingstone, A., \& Henrich, J. (2013). Two ways to the top: Evidence that dominance and prestige are distinct yet viable avenues to social rank and influence. Journal of Personality and Social Psychology, 104(1), 103-125.

Cheng, J. T., Tracy, J. L., \& Henrich, J. (2010). Pride, personality, and the evolutionary foundations of human social status. Evolution and Human Behavior, 31(5), 334-347. 
Chiniara, M., \& Bentein, K. (2016). Linking servant leadership to individual performance: Differentiating the mediating role of autonomy, competence and relatedness need satisfaction. Leadership Quarterly, 27(1), 124-141.

Chipperfield, J. G., Perry, R. P., \& Weiner, B. (2003). Discrete emotions in later life. The Journals of Gerontology Series B: Psychological Sciences and Social Sciences, 58(1), 2334.

Chirkov, V., Ryan, R. M., Kim, Y., \& Kaplan, U. (2003). Differentiating autonomy from individualism and independence: A self-determination theory perspective on internalization of cultural orientations and well-being. Journal of Personality and Social Psychology, 84(1), 97-110.

Chiu, W. C. K., Chan, A. W., Snape, E., \& Redman, T. (2001). Age stereotypes and discriminatory attitudes towards older workers: An East-West comparison. Human Relations, 54(5), 629-661.

Cicchetti, D., Ackerman, B. P., \& Izard, C. E. (1995). Emotions and emotion regulation in developmental psychopathology. Development and psychopathology, 7(1), 1-10.

Clark G. (1995) Meaning-in-the-workplace as social change. International Forum for Logotherapy, 18(2), 87-96.

Cogliser, C. C., \& Schriesheim, C. A. (2000). Exploring work unit context and leader-member exchange: A multi-level perspective. Journal of Organizational Behavior, 21(5), 487-511.

Connidis, I. A., \& McMullin, J. A. (2002). Sociological ambivalence and family ties: A critical perspective. Journal of Marriage and Family, 64, 558-567.

Conner, M., \& Sparks, P. (2002). Ambivalence and attitudes. European Review of Social Psychology, 12(1), 37-70. 
Cooper, J. (2012). Cognitive dissonance theory. In P. A. M. Lange, A. W. Kruglanski, \& E. T. Higgins (Eds.), Handbook of theories of social psychology (pp. 377-397). Thousand Oaks, CA: Sage.

Costa, P. T., \& McCrae, R. R. (1992). Revised NEO Personality Inventory (NEO-PI-R) and NEO Five-Factor Inventory (NEO-FFI) professional manual. Odessa, FL: PAR.

Costarelli, S., \& Colloca, P. (2004). The effects of attitudinal ambivalence on pro-environmental behavioural intentions. Journal of Environmental Psychology, 24(3), 279-288.

Cropanzano, R., \& Mitchell, M. S. (2005). Social exchange theory: An interdisciplinary review. Journal of Management, 31(6), 874-900.

Cropanzano, R., Anthony, E. L., Daniels, S. R., \& Hall, A. V. (2017). Social exchange theory: A critical review with theoretical remedies. Academy of Management Annals, 11(1), 479-516.

Dansereau, F., Jr., Graen, G., \& Haga, W.J. (1975). A vertical dyad linkage approach to leadership within formal organizations: A longitudinal investigation of the role making process. Organizational Behavior and Human Performance, 13, 46-78.

De Cooman, R., Stynen, D., Van den Broeck, A., Sels, L., \& De Witte, H. (2013). How job characteristics relate to need satisfaction and autonomous motivation: Implications for work effort. Journal of Applied Social Psychology, 43(6), 1342-1352.

De Waal-Andrews, W., Gregg, A. P., \& Lammers, J. (2015). When status is grabbed and when status is granted: Getting ahead in dominance and prestige hierarchies. British Journal of Social Psychology, 54, 445-464.

Deci, E. L., Connell, J. P., \& Ryan, R. M. (1989). Self-determination in a work organization. Journal of Applied Psychology, 74(4), 580-590. 
Deci, E. L., Eghrari, H., Patrick, B. C., \& Leone, D. R. (1994). Facilitating internalization: The self-determination theory perspective. Journal of Personality, 62, 119-142.

Deci, E. L., Olafsen, A. H., \& Ryan, R. M. (2017). Self-determination theory in work organizations: The state of a science. Annual Review of Organizational Psychology and Organizational Behavior, 4, 19-43.

Deci, E. L., \& Ryan, R. M. (1985). Intrinsic motivation and self-determination in human behavior. New York, NY: Plenum.

Deci, E. L., \& Ryan, R. M. (2000). The "what" and "why" of goal pursuits: Human needs and the self-determination of behavior. Psychological inquiry, 11(4), 227-268.

Deci, E. L., \& Ryan, R. M. (2008). Self-determination theory: A macrotheory of human motivation, development, and health. Canadian Psychology/Psychologie Canadienne, 49(3), 182-185.

Deci, E. L., Ryan, R. M., Gagné, M., Leone, D. R., Usunov, J., \& Kornazheva, B. P. (2001). Need satisfaction, motivation, and well-being in the work organizations of a former eastern bloc country: A cross-cultural study of self-determination. Personality and Social Psychology Bulletin, 27(8), 930-942.

Deffenbacher, J. L., Oetting, E. R., Lynch, R. S., \& Morris, C.D. (1996). The expression of anger and its consequences. Behavior Research and Therapy, 34, 575-590.

Deffenbacher, J. L., Oetting, E. R., Thwaites, G. A., Lynch, R. S., Baker, D. A., Stark, R. S., Thacker, S., \& Eiswerth-Cox, L. (1996). State-Trait Anger Theory and the utility of the Trait Anger Scale. Journal of Counseling Psychology, 43(2), 131-148. 
DeHaan, C. R., \& Ryan, R. M. (2014). Symptoms of wellness: Happiness and eudaimonia from a self-determination perspective. In K.M. Sheldon \& R.E. Lucas (Eds), Stability of happiness (pp. 37-55). Academic Press.

DeMarree, K. G., Wheeler, S. C., Brinol, P., \& Petty, R. E. (2014). Wanting other attitudes: Actual-desired attitude discrepancies predict feelings of ambivalence and ambivalence consequences. Journal of Experimental Social Psychology, 53, 5-18.

Demerouti, E., Bakker, A. B., \& Bulters, A. J. (2004). The loss spiral of work pressure, workhome interference and exhaustion: Reciprocal relations in a three-wave study. Journal of Vocational Behavior, 64, 131-149.

Denson, T. F., Pedersen, W. C., \& Miller, N. (2006). The displaced aggression questionnaire. Journal of Personality and Social Psychology, 90(6), 1032-1051.

Detert, J. R., \& Trevino, L. K. (2010). Speaking up to higher-ups: How supervisors and skiplevel leaders influence employee voice. Organization Science, 21, 249-270.

Dienesch, R. M. \& Liden, R. C. (1986). Leader-member exchange model of leadership: A critique and further development. Academy of Management Review, 11, 618-634.

Digman, J. M. (1990). Personality structure: Emergence of the five-factor model. Annual Review of Psychology, 41(1), 417-440.

Duffy, R. D., \& Dik, B. J. (2013). Research on calling: What have we learned and where are we going? Journal of Vocational Behavior, 83(3), 428-436.

Duffy, M. K., Ganster, D. C., \& Pagon, M. (2002). Social undermining in the workplace. Academy of Management Journal, 45(2), 331-351. 
Dulebohn, J. H., Bommer, W. H., Liden, R. C., Brouer, R. L., \& Ferris, G. R. (2012). A metaanalysis of antecedents and consequences of leader-member exchange: Integrating the past with an eye toward the future. Journal of Management, 38(6), 1715-1759.

Eagly, A. H. (1987). Reporting sex differences. American Psychologist, 42(7), 756-757.

Eagly, A. H., \& Karau, S. J. (2002). Role congruity theory of prejudice toward female leaders. Psychological Review, 109(3), 573-598.

Eagly, A. H., Mladinic, A., \& Otto, S. (1994). Cognitive and affective bases of attitudes toward social groups and social policies. Journal of Experimental Social Psychology, 30, 113-137.

Eagly, A. H., Wood, W., \& Diekman, A. B. (2000). Social role theory of sex differences and similarities: A current appraisal. In T. Eckes \& H. M. Trautner (Eds.), The developmental social psychology of gender (pp. 123-174). Mahwah, NJ: Erlbaum.

Earley, P. C. (1989). Social loafing and collectivism: A comparison of the United States and the People's Republic of China. Administrative Science Quarterly, 34, 565-581.

Earley, P. C. (1993). East meets West meets Mideast: Further explorations of collectivistic and individualistic work groups. Academy of Management Journal, 36, 319-348.

Edwards, J. R., \& Lambert, L. S. (2007). Methods for integrating moderation and mediation: a general analytical framework using moderated path analysis. Psychological Methods, 12(1), 1-22.

Ehrhart, M. G., Ehrhart, K. H., Roesch, S. C., Chung-Herrera, B. G., Nadler, K., \& Bradshaw, K. (2009). Testing the latent factor structure and construct validity of the ten-item personality inventory. Personality and Individual Differences, 47(8), 900-905.

Elias, S. (2008). Fifty years of influence in the workplace: The evolution of the French and Raven power taxonomy. Journal of Management History, 14(3), 267-283. 
Emerson, R. M. (1962). Power-dependence relations. American Sociological Review, 27(1), 31 41.

Emmons, R. A., \& Colby, P. M. (1995). Emotional conflict and well-being: Relation to perceived availability, daily utilization, and observer reports of social support. Journal of Personality and Social Psychology, 68(5), 947-959.

Emmons, R. A., \& King, L. A. (1988). Conflict among personal strivings: Immediate and longterm implications for psychological and physical well-being. Journal of Personality and Social Psychology, 54(6), 1040-1048.

Epitropaki, O., \& Martin, R. (1999). The impact of relational demography on the quality of leader-member exchanges and employees' work attitudes and well-being. Journal of Occupational and Organizational Psychology, 72(2), 237-240.

Epitropaki, O., \& Martin, R. (2015). LMX and work attitudes: is there anything left unsaid or unexamined? In T.N. Bauer \& B. Erdogan (Eds.), The Oxford handbook of leader-member exchange (pp.139-156). New York, NY, US: Oxford University Press.

Erez, M., \& Earley, P. C. (1987). Comparative analysis of goal-setting strategies across cultures. Journal of Applied Psychology, 72(4), 658-665.

Erdogan, B., \& Liden, R. C. (2006). Collectivism as a moderator of responses to organizational justice: implications for leader-member exchange and ingratiation. Journal of Organizational Behavior, 27(1), 1-17.

Eva, N., Robin, M., Sendjaya, S., van Dierendonck, D., \& Liden, R. C. (2019). Servant leadership: A systematic review and call for future research. Leadership Quarterly, 30(1), 111-132. 
Fernet, C., Austin, S., Trépanier, S. G., \& Dussault, M. (2013). How do job characteristics contribute to burnout? Exploring the distinct mediating roles of perceived autonomy, competence, and relatedness. European Journal of Work and Organizational Psychology, 22(2), 123-137.

Festinger, L. (1957). A theory of cognitive dissonance. Stanford university press.

Fingerman, K. (2001). A distant closeness: Intimacy between parents and their children in later life. Generations, 25, 26-33.

Fingerman, K. L., Chen, P. C., Hay, E., Cichy, K. E., \& Lefkowitz, E. S. (2006). Ambivalent reactions in the parent and offspring relationship. The Journals of Gerontology Series B: Psychological Sciences and Social Sciences, 61(3), 152-160.

Fingerman, K. L., Pitzer, L., Lefkowitz, E. S., Birditt, K. S., \& Mroczek, D. (2008). Ambivalent relationship qualities between adults and their parents: Implications for the well-being of both parties. The Journals of Gerontology Series B: Psychological Sciences and Social Sciences, 63(6), 362-371.

Fiorilli, C., Schneider, B., Buonomo, I., \& Romano, L. (2019). Family and nonfamily support in relation to burnout and work engagement among Italian teachers. Psychology in the Schools, 56(5), 781-791.

Fischer, R., Ferreira, M. C., Assmar, E., Redford, P., Harb, C., Glazer, S., Cheng, B., Jiang, D., Wong, C. C., Kumar, N., Kärtner, J., Hofer, J., \& Achoui, M. (2009). Individualismcollectivism as descriptive norms: Development of a subjective norm approach to culture measurement. Journal of Cross-Cultural Psychology, 40(2), 187-213.

Flynn, F. J. (2005). Identity orientations and forms of social exchange in organizations. Academy of Management Review, 30, 737-750. 
Foa, U. G., \& Foa, E. B. (1974). Societal structures of the mind. Springfield, IL: Charles C. Thomas.

Fong, C. T. (2006). The effects of emotional ambivalence on creativity. Academy of Management Journal, 49(5), 1016-1030.

Fong, C. T., \& Tiedens, L. Z. (2002). Dueling experiences and dual ambivalences: Emotional and motivational ambivalence of women in high status positions. Motivation and Emotion, 26(1), 105-121.

Forgays, D. G., Forgays, D. K. \& Spielberger, C. D. (1997). Factor structure of the State-Trait Anger Expression Inventory. Journal of Personality Assessment, 69, 497-507.

Fried, Y., \& Ferris, G. R. (1987). The validity of the job characteristics model: A review and meta-analysis. Personnel Psychology, 40, 287-322.

Furnham, A., \& Thorne, J. D. (2013). Need for cognition: Its dimensionality and personality and intelligence correlates. Journal of Individual Differences, 34(4), 230-240.

Gabris, G. T., \& Ihrke, D. M. (2007). No end to hierarchy: Does rank make a difference in perceptions of leadership credibility? Administration \& Society, 39(1), 107-123.

Gagné, M. (2003). The role of autonomy support and autonomy orientation in prosocial behavior engagement. Motivation and Emotion, 27, 199-223.

Gagné, M., \& Deci, E. L. (2005). Self-determination theory and work motivation. Journal of Organizational Behavior, 26, 331-362.

Gagné, M., \& Vansteenkiste, M. (2013). Self-determination Theory's contribution to positive organizational psychology. In A. B. Bakker (Ed), Advances in positive organizational psychology (Vol. 1, pp. 61-82). Bingley, UK: Emerald Group Publishing Limited. 
Gallo, L. C. \& Smith, T. W. (1997). Construct validation of health-relevant personality traits: Interpersonal circumplex and five-factor model analyses of the Aggression Questionnaire. International Journal of Behavioral Medicine, 5, 129-147.

Gerstner, C. R., \& Day, D. V. (1997). Meta-Analytic review of leader-member exchange theory: Correlates and construct issues. Journal of Applied Psychology, 82(6), 827-844.

Gillet, N., Caesens, G., Morin, A. J. S., \& Stinglhamber, F. (2019). Complementary variable- and person-centred approaches to the dimensionality of work engagement: A longitudinal investigation. European Journal of Work and Organizational Psychology, 28(2), 239-258.

Gilbert, G. R., Collins, R. W., \& Brenner, R. (1990). Age and leadership effectiveness: From the perceptions of the follower. Human Resource Management, 29(2), 187-196.

Gillet, N., Fouquereau, E., Forest, J., Brunault, P., \& Colombat, P. (2012). The impact of organizational factors on psychological needs and their relations with well-being. Journal of Business and Psychology, 27(4), 437-450.

Goldberg, L. R. (1990). An alternative "description of personality": the big-five factor structure. Journal of Personality and Social Psychology, 59(6), 1216-1229.

Goldberg, L. R. (1992). The development of markers for the Big-Five factor structure. Psychological Assessment, 4, 26-42

Goldberg, L. R. (1993). The structure of phenotypic personality traits. American Psychologist, $48,26-34$.

Goldberg, L. R., Johnson, J. A., Eber, H. W., Hogan, R., Ashton, M. C., Cloninger, C. R., \& Gough, H. G. (2006). The international personality item pool and the future of publicdomain personality measures. Journal of Research in Personality, 40(1), 84-96. 
González-Romá, V., Schaufeli, W. B., Bakker, A. B., \& Lloret, S. (2006). Burnout and work engagement: Independent factors or opposite poles? Journal of Vocational Behavior, 68(1), $165-174$.

Gosling, S. D., Rentfrow, P. J., \& Swann, W. B., Jr. (2003). A very brief measure of the Big-Five personality domains. Journal of Research in Personality, 37, 504-528.

Graen, G. B. (1976). Role making processes within complex organizations. In M. D. Dunnette (Ed.), Handbook of industrial and organizational psychology (pp. 1201-1245). Chicago, IL: Rand-McNally.

Graen, G. B., \& Scandura, T. (1987). Toward a psychology of dyadic organizing. In B. Staw \& L.L. Cumming (Eds.), Research in organizational behavior (Vol. 9, pp. 175-208). Greenwich, CT: JAI Press.

Graen, G. B., \& Uhl-Bien, M. (1995). Relationship-based approach to leadership: Development of leader-member exchange (LMX) theory of leadership over 25 years: Applying a multilevel multi-domain perspective. Leadership Quarterly, 6(2), 219-247.

Grant, A. M. (2008). The significance of task significance: Job performance effects, relational mechanisms, and boundary conditions. Journal of Applied Psychology, 93(1), 108-124.

Graves, L. M., \& Luciano, M. M. (2013). Self-determination at work: Understanding the role of leader-member exchange. Motivation and Emotion, 37(3), 518-536.

Graziano, W. G., \& Eisenberg, N. (1997). Agreeableness: A dimension of personality. In R. Hogan, J. Johnson, \& S. Briggs (Eds.), Handbook of personality psychology (pp. 795-824). San Diego, CA: Academic Press

Griffin, B., \& Hesketh, B. (2004). Why openness to experience is not a good predictor of job performance. International Journal of Selection and Assessment, 12(3), 243-251. 
Hackman, J. R., \& Oldham, G. R. (1976). Motivation through the design of work: Test of a theory. Organizational Behavior and Human Performance, 16, 250-279.

Halbesleben, J. R. B. (2006). Sources of social support and burnout: a meta-analytic test of the Conservation of Resources Model. Journal of Applied Psychology, 91(5), 1134-1145. Halevy, N., Chou, E. Y., Cohen, T. R., \& Livingston, R. W. (2012). Status conferral in intergroup social dilemmas: behavioral antecedents and consequences of prestige and dominance. Journal of Personality and Social Psychology, 102(2), 351-366.

Hall, J. A., \& Friedman, G. B. (1999). Status, gender, and nonverbal behavior: A study of structured interactions between employees of a company. Personality and Social Psychology Bulletin, 25, 1082-1091.

Harmon-Jones, E., \& Harmon-Jones, C. (2007). Cognitive dissonance theory after 50 years of development. Zeitschrift für Sozialpsychologie, 38(1), 7-16.

Harpaz, I., \& Fu, X. (2002). The structure of the meaning in work: A relative stability amidst change. Human Relations, 55(6), 639-667.

Harris, K. J., Kacmar, K. M., \& Zivnuska, S. (2007). An investigation of abusive supervision as a predictor of performance and the meaning in work as a moderator of the relationship. Leadership Quarterly, 18(3), 252-263.

Harris, K. J., Wheeler, A. R., \& Kacmar, K. M. (2009). Leader-member exchange and empowerment: Direct and interactive effects on job satisfaction, turnover intentions, and performance. Leadership Quarterly, 20(3), 371-382.

Hass, R. G., Katz, I., Rizzo, N., Bailey, J., \& Moore, L. (1992). When racial ambivalence evokes negative affect, using a disguised measure. Personality and Social Psychology Bulletin, 18, 786-797. 
Hayes, A. F. (2018). Introduction to mediation, moderation, and conditional process analysis: A regression-based approach (2nd edition). New York: The Guilford Press.

Hays, N. A., \& Bendersky, C. (2015). Not all inequality is created equal: Effects of status versus power hierarchies on competition for upward mobility. Journal of Personality and Social Psychology, 108, 867-882.

Heaton, A. W., \& Kruglanski, A. W. (1991). Person perception by introverts and extraverts under time pressure: Effects of need for closure. Personality and Social Psychology Bulletin, 17(2), 161-165.

Heider, F. (1946). Attitudes and cognitive organization. The Journal of Psychology, 21(1), 107112.

Henrich, J., Chudek, M., \& Boyd, R. (2015). The Big Man Mechanism: how prestige fosters cooperation and creates prosocial leaders. Philosophical Transactions of the Royal Society B: Biological Sciences, 370(1683), 1-13.

Henrich, J., \& Gil-White, F. J. (2001). The evolution of prestige: Freely conferred deference as a mechanism for enhancing the benefits of cultural transmission. Evolution and Human Behavior, 22(3), 165-196.

Herzberg, P. Y., \& Brähler, E. (2006). Assessing the Big-Five personality domains via short forms. European Journal of Psychological Assessment, 22(3), 139-148.

Hetland, J., Hetland, H., Bakker, A. B., Demerouti, E., Andreassen, C. S., \& Pallesen, S. (2015). Psychological need fulfillment as a mediator of the relationship between transformational leadership and positive job attitudes. Career Development International, 20(5), 464-481. 
Hinojosa, A. S., Gardner, W. L., Walker, H. J., Cogliser, C., \& Gullifor, D. (2017). A review of cognitive dissonance theory in management research: Opportunities for further development. Journal of Management, 43(1), 170-199.

Hofmans, J., Kuppens, P., \& Allik, J. (2008). Is short in length short in content? An examination of the domain representation of the Ten Item Personality Inventory scales in Dutch language. Personality and Individual Differences, 45(8), 750-755.

Hofstede, G. H. (1980). Culture's consequences: International differences in work-related values. Beverly Hills, CA: Sage.

Hogan, R., \& Roberts, B. W. (2004). A socioanalytic model of maturity. Journal of Career Assessment, 12, 207-217.

Hohman, Z. P., Crano, W. D., \& Niedbala, E. M. (2016). Attitude ambivalence, social norms, and behavioral intentions: Developing effective antitobacco persuasive communications. Psychology of Addictive Behaviors, 30(2), 209-219.

Holt-Lunstad, J., Uchino, B. N., Smith, T. W., \& Hicks, A. (2007). On the importance of relationship quality: The impact of ambivalence in friendships on cardiovascular functioning. Annals of Behavioral Medicine, 33, 278-290.

Holt-Lunstad, J., Uchino, B. N., Smith, T. W., Olson-Cerny, C., \& Nealey-Moore, J. B. (2003). Social relationships and ambulatory blood pressure: Structural and qualitative predictors of cardiovascular function during everyday social interactions. Health Psychology, 22(4), 388-397.

Hough, L. M., Oswald, F. L., \& Ock, J. (2015). Beyond the big five: New directions for personality research and practice in organizations. Annual Review of Organizational Psychology and Organizational Behavior, 2(1), 183-209. 
Hui, C. H. (1988). Measurement of individualism-collectivism. Journal of Research in Personality, 22, 17-36.

Ingram, P., \& Zou, X. (2008). Business friendships. Research in Organizational Behavior, 28, 167-184.

Jackson, E. M., \& Johnson, R. E. (2012). When opposites do (and do not) attract: Interplay of leader and follower self-identities and its consequences for leader-member exchange. Leadership Quarterly, 23, 488-501.

Jamieson, D. W. (1993). The attitude ambivalence construct: Validity, utility, and measurement. Paper presented at the annual meeting of the American Psychological Association, Toronto

John, O. P., Donahue, E. M., \& Kentle, R. L. (1991). The Big Five Inventory-Versions 4a and 54. Berkeley, CA: University of California, Berkeley, Institute of Personality and Social Research.

John, O. P., Naumann, L. P., \& Soto, C. J. (2008). Paradigm shift to the integrative big five trait taxonomy. In O. P. John, R. W. Robins \& L. A. Pervin ( $3^{\text {rd }}$ Eds.), Handbook of personality: Theory and research (pp. 114-158). New York: Guilford Press

John, O. P., \& Srivastava, S. (1999). The Big Five trait taxonomy: History, measurement, and theoretical perspectives. In L. A. Pervin, \& O. P. John (Eds.), Handbook of personality: Theory and research (pp. 102-138). New York: Guilford Press

Johnson, R. E., \& Saboe, K. N. (2011). Measuring implicit traits in organizational research: Development of an indirect measure of employee implicit self-concept. Organizational Research Methods, 14(3), 530-547. 
Jonas, K., Diehl, M., \& Brömer, P. (1997). Effects of attitudinal ambivalence on information processing and attitude-intention consistency. Journal of Experimental Social Psychology, $33,190-210$.

Jonason, P. K., Teicher, E. A., \& Schmitt, D. P. (2011). The TIPI's validity confirmed: Associations with sociosexuality and self-esteem. Individual Differences Research, 9, 5260.

Judge, T. A., Bono, J. E., Ilies, R., \& Gerhardt, M. W. (2002). Personality and leadership: a qualitative and quantitative review. Journal of Applied Psychology, 87(4), 765-780.

Judge, T. A., \& Ilies, R. (2002). Relationship of personality to performance motivation: A metaanalytic review. Journal of Applied Psychology, 87(4), 797-807.

Judge, T. A., \& LePine, J. A. (2007). The bright and dark sides of personality: Implications for personnel selection in individual and team contexts. In J. Langan-Fox, C. L. Cooper, \& R. J. Klimoski (Eds.), New horizons in management. Research companion to the dysfunctional workplace: Management challenges and symptoms (pp. 332-355). Northampton, MA, US: Edward Elgar Publishing.

Judge, T. A., Piccolo, R. F., \& Kosalka, T. (2009). The bright and dark sides of leader traits: A review and theoretical extension of the leader trait paradigm. Leadership Quarterly, 20(6), 855-875.

Kahn, W. A. (1990). Psychological conditions of personal engagement and disengagement at work. Academy of Management Journal, 33, 692-724.

Kahn, W. A. (1992). To be fully there: Psychological presence at work. Human Relations, 45, 321-349. 
Kahn, R. L., Wolfe, D. M., Quinn, R. P., Snoek, J. D., \& Rosenthal, R. A. (1964). Organizational stress. New York, NY: Wiley.

Kakkar, H., \& Sivanathan, N. (2017). When the appeal of a dominant leader is greater than a prestige leader. Proceedings of the National Academy of Sciences, 114(26), 6734-6739.

Kamdar, D., \& Van Dyne, L. (2007). The joint effects of personality and workplace social exchange relationships in predicting task performance and citizenship performance. Journal of Applied Psychology, 92(5), 1286-1298.

Kim, U. (1994). Individualism and collectivism: Conceptual clarification and elaboration. In U. Kim, H. C. Triandis, C. Kagitcibasi, S. Choi, \& G. Yoon (Eds.), Individualism and collectivism: Theory, method, and applications (pp. 19-40). Thousand Oaks, CA: Sage.

King, L. A., Richards, J. H., \& Stemmerich, E. (1998). Daily goals, life goals, and worst fears: Means, ends, and subjective well - being. Journal of Personality, 66(5), 713-744.

Kinjerski, V., \& Skrypnek, B.J. (2004). Defining spirit at work: Finding common ground. Journal of Organizational Change Management, 17(1), 26-42.

Kirkman, B. L., \& Shapiro, D. L. (2001). The impact of cultural values on job satisfaction and organizational commitment in self-managing work teams: The mediating role of employee resistance. Academy of Management Journal, 44(3), 557-569.

Kite, M. E., Stockdale, G. D., Whitley Jr, B. E., \& Johnson, B. T. (2005). Attitudes toward younger and older adults: An updated meta-analytic review. Journal of Social Issues, 61(2), 241-266.

Kokkonen, M., \& Pulkkinen, L. E. A. (2001). Extraversion and neuroticism as antecedents of emotion regulation and dysregulation in adulthood. European Journal of Personality, $15(6), 407-424$. 
Koval, P., \& Kuppens, P. (2012). Changing emotion dynamics: Individual differences in the effect of anticipatory social stress on emotional inertia. Emotion, 12(2), 256-267.

Kovjanic, S., Schuh, S. C., \& Jonas, K. (2013). Transformational leadership and performance: An experimental investigation of the mediating effects of basic needs satisfaction and work engagement. Journal of Occupational and Organizational Psychology, 86(4), 543-555.

Kraimer, M. L., Seibert, S. E., \& Astrove, S.L. (2015) Consequences of high LMX: Career mobility and success. In T. N. Bauer and B. Erdogan (Eds.), The Oxford handbook of leader-member exchange (pp. 241-259). New York, NY, US: Oxford University Press.

Kramer, D. A. (1989). A developmental framework for understanding conflict resolution processes. In J. D. Sinnott (Ed.), Everyday problem solving in adulthood (pp. 133-152). New York: Praeger.

Kramer, D. A., \& Melchior, J. (1990). Gender, role conflict, and the development of relativistic and dialectical thinking. Sex Roles, 23(9-10), 553-575.

Kruglanski, A. W. (1980). Lay epistemo-logic_process and contents: Another look at attribution theory. Psychological Review, 87(1), 70-87.

Kruse, L., \& Wintermantel, M. (1986). Leadership Ms.-qualified: I. The gender bias in everyday and scientific thinking. In Graumann, C. F., \& Moscovici, S. (Eds.), Changing conceptions of leadership (pp. 171-197). New York, NY: Springer.

La Guardia, J. G., Ryan, R. M., Couchman, C. E., \& Deci, E. L. (2000). Basic Psychological Needs Scales. Journal of Personality and Social Psychology, 79, 367-384.

Laghai, A., \& Joseph, S. (2000). Attitudes towards emotional expression: Factor structure, convergent validity and associations with personality. British Journal of Medical Psychology, 73, 381-384. 
Larsen, J., McGraw, A., \& Cacioppo, J. (2001). Can people feel happy and sad at the same time? Journal of Personality and Social Psychology, 81(4), 684-696.

Laustsen, L., \& Petersen, M. B. (2017). Perceived conflict and leader dominance: Individual and contextual factors behind preferences for dominant leaders. Political Psychology, 38(6), 1083-1101.

Lawton, M. P. (2001). Emotion in later life. Current Directions in Psychological Science, 10(4), $120-123$.

Lee, S. (2015). A concept analysis of "Meaning in work" and its implications for nursing. Journal of Advanced Nursing, 71(10), 2258-2267.

Lee, A. (2016). Leader-member exchange and attitudes: a theoretical and empirical integration. Doctoral dissertation, Aston University, UK.

Lee, A., Martin, R., Thomas, G., Guillaume, Y., \& Maio, G. R. (2015). Conceptualizing leadership perceptions as attitudes: Using attitude theory to further understand the leadership process. Leadership Quarterly, 26(6), 910-934.

Lee, A., Thomas, G., Martin, R., \& Guillaume, Y. (2019). Leader-Member exchange (LMX) ambivalence and task Performance: The cross-domain buffering role of social support. Journal of Management, 45(5), 1927-1957.

Leiter, M. P., \& Shaughnessy, K. (2006). The areas of worklife model of burnout: tests of mediation relationships. Ergonomia: An International Journal, 28, 327-341.

Lemerise, E. A., \& Dodge, K. A. (2008). The development of anger and hostile interactions. In M. Lewis, J. M. Haviland-Jones, \& L. F. Barrett (Eds.), Handbook of emotions (pp. 730741). New York, NY, US: The Guilford Press. 
Leroy, H., Anseel, F., Gardner, W. L., \& Sels, L. (2015). Authentic leadership, authentic followership, basic need satisfaction, and work role performance: A cross-level study. Journal of Management, 41(6), 1677-1697.

Lian, H., Ferris, D. L., \& Brown, D. J. (2012). Does taking the good with the bad make things worse? How abusive supervision and leader-member exchange interact to impact need satisfaction and organizational deviance. Organizational Behavior and Human Decision Processes, 117, 41-52.

Liden, R. C., \& Maslyn, J. M. (1998). Multidimensionality of leader-member exchange: An empirical assessment through scale development. Journal of Management, 24(1), 43-72.

Liden, R. C., Sparrowe, R. T., and Wayne, S. J. (1997). Leader-member exchange theory: The past and potential for the future. Research in Personnel and Human Resource Management, 15, 47-119.

Liden, R. C.,Wayne, S. J., \& Sparrowe, R. T. (2000). An examination of the mediating role of psychological empowerment on the relations between the job, interpersonal relationships, and work outcomes. Journal of Applied Psychology, 85, 407-416.

Lin, X., \& Leung, K. (2010). Differing effects of coping strategies on mental health during prolonged unemployment: A longitudinal analysis. Human Relations, 63, 637-665.

Littman-Ovadia, H., \& Steger, M. (2010). Character strengths and well-being among volunteers and employees: Toward an integrative model. The Journal of Positive Psychology, 5(6), 419-430.

Magee, J. C., \& Galinsky, A. D. (2008). Social hierarchy: The self-reinforcing nature of power and status. Academy of Management Annals, 2 (1), 351-398. 
Maner, J. K. (2017). Dominance and prestige: A tale of two hierarchies. Current Directions in Psychological Science, 26(6), 526-531.

Maner, J. K., \& Case, C. R. (2016). Dominance and prestige: Dual strategies for navigating social hierarchies. In J. M. Olson \& M. P. Zanna (Eds.), Advances in experimental social psychology (Vol. 54, pp. 129-180). Academic Press.

Markus, H. R., \& Kitayama, S. (1991). Culture and the self: Implications for cognition, emotion, and motivation. Psychological Review, 98(2), 224-253.

Martin, R., Guillaume, Y., Thomas, G., Lee, A., \& Epitropaki, O. (2016). Leader-member exchange (LMX) and performance: A meta-analytic review. Personnel Psychology, 69(1), $67-121$

Martinez, A. D., Kane, R. E., Ferris, G. R., \& Brooks, C. D. (2012). Power in leader-follower work relationships. Journal of Leadership \& Organizational Studies, 19(2), 142-151.

Maslach, C., \& Jackson, S. E. (1981). The measurement of experienced burnout. Journal of Organizational Behavior, 2(2), 99-113.

Maslach, C., Schaufeli, W. B., \& Leiter, M. P. (2001). Job burnout. Annual Review of Psychology, 52(1), 397-422.

Matta, F. K., Scott, B. A., Koopman, J., \& Conlon, D. E. (2015). Does seeing “eye to eye” affect work engagement and organizational citizenship behavior? A role theory perspective on LMX agreement. Academy of Management Journal, 58(6), 1686-1708.

May, D. R., Gilson, R. L., \& Harter, L. M. (2004). The psychological conditions of meaningfulness, safety and availability and the engagement of the human spirit at work. Journal of Occupational and Organizational Psychology, 77(1), 11-37. 
Mayer, D. M. (2010). Servant leadership and follower need satisfaction: Where do we go from here? In D. van Dierendonck, \& K. Patterson (Eds.), Servant leadership. Developments in theory and practice (pp. 147-154). Hampshire, UK: Palgrave Macmillan.

Mayer, D. M., Bardes, M., \& Piccolo, R. F. (2008). Do servant-leaders help satisfy follower needs? An organizational justice perspective. European Journal of Work and Organizational Psychology, 17(2), 180-197.

McClane, W. E. (1991). The interaction of leader and member characteristics in the leadermember exchange (LMX) model of leadership. Small Group Research, 22(3), 283-300.

McClelland, D. C., Koestner, R., \& Weinberger, J. (1992). How do self-attributed and implicit motives differ? In C. P. Smith (Ed.), Motivation and personality: Handbook of thematic content analysis (pp. 49-72). New York: Cambridge University Press.

McCrae, R. R. (1987). Creativity, divergent thinking, and openness to experience. Journal of Personality and Social Psychology, 52(6), 1258-1265.

McCrae, R. R., \& Costa, P. T. (1987). Validation of the five-factor model of personality across instruments and observers. Journal of Personality and Social Psychology, 52(1), 81-90.

McCrae, R. R., \& Costa Jr, P. T. (1997). Conceptions and correlates of openness to experience. In R. Hogan, J. Johnson \& S. Briggs (Eds.), Handbook of personality psychology (pp. 825847). Academic Press.

McCrae, R. R., \& Costa, P. T. (2008). The five-factor theory of personality. In O. P. John, R. W. Robins, \& L. A. Pervin (Eds.), Handbook of personality: Theory and research (pp. 159181). New York, NY, US: The Guilford Press.

McCrae, R. R., \& Costa Jr, P. T. (2004). A contemplated revision of the NEO Five-Factor Inventory. Personality and Individual Differences, 36(3), 587-596. 
Merolla, J. L., \& Zechmeister, E. J. (2009). Terrorist threat, leadership, and the vote: Evidence from three experiments. Political Behavior, 31, 575-601.

Methot, J. R., Melwani, S., \& Rothman, N. B. (2017). The space between us: A social-functional emotions view of ambivalent and indifferent workplace relationships. Journal of Management, 43(6), 1789-1819.

Meyerson, D. E. \& Scully, M. A. (1995). Tempered radicalism and the politics of ambivalence and change. Organization Science, 6, 585-600.

Mikulincer, M., \& Shaver, P. R. (2005). Attachment theory and emotions in close relationships: Exploring the attachment-related dynamics of emotional reactions to relational events. Personal Relationships, 12(2), 149-168.

Mikulincer, M., \& Shaver, P. R. (2007). Attachment in adulthood: Structure, dynamics, and change. New York, NY: Guilford Press.

Mikulincer, M., Shaver, P. R., Bar-On, N., \& Ein-Dor, T. (2010). The pushes and pulls of close relationships: Attachment insecurities and relational ambivalence. Journal of Personality and Social Psychology, 98(3), 450-468.

Milyavskaya, M., \& Koestner, R. (2011). Psychological needs, motivation, and well-being: A test of self-determination theory across multiple domains. Personality and Individual Differences, 50(3), 387-391

Mitchell, T. R., \& James, L. R. (2001). Building better theory: Time and the specification of when things happen. Academy of Management Review, 26(4), 530-547.

Moorman, R.H., \& Blakely, G.L. (1995). Individualism-collectivism as an individual difference predictor of organizational citizenship behavior. Journal of Organizational Behavior, 16, 127-142. 
Morrison E. E., Burke I. \& Greene L. (2007). Meaning in motivation: does your organization need an inner life? Journal of Health \& Human Services Administration, 30(1), 98-115.

Mount, M. K., \& Barrick, M. R. (1995). The Big Five personality dimensions: implications for research and practice in human resources management. Research in Personnel and Human Resources Management, 13, 153- 200.

Nahrgang, J. D., Morgeson, F. P., \& Ilies, R. (2009). The development of leader--member exchanges: Exploring how personality and performance influence leader and member relationships over time. Organizational Behavior and Human Decision Processes, 108(2), 256-266.

Nahrgang, J. D., \& Seo, J. J. (2015). How and why high leader-member exchange (LMX) relationships develop. In T.N. Bauer \& B. Erdogan (Eds.), The Oxford handbook of leadermember exchange (pp.87-117). New York, NY: Oxford University Press.

Neuberg, S. L., Judice, T. N., \& West, S. G. (1997). What the Need for Closure Scale measures and what it does not: Toward differentiating among related epistemic motives. Journal of Personality and Social Psychology, 72(6), 1396.

Ng, T. W. H., \& Feldman, D. C. (2008). The relationship of age to ten dimensions of job performance. Journal of Applied Psychology, 93(2), 392-423.

Ng, J. Y. Y., Ntoumanis, N., Thogersen-Ntoumani, C., Deci, E. L., Ryan, R. M., Duda, J. L., \& Williams, G. C. (2012). Self-determination theory applied to health contexts: A metaanalysis. Perspectives on Psychological Science, 7, 325-340.

Nikolova, I., Schaufeli, W., \& Notelaers, G. (2019). Engaging leader- engaged employees? A cross-lagged study on employee engagement. European Management Journal, available online first. 
Nordgren, L. F., Van Harreveld, F., \& Van der Pligt, J. (2006). Ambivalence, discomfort, and motivated information processing. Journal of Experimental Social Psychology, 42(2), 252258.

Norman, R. M. G., \& Watson, L. D. (1976). Extroversion and reactions to cognitive in consistency. Journal of Research in Personality, 10, 446-456.

O’Meara, M. S., \& South, S. C. (2019). Big Five personality domains and relationship satisfaction: Direct effects and correlated change over time. Journal of Personality, 87(6), 1206-1220.

Oglensky, B. D. (2008). The ambivalent dynamics of loyalty in mentorship. Human Relations, 61(3), 419-448.

Olafsen, A. H., Deci, E. L., \& Halvari, H. (2018). Basic psychological needs and work motivation: A longitudinal test of directionality. Motivation and Emotion, 42(2), 178-189.

Olsen, S. O., Wilcox, J., \& Olsson, U. (2005). Consequences of ambivalence on satisfaction and loyalty. Psychology \& Marketing, 22(3), 247-269.

Ones, D. S. (2005). Personality at work: Raising awareness and correcting misconceptions. Human Performance, 18(4), 389-404.

Ong, A. D., \& Bergeman, C. S. (2004). The complexity of emotions in later life. The Journals of Gerontology Series B: Psychological Sciences and Social Sciences, 59(3), 117-122.

Örtqvist, D. \& Wincent, J., (2006). Prominent consequences of role stress: A meta-analytic review. International Journal of Stress Management, 13(4), 399-422.

Oshagbemi, T. (2004). Age influences on the leadership styles and behaviour of managers. Employee Relations, 26(1), 14-29. 
Oshio, A., Shingo, A. B. E., \& Cutrone, P. (2012). Development, Reliability, and Validity of the Japanese Version of Ten Item Personality Inventory (TIPI-J). Japanese Journal of Personality, 21(1), 40-52.

Oswald, F. L., Hough, L. \& Ock, J. (2013). Theoretical and empirical structures of personality: Implications for measurement, modeling, and prediction. In C. Neil, and R. Tett (Eds), Handbook of personality at work (pp. 49-67). New York: Routledge.

Oyserman, D., Coon, H. M., \& Kemmelmeier, M. (2002). Rethinking individualism and collectivism: Evaluation of theoretical assumptions and meta-analyses. Psychological Bulletin, 128(1), 3-72.

Parrott, D. J., \& Zeichner, A. (2003). Effects of trait anger and negative attitudes towards women on physical assault in dating relationships. Journal of Family Violence, 18(5), 301-307.

Perugini, M., Gallucci, M., Presaghi, F., \& Ercolani, A. P. (2003). The personal norm of reciprocity. European Journal of Personality, 17(4), 251-283.

Phillips, A. S., \& Bedeian, A. G. (1994). Leader-follower exchange quality: The role of personal and interpersonal attributes. Academy of Management Journal, 37(4), 990-1001.

Piedmont, R. L. (1998). The revised NEO Personality Inventory: Clinical and research applications. New York: Plenum Press.

Pinder, C. C., \& Pinto, P. R. (1974). Demographic correlates of managerial style. Personnel Psychology, 27(2), 257-270.

Podsakoff, P. M., MacKenzie, S. B., \& Podsakoff, N. P. (2012). Sources of method bias in social science research and recommendations on how to control it. Annual Review of Psychology, $63,539-569$. 
Porter, L. S., Keefe, F. J., Lipkus, I., \& Hurwitz, H. (2005). Ambivalence over emotional expression in patients with gastrointestinal cancer and their caregivers: Associations with patient pain and quality of life. Pain, 117(3), 340-348.

Posthuma, R. A., \& Campion, M. A. (2009). Age stereotypes in the workplace: Common stereotypes, moderators, and future research directions. Journal of Management, 35(1), 158-188.

Pratt, M. G. (2000). The good, the bad, and the ambivalent: Managing identification among Amway distributors. Administrative Science Quarterly, 45(3), 456-493.

Pratt, M. G., \& Ashforth, B. E. (2003). Fostering meaningfulness in working and at work. In K. S. Cameron, J. E. Dutton, \& R. E. Quinn (Eds.), Positive organizational scholarship (pp. 309-327). San Francisco: Berrett-Koehler Publishers, Inc.

Pratt, M. G., \& Doucet, L. (2000). Ambivalent feelings in organizational relationships. In S. Fineman (Ed.), Emotion in organizations (2nd ed., pp. 204-226). London: Sage.

Pratt, M. G., \& Pradies, C. (2011). Just a good place to visit? Exploring positive responses to ambivalence. K. Cameron \& G. Spreitzer. (Eds.), The Oxford handbook of positive organizational scholarship (pp. 924-937). New York, NY, US: Oxford University Press.

Pratt, M. G., \& Rosa, J. A. (2003). Transforming work-family conflict into commitment in network marketing organizations. Academy of Management Journal, 46(4), 395-418.

Quintanilla S.A. (1991) Introduction: the meaning in work. European Work \& Organizational Psychologist, 1(2), 81-89.

Reblin, M., Uchino, B. N., \& Smith, T. W. (2010). Provider and recipient factors that may moderate the effectiveness of received support: Examining the effects of relationship 
quality and expectations for support on behavioral and cardiovascular reactions. Journal of Behavioral Medicine, 33(6), 423-431.

Redhead, D., Cheng, J. T., Driver, C., Foulsham, T., \& O’Gorman, R. (2019). On the dynamics of social hierarchy: A longitudinal investigation of the rise and fall of prestige, dominance, and social rank in naturalistic task groups. Evolution and Human Behavior, 40(2), 222-234

Rockstuhl, T., Dulebohn, J. H., Ang, S., \& Shore, L. M. (2012). Leader-member exchange (LMX) and culture: A meta-analysis of correlates of LMX across 23 countries. Journal of Applied Psychology, 97(6), 1097-1130.

Romero, E., Villar, P., Gómez-Fraguela, J. A., \& López-Romero, L. (2012). Measuring personality traits with ultra-short scales: A study of the Ten Item Personality Inventory (TIPI) in a Spanish sample. Personality and Individual Differences, 53(3), 289-293.

Rong, K., Secchi, D \& Shou, Y. (2018). Culture, trust and business ecosystems: the mediating role of online chat in China. International Journal of Mobile Communications, 16(3), 247265.

Ros, M., Schwartz, S. H., \& Surkiss, S. (1999). Basic individual values, work values, and the meaning of work. Applied Psychology: An International Review, 48(1), 49-71.

Rosen, C. C., Ferris, D. L., Brown, D. J., Chen, Y., \& Yan, M. (2013). Perceptions of organizational politics: A need satisfaction paradigm. Organization Science, 25(4), 10261055.

Rosso, B. D., Dekas, K. H., \& Wrzesniewski, A. (2010). On the meaning in work: A theoretical integration and review. Research in Organizational Behavior, 30, 91-127.

Rothmann, S. (2003). Burnout and engagement: A South African perspective. SA Journal of Industrial Psychology, 29(4), 16-25. 
Rothman, N. B., \& Melwani, S. (2017). Feeling mixed, ambivalent, and in flux: The social functions of emotional complexity for leaders, Academy of Management Review, 42(2), $259-282$.

Rothman, N. B., \& Northcraft, G. B. (2015). Unlocking integrative potential: Expressed emotional ambivalence and negotiation outcomes. Organizational Behavior and Human Decision Processes, 126, 65-76.

Rothman, N. B., Pratt, M. G., Rees, L., \& Vogus, T. J. (2017). Understanding the dual nature of ambivalence: Why and when ambivalence leads to good and bad outcomes. Academy of Management Annals, 11(1), 33-72.

Rudolph, T. J. (2011). The dynamics of ambivalence. American Journal of Political Science, 55(3), 561-573.

Ruiz, J. M., Smith, T. W. \& Rhodewalt, F. (2001). Distinguishing narcissism and hostility: Similarities and differences in interpersonal circumplex and five-factor correlates. Journal of Personality Assessment, 76, 537-555.

Rusbult, C. E., \& Van Lange, P. A. (2003). Interdependence, interaction, and relationships. Annual Review of Psychology, 54, 351-375.

Ryan, R. M. (1995). Psychological needs and the facilitation of integrative processes. Journal of Personality, 63(3), 397-427.

Ryan, R. M., \& Deci, E. L. (2000). Self-determination theory and the facilitation of intrinsic motivation, social development, and well-being. American Psychologist, 55(1), 68-78.

Ryan, R. M., \& Deci, E. L. (2001). On happiness and human potentials: A review of research on hedonic and eudaimonic well-being. Annual Review of Psychology, 52(1), 141-166. 
Ryan, R. M., \& Deci, E. L. (2002). On assimilating identities to the self: a self-determination theory perspective on internalization and integrity within cultures. In M. R. Leary, \& J. P. Tangney (Eds.), Handbook of self and identity (pp. 255-273). New York: Guilford.

Ryan, R. M., \& Deci, E. L. (2006). Self-regulation and the problem of human autonomy: Does psychology need choice, self-determination, and will? Journal of Personality, 74(6), 15571586.

Sadowski, C. J., \& Cogburn, H. E. (1997). Need for cognition in the big-five factor structure. The Journal of Psychology, 131(3), 307-312.

Sanz, J., García-Vera, M. P., \& Magán, I. (2010). Anger and hostility from the perspective of the Big Five personality model. Scandinavian Journal of Psychology, 51(3), 262-270.

Schaufeli, W. B., Bakker, A. B., Hoogduin, K., Schaap, C., \& Kladler, A. (2001). On the clinical validity of the Maslach Burnout Inventory and the Burnout Measure. Psychology \& Health, 16(5), 565-582.

Schaufeli, W. B., Leiter, M. P., Maslach, C., \& Jackson, S. E. (1996). MBI-General Survey. In C. Maslach, S. E. Jackson, \& M. P. Leiter (Eds.), Maslach Burnout Inventory manual (3rd ed.). Palo Alto, CA: Consulting Psychologists Press.

Schaufeli, W. B., Maslach, C., \& Marek, T. (1993). The future of burnout. In W. B. Schaufeli, C. Maslach \& T. Marek (Eds.), Professional burnout: Recent developments in theory and research (pp. 253-259). Philadelphia, PA, US: Taylor \& Francis.

Schaufeli, W. B., Salanova, M., González-Romá, V., \& Bakker, A. B. (2002). The measurement of engagement and burnout: A two sample confirmatory factor analytic approach. Journal of Happiness Studies, 3, 71-92. 
Schaufeli, W. B., Shimazu, A., Hakanen, J., Salanova, M., \& De Witte, H. (2017). An ultra-short measure for work engagement: The UWES-3 validation across five countries. European Journal of Psychological Assessment, 1-15.

Schneider, I. K., Van Harreveld, F., Rotteveel, M., Topolinski, S., Van der Pligt, J., Schwarz, N., \& Koole, S. L. (2015). The path of ambivalence: tracing the pull of opposing evaluations using mouse trajectories. Frontiers in Psychology, 6, 1-12.

Schriesheim, C. A., Castro, S. L., \& Cogliser, C. C. (1999). Leader-member exchange (LMX) research: A comprehensive review of theory, measurement, and data-analytic practices. Leadership Quarterly, 10, 63-113.

Schriesheim, C. A., Neider, L. L., Scandura, T. A., \& Tepper, B. J. (1992). Development and preliminary validation of a new scale (LMX-6) to measure leader-member exchange in organizations. Educational and Psychological measurement, 52(1), 135-147.

Schulte, P., \& Vainio, H. (2010). Well-being at work-overview and perspective. Scandinavian Journal of Work, Environment \& Health, 422-429.

Schyns, B. (2015). Leader and follower personality and LMX. In Bauer, T. N. \& Erdogan, B. (Eds.), Oxford handbook of leader-member exchange (pp. 119-138). New York, NY: Oxford University Press.

Sharpe, J. P. \& Desai, S. (2001). The revised NEO personality inventory and the MMPI-2 psychopathology five in the prediction of aggression. Personality and Individual Differences, 31, 505-518.

Sheldon, K., \& Niemiec, C. (2006). It's not just the amount that counts: Balanced need satisfaction also affects well-being. Journal of Personality and Social Psychology, 91, 331341. 
Sincoff, J. (1990). The psychological characteristics of ambivalent people. Clinical Psychology Review, 10, 43-68.

Smelser, N. J. (1998). The rational and the ambivalent in the social sciences. American Sociological Review, 63, 1-16.

Smith, T. W. (1994). Concepts and methods in the study of anger, hostility, and health. In A. W. Siegman, \& T. W. Smith (Eds.), Anger, hostility, and the heart (pp. 23-42). Hillsdale, NJ: Lawrence Erlbaum Associates.

Smith, M. A., \& Canger, J. M. (2004). Effects of supervisor "Big five" personality on subordinate attitudes. Journal of Business and Psychology, 18(4), 465-481.

Smith, D. C., Furlong, M. J., \& Boman, P. (2006). Assessing anger and hostility in school settings. In S. R. Jimerson, \& M. Furlong (Eds.), Handbook of school violence and school safety: From research to practice, (pp. 135-145). Mahwah, NJ: Lawrence Erlbaum Associates Publishers.

Smith, T. W., Glazer, K., Ruiz, J. M., \& Gallo, L. C. (2004). Hostility, anger, aggressiveness, and coronary heart disease: An interpersonal perspective on personality, emotion, and health. Journal of Personality, 72(6), 1217-1270.

Smith, E. R., \& Semin, G. R. (2007). Situated social cognition. Current Directions in Psychological Science, 16, 132-135.

Song, J. H., \& Kim, H. M. (2009). The integrative structure of employee commitment: The influential relations of individuals' characteristics in a supportive learning culture. Leadership \& Organization Development Journal, 30(3), 240-255. 
Sparks, P., Conner, M., James, R., Shepherd, R., \& Povey, R. (1995). Ambivalence about healthrelated behaviours: Relationships to personality measures (unpublished raw data). Institute of Food Research, Reading, UK.

Spielberger, C. D. (1999). Professional manual for the state-trait anger expression inventory-2 (STAXI-2). Odessa, FL: Psychological Assessment Resources

Spielberger, C. D., Jacobs, G., Russell, S., \& Crane, R. (1983). Assessment of anger: The statetrait anger scale. In J. N. Butcher \& C. D. Spielberger (Eds.), Advances in personality assessment (Vol. 3, pp. 112-134). Hillsdale, NJ: Erlbaum.

Spisak, B. R., Homan, A. C., Grabo, A., \& Van Vugt, M. (2012). Facing the situation: Testing a biosocial contingency model of leadership in intergroup relations using masculine and feminine faces. Leadership Quarterly, 23, 273-80.

Spreitzer, G. M., Kizilos, M. A., \& Nason, S. W. (1997). A dimensional analysis of the relationship between psychological empowerment and effectiveness satisfaction, and strain. Journal of Management, 23(5), 679-704.

Steger, M. F., Dik, B. J., \& Duffy, R. D. (2012). Measuring meaningful work: The work and meaning inventory (WAMI). Journal of Career Assessment, 20(3), 322-337.

Stinglhamber, F., \& Vandenberghe, C. (2003). Organizations and supervisors as sources of support and targets of commitment: A longitudinal study. Journal of Organizational Behaviour, 24(3), 251-270.

Tafrate, R. C., Kassinove, H., \& Dundin, L. (2002). Anger episodes in high and low trait anger community adults. Journal of Clinical Psychology, 58, 1573-1590.

Taris, T. W., \& Kompier, M. A. J. (2014). Cause and effect: Optimizing the designs of longitudinal studies in occupational health psychology. Work \& Stress, 28(1), 1-8. 
Thomas, C. H., \& Lankau, M. J. (2009). Preventing burnout: The effects of LMX and mentoring on socialization, role stress, and burnout. Human Resource Management, 48(3), 417-432.

Thompson, M. M., Naccarato, M. E., Parker, K. C., \& Moskowitz, G. B. (2001). The personal need for structure and personal fear of invalidity measures: Historical perspectives, current applications, and future directions. In G. B. Moskowitz (Ed), Cognitive social psychology:

The Princeton symposium on the legacy and future of social cognition (pp. 19-39).

Mahwah, NJ: Lawrence Erlbaum Associates.

Thompson, M. M., Zanna, M. P., \& Griffin, D. W. (1995). Let's not be indifferent about (attitudinal) ambivalence. In R. E. Petty \& J. A. Krosnick (Eds.), Attitude strength: Antecedents and consequences (pp. 361-386). Hillsdale, NJ: Erlbaum.

Thompson, M. M., \& Zanna, M. P. (1995). The conflicted individual: Personality-based and domain specific antecedents of ambivalent social attitudes. Journal of Personality, 63(2), $259-288$.

Tierney, P., Farmer, S. M., \& Graen, G. B. (1999). An examination of leadership and employee creativity: The relevance of traits and relationships. Personnel Psychology, 52(3), 591-620.

Tordera, N., González-Romá, V. \& Peiró, J. M. (2008). The moderator effect of psychological climate on the relationship between leader-member exchange (LMX) quality and role overload. European Journal of Work and Organizational Psychology, 17(1), 55-72.

Trafimow, D., Triandis, H. C., \& Goto, S. G. (1991). Some tests of the distinction between the private self and the collective self. Journal of Personality and Social Psychology, 60(5), 649-655. 
Traupman, E. K., Smith, T. W., Uchino, B. N., Berg, C. A., Trobst, K. K., \& Costa, P. T., Jr. (2009). Interpersonal circumplex octant, control, and affiliation scales for the NEO-PI-R. Personality and Individual Differences, 47, 457-463.

Trépanier, S. G., Fernet, C., \& Austin, S. (2013). Workplace bullying and psychological health at work: The mediating role of satisfaction of needs for autonomy, competence and relatedness. Work \& Stress, 27(2), 123-140.

Triandis, H. C. (1990). Theoretical concepts that are applicable to the analysis of ethnocentrism. Applied Cross-cultural Psychology, 14, 34-55.

Triandis, H. C. (1995). Individualism and collectivism. Boulder, CO: Westview.

Triandis, H. C., Bontempo, R., Villareal, M. J., Asai, M., \& Lucca, N. (1988). Individualism and collectivism: Cross-cultural perspectives on self-ingroup relationships. Journal of Personality and Social Psychology, 54, 323-338.

Triandis, H. C., Leung, K., Villareal, M. J., \& Clack, F. I. (1985). Allocentric versus idiocentric tendencies: Convergent and discriminant validation. Journal of Research in Personality, 19(4), 395-415.

Tucker, J. S., Winkelman, D. K., Katz, J. N., \& Berman, B. L. (2006). Ambivalence over emotional expression and psychological well-being among rheumatoid arthritis patients and their spouses. Journal of Applied Social Psychology, 29, 271-290.

Uchino, B. N., Holt-Lunstad, J., Smith, T. W., \& Bloor, L. (2004). Heterogeneity in social networks: A comparison of different models linking relationships to psychological outcomes. Journal of Social and Clinical Psychology, 23(2), 123-139.

Uchino, B. N., Holt-Lunstad, J., Uno, D., Campo, R., \& Reblin, M. (2007). The social neuroscience of relationships. In E. Harmon-Jones \& P. Winkielman (Eds.), Social 
neuroscience: Integrating biological and psychological explanations of social behavior (pp. 474-487). New York: Guilford Press.

Uchino, B. N., Holt-Lunstad, J., Uno, D., \& Flinders, J. B. (2001). Heterogeneity in the social networks of young and older adults: Prediction of mental health and cardiovascular reactivity during acute stress. Journal of Behavioral Medicine, 24(4), 361-382.

Uchino, B. N., Smith, T. W., \& Berg, C. A. (2014). Spousal relationship quality and cardiovascular risk: Dyadic perceptions of relationship ambivalence are associated with coronary-artery calcification. Psychological Science, 25, 1037-1042.

Uhl-Bien, M. (2006). Relational leadership theory: Exploring the social processes of leadership and organizing. Leadership Quarterly, 17(6), 654-676.

Uhl-Bien, M., \& Maslyn, J. M. (2003). Reciprocity in manager-subordinate relationships: Components, configurations, and outcomes. Journal of Management, 29, 511-532.

Uysal, A., Lin, H. L., \& Knee, C. R. (2010). The role of need satisfaction in self-concealment and well-being. Personality and Social Psychology Bulletin, 36, 187-199.

Vadera, A. K., \& Pratt, M. G. (2013). Love, hate, ambivalence, or indifference? A conceptual examination of workplace crimes and organizational identification. Organization Science, 24(1), 172-188.

Vander Elst, T., Van den Broeck, A., De Witte, H., \& De Cuyper, N. (2012). The mediating role of frustration of psychological needs in the relationship between job insecurity and workrelated well-being. Work \& Stress, 26(3), 252-271.

Van den Broeck, A., Ferris, D. L., Chang, C. H., \& Rosen, C. C. (2016). A review of selfdetermination theory's basic psychological needs at work. Journal of Management, 42(5), 1195-1229. 
Van den Broeck, A., Vansteenkiste, M., De Witte, H., \& Lens, W. (2008). Explaining the relationships between job characteristics, burnout, and engagement: The role of basic psychological need satisfaction. Work \& Stress, 22(3), 277-294.

Van der Cammen, L., Hofmans, J., \& Theuns, P. (2014). The mediating role of affect in the relationship between need satisfaction and autonomous motivation. Journal of Occupational and Organizational Psychology, 87(1), 62-79.

Van Dierendonck, D., Stam, D., Boersma, P., De Windt, N., \& Alkema, J. (2014). Same difference? Exploring the differential mechanisms linking servant leadership and transformational leadership to follower outcomes. Leadership Quarterly, 25(3), 544-562.

Van Dyne, L., Vandewalle, D., Kostova, T., Latham, M. E., \& Cummings, L. L. (2000).

Collectivism, propensity to trust and self-esteem as predictors of organizational citizenship in a non-work setting. Journal of Organizational Behavior, 21(1), 3-23.

Van Harreveld, F., Nohlen, H. U., \& Schneider, I. K. (2015). The ABC of ambivalence:

Affective, behavioral, and cognitive consequences of attitudinal conflict. In J. Olson, \& M. Zanna (Eds.), Advances in experimental social psychology (Vol. 52, pp. 285-324). UK: Academic Press.

Van Harreveld, F., Rutjens, B., Rotteveel, M., Nordgren, L., \& Van der Pligt, J. (2009). Ambivalence and decisional conflict as a cause of psychological discomfort: Feeling tense before jumping off the fence. Journal of Experimental Social Psychology, 45, 167-173.

Van Harreveld, F., Rutjens, B. T., Schneider, I. K., Nohlen, H. U., \& Keskinis, K. (2014). In doubt and disorderly: Ambivalence promotes compensatory perceptions of order. Journal of Experimental Psychology: General, 143(4), 1666-1676. 
Van Knippenberg, D., Van Knippenberg, B., De Cremer, D., \& Hogg, M. A. (2004). Leadership, self, and identity: A review and research agenda. The Leadership Quarterly, 15(6), 825856.

Van Knippenberg, D., Van Knippenberg, B., De Cremer, D., \& Hogg, M. A. (2005). Research in leadership, self, and identity: A sample of the present and a glimpse of the future. Leadership Quarterly, 16, 495-499.

Vansteenkiste, M., Neyrinck, B., Niemiec, C. P., Soenens, B., De Witte, H., \& Van Den Broeck, A. (2007). On the relations among work value orientations, psychological need satisfaction, and job outcomes: A self-determination theory approach. Journal of Occupational and Organizational Psychology, 80, 251-277.

Van Vugt, M. (2006). Evolutionary origins of leadership and followership. Personality and Social Psychology Review, 10(4), 354-371.

Vecchio, R. P. (1993). The impact of differences in subordinate and supervisor age on attitudes and performance. Psychology and Aging, 8(1), 112-119.

Von Rueden, C., Gurven, M., Kaplan, H., \& Stieglitz, J. (2014). Leadership in an egalitarian society. Human Nature, 25, 538-566.

Wagner, J. A. (1995). Studies of individualism-collectivism: Effects of cooperation in groups. Academy of Management Journal, 38, 152-172.

Wagner, J.A., \& Moch, M.K. (1986). Individualism-collectivism: Concept and measure. Group and Organization Studies, 11, 280-304.

Walter, F., \& Scheibe, S. (2013). A literature review and emotion-based model of age and leadership: New directions for the trait approach. Leadership Quarterly, 24(6), 882-901. 
Warren, D. E., Dunfee, T. W., \& Li, N. (2004). Social exchange in China: The double-edged sword of guanxi. Journal of Business Ethics, 55(4), 353-370.

Wayne, J. H., Musisca, N., \& Fleeson, W. (2004). Considering the role of personality in the work-family experience: Relationships of the big five to work-family conflict and facilitation. Journal of Vocational Behavior, 64(1), 108-130.

Werbel, J. D., \& Lopes Henriques, P. (2009). Different views of trust and relational leadership: Supervisor and subordinate perspectives. Journal of Managerial Psychology, 24(8), 780796.

Webster, G. D., DeWall, C. N., Pond Jr, R. S., Deckman, T., Jonason, P. K., Le, B. M., Nichols, A. L., Schember, T. O., Crysel, L. C., Crosier, B. S., Smith, C. V., Paddock, E. L., Nezlek, J. B., Kirkpatrick, L. A., Bryan, A. D., \& Bator, R. (2014). The brief aggression questionnaire: Psychometric and behavioral evidence for an efficient measure of trait aggression. Aggressive behavior, 40(2), 120-139.

Webster, G. D., DeWall, C. N., Pond Jr, R. S., Deckman, T., Jonason, P. K., Le, B. M., Nichols, A. L., Schember, T. O., Crysel, L. C., Crosier, B. S., Smith, C. V., Paddock, E. L., Nezlek, J. B., Kirkpatrick, L. A., Bryan, A. D., \& Bator, R. (2015). The brief aggression questionnaire: Structure, validity, reliability, and generalizability. Journal of Personality Assessment, 97(6), 638-649.

Webster, D. M., \& Kruglanski, A. W. (1994). Individual differences in need for cognitive closure. Journal of Personality and Social Psychology, 67, 1049-1062.

Weiss, E. M., \& Maurer, T. J. (2004). Age discrimination in personnel decisions: A reexamination. Journal of Applied Social Psychology, 34(8), 1551-1562. 
Whiteman, M. C., Bedford, A., Grant, E., Fowkes, F. G. R. \& Deary, I. J. (2001). The five-factor model (NEO-FFI) and the Personality Deviance Scales-Revised (PDS-R): Going around in interpersonal circles. Personality and Individual Differences, 31, 259-267.

Williams, G. C., Halvari, H., Niemiec, C. P., Sørebø, Ø., Olafsen, A. H., \& Westbye, C. (2014). Managerial support for basic psychological needs, somatic symptom burden and workrelated correlates: A self-determination theory perspective. Work \& Stress, 28(4), 404-419.

Willson, A., Shuey, K., \& Elder, G. (2003). Ambivalence in the Relationship of Adult Children to Aging Parents and In-Laws. Journal of Marriage and Family, 65(4), 1055-1072.

Wilson, K., Sin, H. \& Conlon, D. (2010). What about the leader in Leader-Member Exchange? The impact of resource exchanges and substitutability on the leader. Academy of Management Review, 35, 358-372.

Witkower, Z., Tracy, J. L., Cheng, J. T., \& Henrich, J. (2019). Two Signals of Social Rank: Prestige and dominance are associated with distinct nonverbal displays. Journal of Personality and Social Psychology, Epub ahead of print available at https://www.ncbi.nlm.nih.gov/pubmed/31021104.

Wrenn, K. A., \& Maurer, T. J. (2004). Beliefs about older workers' learning and development behavior in relation to beliefs about malleability of skills, age-related decline, and control. Journal of Applied Social Psychology, 34(2), 223-242.

Wrzesniewski, A., Dutton, J. E., \& Debebe, G. (2003). Interpersonal sensemaking and the meaning of work. In Kramer, R. M., \& Staw, B. M. (Eds.), Research in Organizational Behavior. Vol. 25 (pp.93-135).

Yang, L. Q., Spector, P. E., Sanchez, J. I., Allen, T. D., Poelmans, S., Cooper, C. L., Lapierre, L. M., O'Driscoll, M. P., Abarca, N., Alexandrova, M., Antoniou, A. S., Beham, B., Brough, 
P., Çarikçi, I., Ferreiro, P., Fraile, G., Geurts, S., Kinnunen, U., Lu, C., Lu, L., MorenoVelázquez, I. F., Pagon, M., Pitariu, H., Salamatov, V., Siu, O., Shima., S., Schulmeyer, M. K., Tillemann, K., Widerszal-Bazyl, M. \& Woo, J. (2012). Individualism-collectivism as a moderator of the work demands-strains relationship: A cross-level and cross-national examination. Journal of International Business Studies, 43(4), 424-443.

Zhang, Y., Waldman, D. A., Han, Y. L., \& Li, X. B. (2015). Paradoxical leader behaviors in people management: Antecedents and consequences. Academy of Management Journal, $58(2), 538-566$.

Zhang, Z., Wang, M. O., \& Shi, J. (2012). Leader-follower congruence in proactive personality and work outcomes: The mediating role of leader-member exchange. Academy of Management Journal, 55(1), 111-130.

Zians, J. (2007). A comparison of trait anger and depression on several variables: Attribution style, dominance, submissiveness, "need for power," efficacy and dependency, Doctoral dissertation, Alliant International University, San Diego.

Zou, X., \& Ingram, P. (2013). The grand duality: Who sees competition within friendship, and how do they perform at work? Academy of Management Proceedings, 15730. 


\section{Figure 1: Antecedents of LMX Ambivalence}

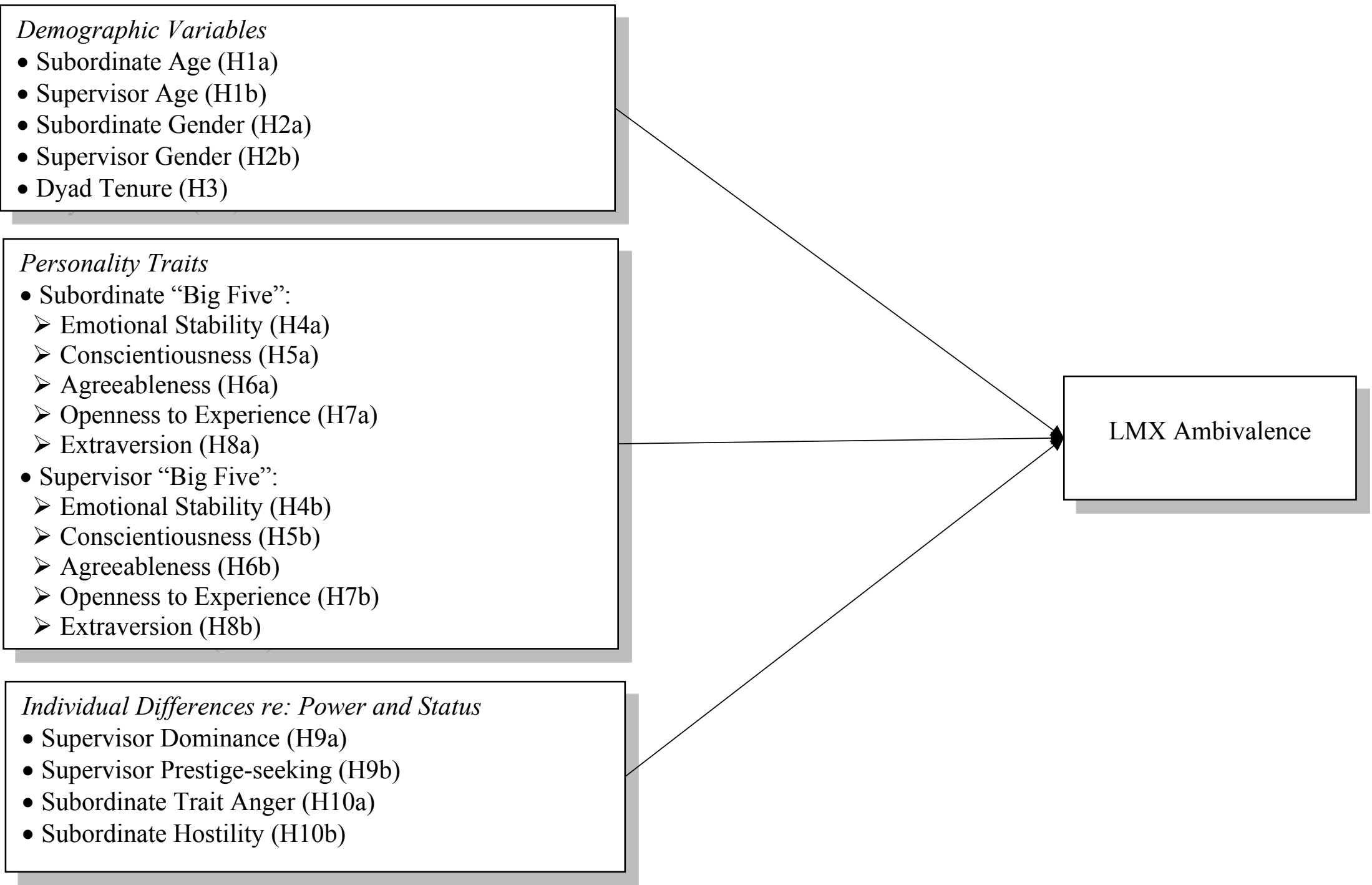


Figure 2: Moderated Mediation Model of the LMX Ambivalence - Work-related Well-being Relationship

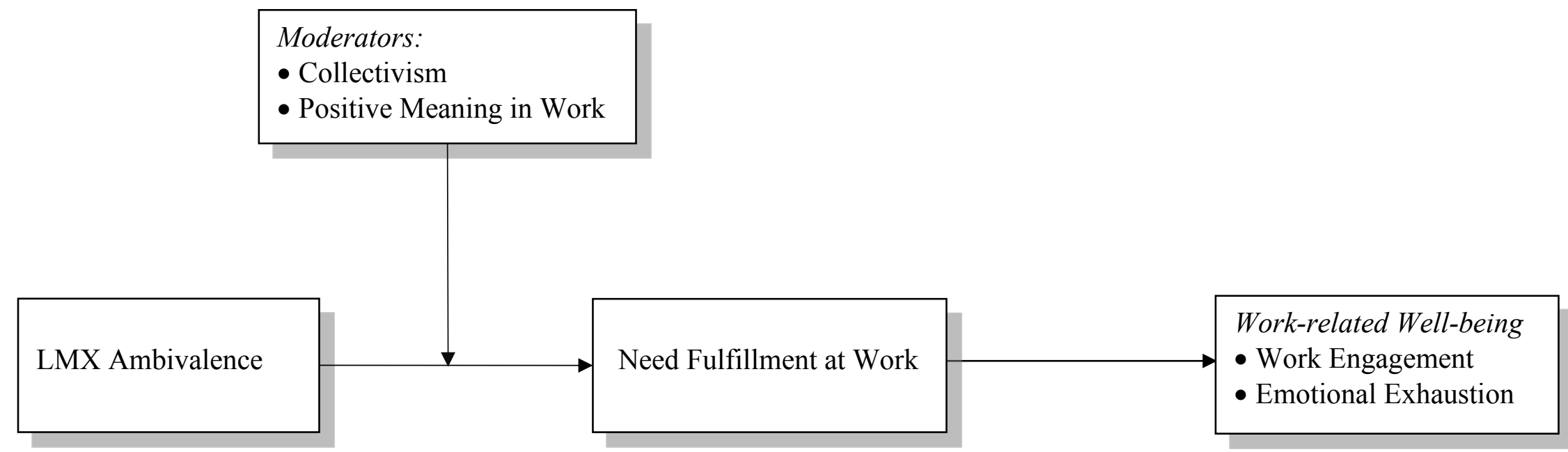


Figure 3: Moderating Role of Collectivism on Relationship between LMX Ambivalence and Need Fulfillment at Work

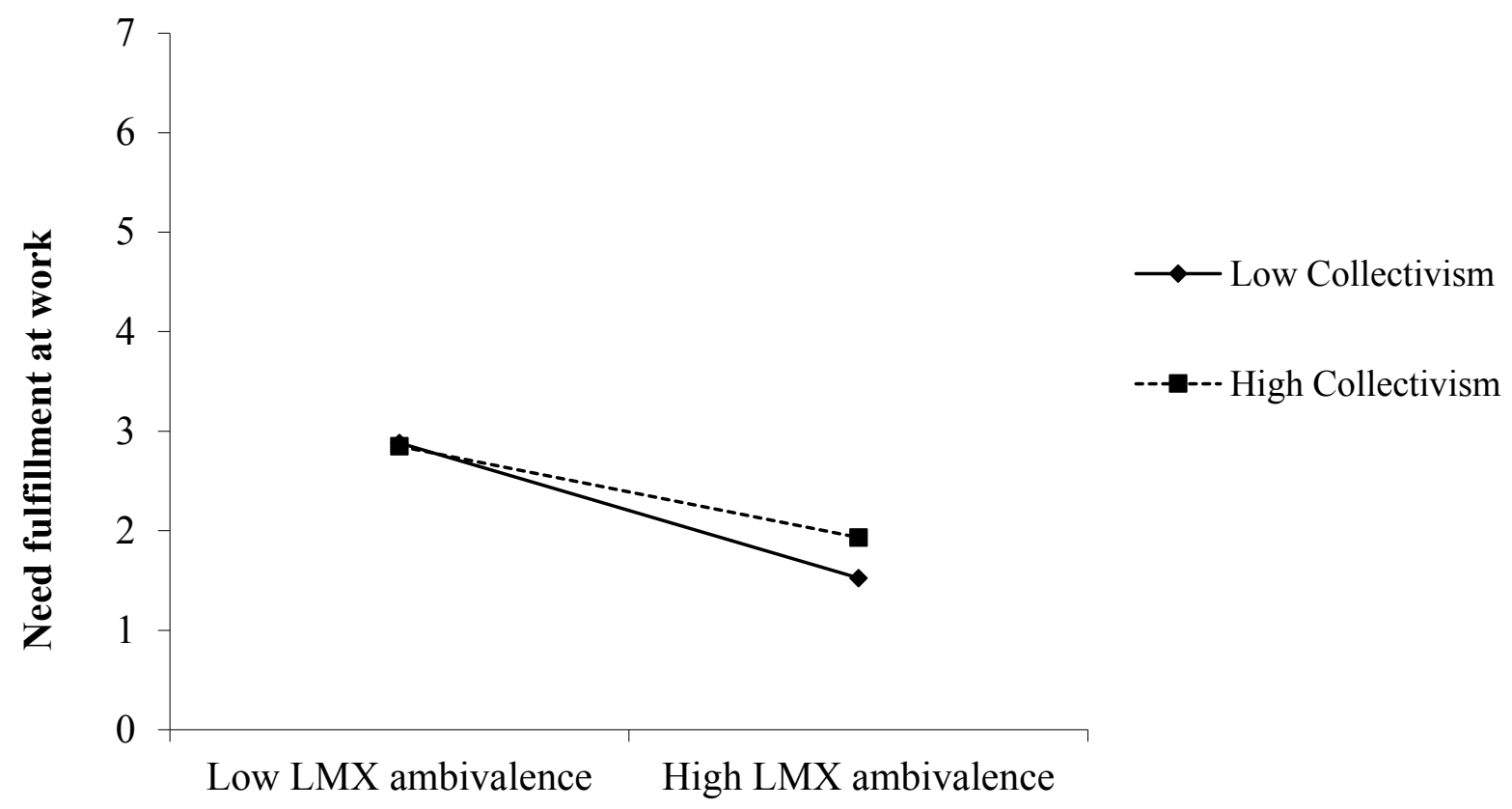


Figure 4: Moderating Role of Positive Meaning on Relationship between LMX Ambivalence and Need Fulfillment at Work

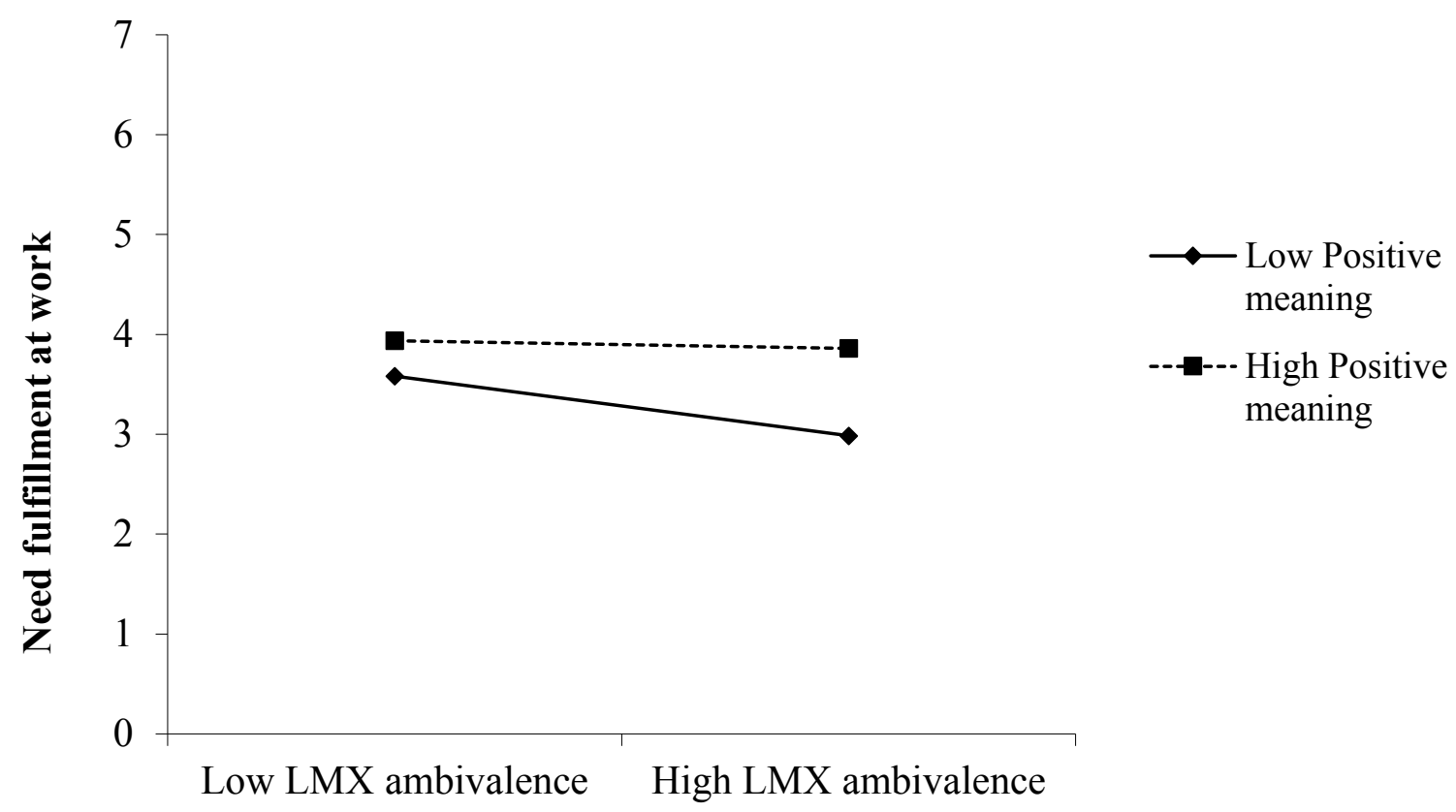


Table 1: Summary of Hypotheses

\begin{tabular}{|c|c|}
\hline Model 1 & Antecedents of LMX Ambivalence \\
\hline H1a & $\begin{array}{l}\text { Subordinates' age is positively associated with their experience of LMX } \\
\text { ambivalence. }\end{array}$ \\
\hline H1b & $\begin{array}{l}\text { Supervisors' age is positively associated with subordinates' experience } \\
\text { of LMX ambivalence. }\end{array}$ \\
\hline H2a & $\begin{array}{l}\text { Subordinates' gender is associated with the experience of LMX } \\
\text { ambivalence, such that female subordinates will report more LMX } \\
\text { ambivalence than men. }\end{array}$ \\
\hline H2b & $\begin{array}{l}\text { Supervisors' gender is associated with the experience of LMX } \\
\text { ambivalence, such that subordinates will report more LMX ambivalence } \\
\text { when they have a female supervisor. }\end{array}$ \\
\hline H3 & $\begin{array}{l}\text { Leader-follower dyad tenure is positively associated with subordinates' } \\
\text { experience of LMX ambivalence. }\end{array}$ \\
\hline H4a & $\begin{array}{l}\text { Subordinates' emotional stability is negatively associated with their } \\
\text { experience of LMX ambivalence. }\end{array}$ \\
\hline H4b & $\begin{array}{l}\text { Supervisors' emotional stability is negatively associated with } \\
\text { subordinates' experience of LMX ambivalence. }\end{array}$ \\
\hline H5a & $\begin{array}{l}\text { Subordinates' conscientiousness is negatively associated with their } \\
\text { experience of LMX ambivalence. }\end{array}$ \\
\hline H5b & $\begin{array}{l}\text { Supervisors' conscientiousness is negatively associated with } \\
\text { subordinates' experience of LMX ambivalence. }\end{array}$ \\
\hline H6a & $\begin{array}{l}\text { Subordinates' agreeableness is negatively associated with their } \\
\text { experience of LMX ambivalence. }\end{array}$ \\
\hline H6b & $\begin{array}{l}\text { Supervisors' agreeableness is negatively associated with subordinates' } \\
\text { experience of LMX ambivalence. }\end{array}$ \\
\hline H7a & $\begin{array}{l}\text { Subordinates' openness to experience is positively associated with their } \\
\text { experience of LMX ambivalence. }\end{array}$ \\
\hline H7b & $\begin{array}{l}\text { Supervisors' openness to experience is positively associated with } \\
\text { subordinates' experience of LMX ambivalence. }\end{array}$ \\
\hline H8a & $\begin{array}{l}\text { Subordinates' extraversion is positively associated with their experience } \\
\text { of LMX ambivalence. }\end{array}$ \\
\hline H8b & $\begin{array}{l}\text { Supervisors' extraversion is positively associated with subordinates' } \\
\text { experience of LMX ambivalence. }\end{array}$ \\
\hline H9a & $\begin{array}{l}\text { Supervisors' dominance is positively associated with subordinate's } \\
\text { experience of LMX ambivalence. }\end{array}$ \\
\hline
\end{tabular}




\begin{tabular}{|c|c|}
\hline H9b & $\begin{array}{l}\text { Supervisors' prestige-seeking is negatively associated with subordinates' } \\
\text { experience of LMX ambivalence. }\end{array}$ \\
\hline H10a & $\begin{array}{l}\text { Subordinates' trait anger is positively associated with their experience of } \\
\text { LMX ambivalence. }\end{array}$ \\
\hline H10b & $\begin{array}{l}\text { Subordinates' hostility is positively associated with their experience of } \\
\text { LMX ambivalence. }\end{array}$ \\
\hline Model 2 & LMX Ambivalence and Work-Related Well-being \\
\hline H11a & $\begin{array}{l}\text { LMX ambivalence is negatively related to subordinates' work } \\
\text { engagement. }\end{array}$ \\
\hline H11b & $\begin{array}{l}\text { LMX ambivalence is positively related to subordinates' emotional } \\
\text { exhaustion. }\end{array}$ \\
\hline H12 & $\begin{array}{l}\text { LMX ambivalence is negatively associated with basic psychological } \\
\text { need fulfillment at work. }\end{array}$ \\
\hline H13a & $\begin{array}{l}\text { Need fulfillment at work mediates the relationship between LMX } \\
\text { ambivalence and work engagement. }\end{array}$ \\
\hline H13b & $\begin{array}{l}\text { Need fulfillment at work mediates the relationship between LMX } \\
\text { ambivalence and emotional exhaustion. }\end{array}$ \\
\hline H14 & $\begin{array}{l}\text { Collectivism moderates the indirect effect of LMX ambivalence on work } \\
\text { engagement through need fulfillment at work such that the mediated } \\
\text { effect will be stronger for subordinates with low rather than high } \\
\text { collectivism. }\end{array}$ \\
\hline H15 & $\begin{array}{l}\text { Collectivism moderates the indirect effect of LMX ambivalence on } \\
\text { emotional exhaustion through need fulfillment at work such that the } \\
\text { mediated effect will be stronger for subordinates with low rather than } \\
\text { high collectivism. }\end{array}$ \\
\hline H16 & $\begin{array}{l}\text { Positive meaning in work moderates the indirect effect of LMX } \\
\text { ambivalence on work engagement through need fulfillment at work such } \\
\text { that the mediated effect will be stronger for subordinates with less } \\
\text { positive meaning in their work. }\end{array}$ \\
\hline H17 & $\begin{array}{l}\text { Positive meaning in work moderates the indirect effect of LMX } \\
\text { ambivalence on emotional exhaustion through need fulfillment at work } \\
\text { such that the mediated effect will be stronger for subordinates with less } \\
\text { positive meaning in their work. }\end{array}$ \\
\hline
\end{tabular}


Table 2: Confirmatory Factor Analysis on Subordinate Personality Variables

\begin{tabular}{l|c|c|c|c|c|c}
\hline Model & $\mathrm{d} f$ & $\chi^{2}$ & CFI & TLI & RMSEA & AIC \\
\hline One-factor model & 104 & 581.13 & .51 & .37 & .13 & 677.13 \\
\hline Three-factor model & 101 & 442.15 & .65 & .53 & .11 & 544.15 \\
\hline Six-factor model & 89 & 270.13 & .82 & .72 & .09 & 396.13 \\
\hline Seven-factor model & 83 & 189.24 & .89 & .82 & .07 & 327.24 \\
\hline
\end{tabular}

Note: One-factor model combines subordinate Big Five personality traits, trait anger, and hostility.

Three-factor model combines subordinate Big Five personality traits.

Six-factor model combines subordinate trait anger and hostility.

Table 3: Confirmatory Factor Analysis on Supervisor Personality Variables

\begin{tabular}{l|c|c|c|c|c|c}
\hline Model & $\mathrm{d} f$ & $\chi^{2}$ & CFI & TLI & RMSEA & AIC \\
\hline One-factor model & 135 & 745.36 & .689 & .61 & .13 & 853.36 \\
\hline Three-factor model & 132 & 332.97 & .898 & .87 & .07 & 446.97 \\
\hline Six-factor model & 120 & 496.46 & .808 & .73 & .11 & 634.46 \\
\hline Seven-factor model & 114 & 213.67 & .949 & .92 & .06 & 363.67 \\
\hline
\end{tabular}

Note: One-factor model combines supervisor Big Five personality traits, dominance, and prestige.

Three-factor model combines supervisor Big Five personality traits.

Six-factor model combines supervisor dominance and prestige. 
Table 4: Confirmatory Factor Analysis on LMX Quality and LMX Ambivalence

\begin{tabular}{l|c|c|c|c|c|c}
\hline Model & $\mathrm{d} f$ & $\chi^{2}$ & CFI & TLI & RMSEA & AIC \\
\hline One-factor model & 65 & 903.82 & .63 & .48 & .21 & 981.82 \\
\hline Two-factor model & 50 & 132.73 & .96 & .94 & .08 & 212.72 \\
\hline
\end{tabular}

Note: One-factor model combines subordinate perceived LMX quality and LMX ambivalence.

Table 5: Confirmatory Factor Analysis of Perceptual Variables in the Moderated Mediation Model

\begin{tabular}{l|c|c|c|c|c|c}
\hline Model & $\mathrm{d} f$ & $\chi^{2}$ & CFI & TLI & RMSEA & AIC \\
\hline Five-factor model & 158 & 357.86 & .91 & .89 & .08 & 501.86 \\
\hline Four-factor model & 163 & 555.67 & .82 & .79 & .10 & 689.67 \\
\hline One-factor model & 170 & 1060.65 & .58 & .8 & .15 & 1180.65 \\
\hline
\end{tabular}

Note: One-factor model combines collectivism, positive meaning in work, need fulfillment at work, emotional exhaustion, and work engagement.

Four-factor model combines emotional exhaustion, and work engagement. 
Table 6: Means, Standard Deviations and Zero-order Correlations of the Variables in Model 1

\begin{tabular}{|c|c|c|c|c|c|c|c|c|c|c|c|c|c|c|c|c|c|c|c|c|c|}
\hline & $\mathrm{M}$ & $\mathrm{SD}$ & 1 & 2 & 3 & 4 & 5 & 6 & 7 & 8 & 9 & 10 & 11 & 12 & 13 & 14 & 15 & 16 & 17 & 18 & 19 \\
\hline 1. Age $(\mathrm{E})$ & 43.78 & 8.51 & - & & & & & & & & & & & & & & & & & & \\
\hline 2. Age (S) & 47.42 & 6.03 & .16 & - & & & & & & & & & & & & & & & & & \\
\hline 3. Gender $(\mathrm{E})^{\mathrm{a}}$ & 1.26 & .44 & $.13^{*}$ & .10 & - & & & & & & & & & & & & & & & & \\
\hline 4. Gender $(\mathrm{S})^{\mathrm{a}}$ & 1.08 & .27 & .03 & .02 & -.18 & - & & & & & & & & & & & & & & & \\
\hline 5. Dyad Tenure & 16.78 & 16.93 & $.20^{* *}$ & .11 & .05 & -.10 & - & & & & & & & & & & & & & & \\
\hline 6. ES (E) & 4.01 & .88 & .04 & .26 & -.07 & -.09 & $-.12^{*}$ & - & & & & & & & & & & & & & \\
\hline 7. ES (S) & 4.12 & .79 & .17 & .24 & .07 & -.04 & .03 & .01 & - & & & & & & & & & & & & \\
\hline 8. Cons. (E) & 4.43 & .71 & .00 & .13 & .00 & -.16 & .05 & $.36^{* *}$ & .09 & - & & & & & & & & & & & \\
\hline 9. Cons. (S) & 4.34 & .73 & .02 & -.11 & .00 & .10 & -.11 & .02 & $.39^{* *}$ & .04 & - & & & & & & & & & & \\
\hline 10. Agr. (E) & 3.58 & .90 & $.20^{* *}$ & .17 & $.21^{* *}$ & .07 & .06 & $.22^{* *}$ & .11 & $.17^{* *}$ & -.04 & - & & & & & & & & & \\
\hline 11. Agr. (S) & 3.80 & .77 & .12 & $.37^{* *}$ & .12 & .02 & -.01 & .04 & $.41^{* *}$ & .10 & $.22^{*}$ & $.18^{*}$ & - & & & & & & & & \\
\hline 12. Open. (E) & 3.86 & .75 & .07 & .05 & -.01 & -.07 & .09 & .12 & .15 & $.21^{* *}$ & .03 & $.20^{* *}$ & .11 & - & & & & & & & \\
\hline 13. Open. (S) & 4.07 & .72 & -.01 & .09 & -.02 & .21 & -.00 & .05 & .11 & .04 & $.30^{* *}$ & .06 & $.27^{* *}$ & .09 & - & & & & & & \\
\hline 14. Ext. (E) & 3.29 & 1.07 & .10 & .04 & $.14^{*}$ & .09 & -.03 & .05 & .14 & .10 & .08 & .08 & .02 & $.32^{* *}$ & .08 & - & & & & & \\
\hline 15. Ext. (S) & 3.52 & .98 & .07 & .05 & .01 & $.28^{*}$ & -.07 & .15 & .02 & -.02 & .17 & .07 & .08 & -.09 & $.29^{* *}$ & -.14 & - & & & & \\
\hline 16. Dominance (S) & 3.73 & 1.71 & -.02 & .01 & -.05 & .12 & $.13^{*}$ & $-.13^{*}$ & -.11 & -.08 & .09 & -.09 & -.09 & .03 & .08 & -.08 & .04 & - & & & \\
\hline 17. Prestige $(\mathrm{S})$ & 4.57 & 1.45 & -.01 & -.10 & -.03 & -.07 & -.04 & $.13^{*}$ & -.00 & .09 & -.07 & .08 & -.04 & .02 & -.04 & .06 & -.01 & $-.63^{* *}$ & - & & \\
\hline 18. Anger (E) & 1.93 & .85 & .03 & -.11 & -.03 & .15 & .11 & $-.47^{* *}$ & .13 & -.11 & .10 & $-.29^{* *}$ & -.09 & -.00 & -.10 & .07 & -.03 & .10 & -.04 & - & \\
\hline 19. Hostility (E) & 2.46 & .92 & -.06 & $-.30^{*}$ & -.03 & .11 & .03 & $-.29^{* *}$ & -.06 & $-.18^{* *}$ & .07 & $-.23^{* *}$ & -.08 & -.04 & .03 & -.06 & .13 & $.27^{* *}$ & $-.16^{* *}$ & $.38^{* *}$ & - \\
\hline 20. LMX Amb(T2) & 3.08 & 1.45 & .07 & .07 & $.14^{*}$ & .14 & .07 & $-.16^{*}$ & -.02 & -.11 & .04 & .01 & -.05 & .00 & $.19^{*}$ & .03 & .18 & $.35^{* *}$ & $-.34^{* *}$ & $.17^{*}$ & $.21 * *$ \\
\hline
\end{tabular}


Table 7: Results of Multiple Regression Analysis of Subordinate Variables on LMX Ambivalence

\begin{tabular}{lccc}
\hline Variables & \multicolumn{3}{c}{ LMX Ambivalence } \\
\cline { 2 - 4 } & Model 1 & Model 2 & Model 3
\end{tabular}

Step 1

Subordinate Gender ${ }^{\text {a }}$

Subordinate Age

Dyad Tenure
.11

.04

.05
.10

.04

.04
.10

.04

.03

Step 2

Subordinate Extraversion

$$
.02
$$

Subordinate Agreeableness

.01

.05

Subordinate Conscientiousness

$-.06$

Subordinate Openness

.02

.01

Subordinate Emotional stability

$-.12$

$-.06$

Step 3

Subordinate Trait Anger

.07

Subordinate Hostility

$.16^{*}$

F

1.83

1.45

$2.05^{*}$

Adjusted $R^{2}$

.01

.01

.04

$\Delta R^{2}$

.01

.00

.03 
Table 8: Results of Multiple Regression Analysis of Supervisor Variables on LMX Ambivalence

\begin{tabular}{|c|c|c|c|}
\hline \multirow[t]{2}{*}{ Variables } & \multicolumn{3}{|c|}{ LMX Ambivalence } \\
\hline & Model 1 & Model 2 & Model 3 \\
\hline \multicolumn{4}{|l|}{ Step 1} \\
\hline Supervisor Gender ${ }^{\text {a }}$ & .05 & .02 & .01 \\
\hline Supervisor Age & .02 & .03 & .01 \\
\hline Dyad Tenure & .06 & .05 & .06 \\
\hline \multicolumn{4}{|l|}{ Step 2} \\
\hline Supervisor Extraversion & & .09 & .09 \\
\hline Supervisor Agreeableness & & -.07 & -.06 \\
\hline Supervisor Conscientiousness & & -.01 & -.04 \\
\hline Supervisor Openness & & .11 & .10 \\
\hline Supervisor Emotional stability & & .01 & .03 \\
\hline \multicolumn{4}{|l|}{ Step 3} \\
\hline Supervisor Dominance & & & $.19^{* *}$ \\
\hline Supervisor Prestige-seeking & & & $-.17^{*}$ \\
\hline $\mathrm{F}$ & .63 & 1.07 & 4.36 \\
\hline Adjusted $R^{2}$ & .00 & .00 & .11 \\
\hline$\Delta R^{2}$ & .00 & .00 & .11 \\
\hline
\end{tabular}


Table 9: Means, Standard Deviations and Zero-order Correlations of the Variables in Model 2

\begin{tabular}{|c|c|c|c|c|c|c|c|c|c|c|c|c|}
\hline & $\mathrm{M}$ & SD & 1 & 2 & 3 & 4 & 5 & 6 & 7 & 8 & 9 & 10 \\
\hline 1. Age & 43.78 & 8.51 & - & & & & & & & & & \\
\hline 2. Gender ${ }^{a}$ & 1.26 & .44 & $.13^{*}$ & - & & & & & & & & \\
\hline 3. Education & 4.20 & 1.16 & .09 & -.00 & 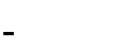 & & & & & & & \\
\hline 4. Job Tenure & 39.32 & 42.41 & $.18^{* *}$ & -.04 & .02 & - & & & & & & \\
\hline 5. LMX & 3.60 & .79 & .02 & -.03 & -.01 & -.07 & - & & & & & \\
\hline 6. LMX Amb. & 3.26 & 1.37 & -.02 & .09 & .05 & .01 & $-.39^{* *}$ & - & & & & \\
\hline 7. Collectivism & 3.47 & .83 & $.15^{*}$ & .05 & .05 & -.03 & .05 & -.05 & - & & & \\
\hline 8. Meaning & 3.79 & .89 & .07 & .01 & -.00 & -.10 & $.32^{* *}$ & -.10 & $.20^{* *}$ & - & & \\
\hline 9. Need Fulfillment & 5.09 & .88 & .09 & .09 & -.07 & -.06 & $.55^{* *}$ & $-.36^{* *}$ & $.17^{* *}$ & $.46^{* *}$ & - & \\
\hline 10. WE & 4.44 & 1.12 & .07 & .04 & -.03 & -.11 & $.40^{* *}$ & $-.22^{* *}$ & $.16^{*}$ & $.62^{* *}$ & $.51^{* *}$ & - \\
\hline 11. EE & 3.95 & 1.27 & -.03 & -.02 & .00 & .05 & $-.29^{* *}$ & $.17^{*}$ & -.06 & $-.34^{* *}$ & $-.52^{* *}$ & $-.48^{* *}$ \\
\hline
\end{tabular}


Table 10: Results of LMX Ambivalence -Work Engagement Mediation Model

\begin{tabular}{|c|c|c|c|c|c|c|}
\hline \multirow[t]{3}{*}{ Variables } & \multicolumn{6}{|c|}{ Mediation Model } \\
\hline & \multicolumn{3}{|c|}{ Need Fulfillment (M) X $\rightarrow \mathrm{M}$} & \multicolumn{3}{|c|}{ Work Engagement $(\mathrm{Y}) \mathrm{M} \rightarrow \mathrm{Y}$} \\
\hline & Coefficient $b$ & $S E$ & $t$ & Coefficient $b$ & $S E$ & $t$ \\
\hline $\begin{array}{l}\text { Intercept } \\
\text { Controls }\end{array}$ & 3.06 & .47 & $6.49^{* * *}$ & .49 & .67 & .74 \\
\hline Age & .01 & .01 & 1.61 & .00 & .01 & .40 \\
\hline Gender $^{\mathrm{a}}$ & .17 & .12 & 1.45 & .01 & .15 & .07 \\
\hline Education & -.05 & .04 & -1.08 & .04 & .06 & .62 \\
\hline Job Tenure & -.00 & .00 & -.79 & -.00 & .00 & -.21 \\
\hline $\begin{array}{l}\mathrm{LMX} \\
X\end{array}$ & .53 & .07 & $7.32^{* * *}$ & .19 & .10 & 1.78 \\
\hline $\begin{array}{l}\mathrm{LMX} \\
\text { Ambivalence } \\
M\end{array}$ & -.10 & .04 & $-2.46^{*}$ & .01 & .05 & .13 \\
\hline $\begin{array}{l}\text { Need } \\
\text { Fulfillment }\end{array}$ & & & & .59 & .09 & $6.42^{* * *}$ \\
\hline$R^{2}$ & $.33^{* * *}$ & & & $.30^{* * *}$ & & \\
\hline
\end{tabular}

Note: ${ }^{*} p<.05 ;{ }^{* *} p<.01 ;{ }^{* * *} p<.001$.

${ }^{\mathrm{a}} 1=$ male, $2=$ female; $\mathrm{N}=214$ 
Table 11: Results of Moderated Mediation Model: LMX Ambivalence $\times$ Collectivism and Positive Meaning on Work Engagement

\begin{tabular}{|c|c|c|c|c|c|c|}
\hline \multirow[t]{3}{*}{ Variables } & \multicolumn{6}{|c|}{ Moderated Mediation } \\
\hline & \multicolumn{3}{|c|}{ Need satisfaction $(\mathrm{M}) \mathrm{X} \rightarrow \mathrm{M}$} & \multicolumn{3}{|c|}{ Work Engagement $(\mathrm{Y}) \mathrm{M} \rightarrow \mathrm{Y}$} \\
\hline & Coefficient $b$ & $S E$ & $t$ & Coefficient $b$ & $S E$ & $t$ \\
\hline $\begin{array}{l}\text { Intercept } \\
\text { Controls }\end{array}$ & 4.36 & .76 & $5.71^{* * *}$ & .49 & .67 & .74 \\
\hline Age & .01 & .01 & .88 & .00 & .01 & .40 \\
\hline Gender $^{\mathrm{a}}$ & .15 & .11 & 1.42 & .01 & .15 & .06 \\
\hline Education & -.07 & .04 & -1.75 & .04 & .06 & .62 \\
\hline Job Tenure & -.00 & .00 & -.25 & -.00 & .00 & -.21 \\
\hline $\begin{array}{l}\mathrm{LMX} \\
X\end{array}$ & .40 & .07 & $5.80^{* * *}$ & .19 & .10 & 1.78 \\
\hline $\begin{array}{l}\mathrm{LMX} \\
\text { Ambivalence } \\
W\end{array}$ & -.75 & .19 & $-4.00^{* * *}$ & .00 & .05 & .13 \\
\hline Collectivism & -.20 & .15 & -1.33 & & & \\
\hline $\begin{array}{l}\text { Positive } \\
\text { Meaning } \\
X \times W\end{array}$ & .06 & .12 & .49 & & & \\
\hline $\begin{array}{l}\text { LMX } \\
\text { Ambivalence } \times \\
\text { Collectivism }\end{array}$ & .10 & .05 & $2.03^{*}$ & & & \\
\hline $\begin{array}{l}\text { LMX } \\
\text { Ambivalence } \times \\
\text { Positive } \\
\text { Meaning } \\
M\end{array}$ & .08 & .04 & $2.05^{*}$ & & & \\
\hline $\begin{array}{l}\text { Need satisfaction } \\
R^{2}\end{array}$ & .47 & & & $\begin{array}{l}.59 \\
.30\end{array}$ & .09 & $6.42^{* * *}$ \\
\hline $\begin{array}{l}\text { Note: }{ }^{*} p<.05 ;^{* *} \\
\text { a } 1=\text { male, } 2=\text { fema } \\
\mathrm{N}=205\end{array}$ & $01 ;{ }^{* * *} p<.0$ & & & & & \\
\hline
\end{tabular}


Table 12: Results of Moderated Mediation Analyses for Work Engagement

Conditional Indirect Effect

LMX ambivalence $(\mathrm{X}) \rightarrow$ Need Fulfillment at work $(\mathrm{M}) \rightarrow$ Work

Engagement (Y)

\begin{tabular}{lcccc}
\hline & Coefficient & SE & LLCI & UCLI \\
\hline Collectivism (PM at & & & & \\
mean) & -.10 & .04 & -.18 & -.04 \\
-1 SD & -.05 & .03 & -.11 & .00 \\
Mean & -.01 & .04 & -.10 & .06 \\
+1 SD & & & & \\
& & & & \\
Positive Meaning & & .04 & -.16 & -.02 \\
(Collectivism at mean) & -.08 & .03 & -.11 & .00 \\
-1 SD & -.05 & .04 & -.09 & .05 \\
Mean & -.01 & & & \\
+1 SD & & & & \\
\hline Note: bootstrapping=10,000 & & & & \\
\hline
\end{tabular}


Table 13: Results of LMX Ambivalence -Emotional Exhaustion Mediation Model

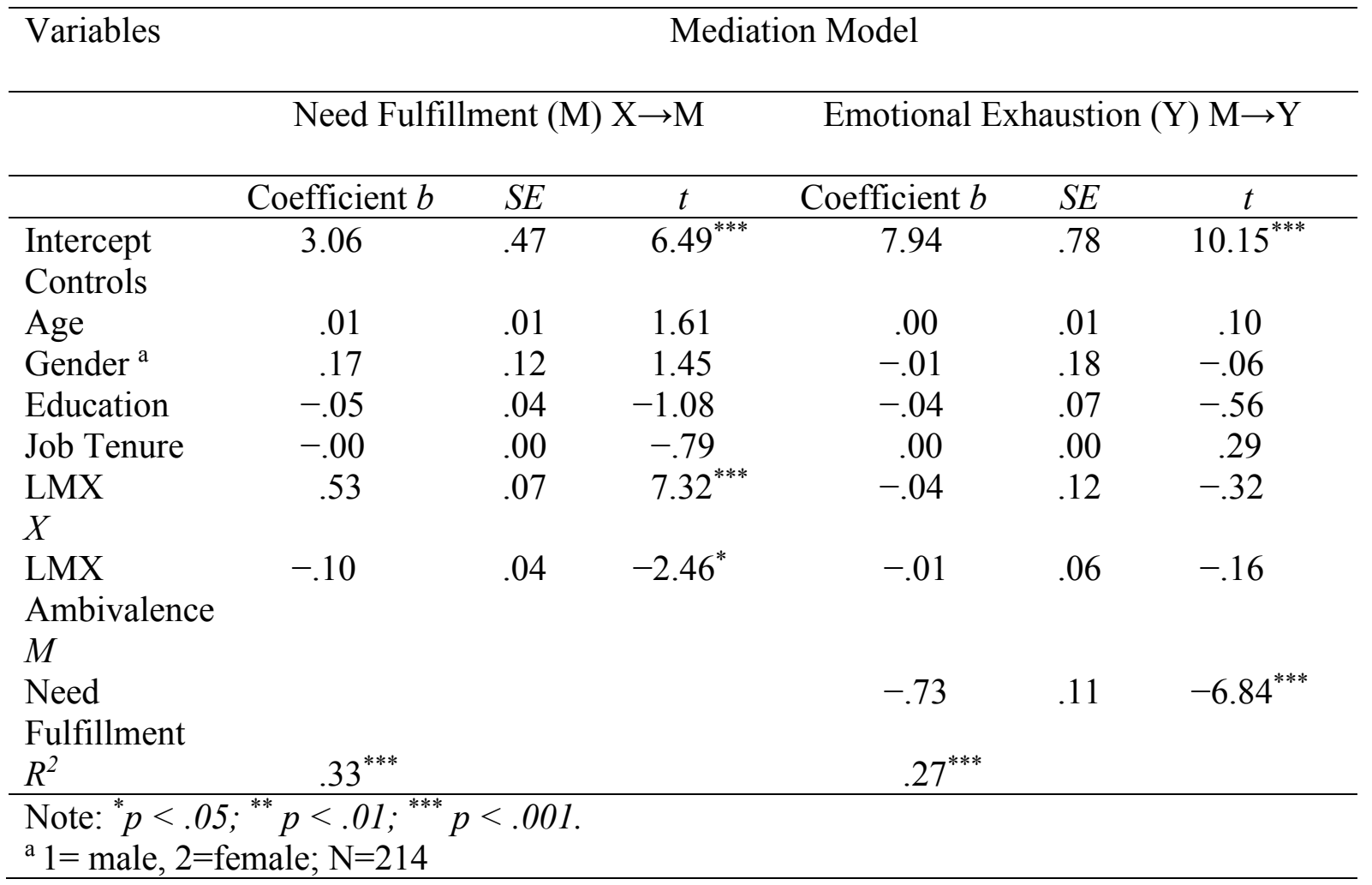


Table 14: Results of Moderated Mediation Model: LMX Ambivalence $\times$ Collectivism and Positive Meaning on Emotional Exhaustion

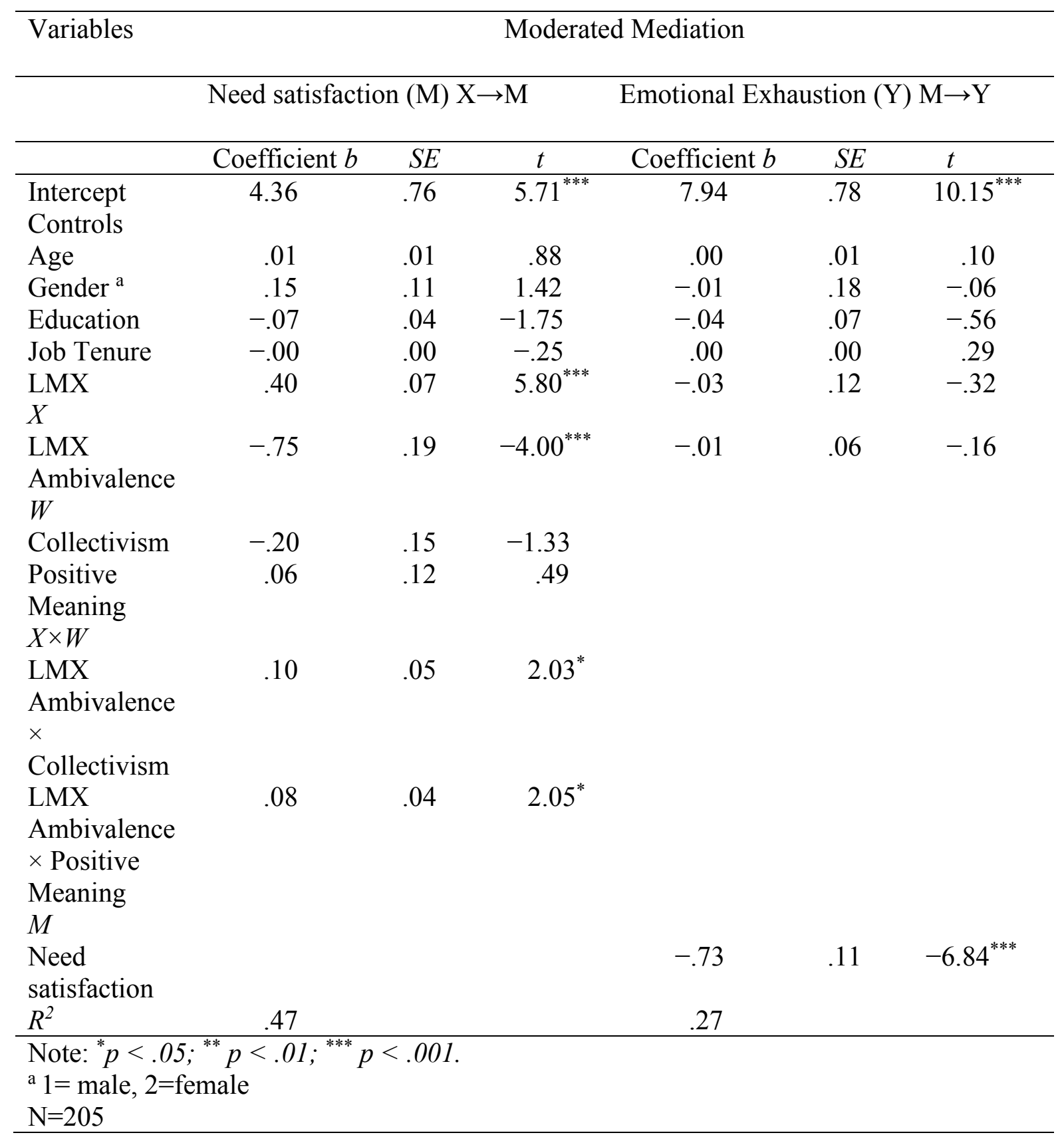


Table 15: Results of Moderated Mediation Analyses on Emotional Exhaustion

Conditional Indirect Effect

LMX ambivalence $(\mathrm{X}) \rightarrow$ Need fulfillment at work $(\mathrm{M}) \rightarrow$

Emotional exhaustion (Y)

\begin{tabular}{lcccc}
\hline & Coefficient & SE & LLCI & UCLI \\
\hline Collectivism (PM at & & & & \\
mean) & & & & \\
-1 SD & .13 & .04 & .05 & .22 \\
Mean & .06 & .03 & -.00 & .13 \\
$+1 \mathrm{SD}$ & .01 & .05 & -.08 & .11 \\
& & & & \\
Positive Meaning & & & & \\
(Collectivism at mean) & & & & .19 \\
-1 SD & .10 & .04 & .03 & .13 \\
Mean & .06 & .03 & -.00 & .11 \\
+1 SD & .01 & .04 & -.07 & \\
\hline Note: bootstrapping=10,000 & & & & \\
\hline
\end{tabular}




\section{APPENDIX: SCALE ITEMS}

\section{LMX}

1. The way my supervisor sees it, the importance of my job to his/her performance is: (5-point scale: $1=$ slight-it has little effect on his/her performance; $5=$ very great-it critically affects his/her performance).

2. The way my supervisor sees me, he/she would probably say that my ability to do my job well is: (5-point scale: 1 = poor; $5=$ exceptional).

3 . My supervisor would probably say that my work goals and his/her are: $(5$-point scale: $1=$ opposite; 5 = the same).

4. I feel that my work goals and those of my supervisor are: $(5$-point scale: $1=$ opposite; $5=$ the same).

5. This is how I feel about the way my supervisor and I understand each other: (5-point scale: $1=$ very dissatisfied; 5 = very satisfied).

6. This is how I feel about the way my supervisor provides help on hard problems: (5-point scale: $1=$ very dissatisfied; $5=$ very satisfied).

\section{LMX ambivalence}

1. I have conflicting thoughts: sometimes I think that my working relationship with my supervisor is very good, while at other times I don't.

2. I have conflicting thoughts: sometimes I think my supervisor understands my problems and needs, while at other times I don't.

3. I have conflicting thoughts: sometimes I think my supervisor would use his/her power to help to solve problems in my work, while at other times I don't.

4. I have conflicting thoughts: sometimes I think I know where I stand with my supervisor, while at other times I don't.

5. I have conflicting thoughts: sometimes I think that my supervisor would "bail me out" at his/her expense, while at other times I don't.

6. I have conflicting thoughts: sometimes I think my supervisor recognizes my potential, while at other times I don't.

7. I have conflicting thoughts: sometimes I think that I would defend and justify my supervisor's decisions if he/she were not present to do so, while at other times I don't.

(7-point scale: $1=$ Strongly Disagree; $7=$ Strongly Agree)

\section{"Big Five"}

I see myself as someone who is...

1. Extraverted, enthusiastic

2. Critical, quarrelsome (R)

3. Dependable, self-disciplined 
4. Anxious, easily upset (R)

5. Open to new experiences, complex

6. Reserved, quiet (R)

7. Sympathetic, warm

8. Disorganized, careless (R)

9. Calm, emotionally stable

10. Conventional, uncreative $(\mathrm{R})$

(5-point scale: 1 = Strongly Disagree; 5= Strongly Agree)

\section{Dominance of supervisor}

1. My supervisor enjoys having control over other members of the group.

2. My supervisor often tries to get his/her own way regardless of what others in the group may want.

3. My supervisor is willing to use aggressive tactics to get his/her way.

4. My supervisor tries to control others rather than permit them to control him/her.

(7-point scale: $1=$ Not at All; $7=$ Very Much)

\section{Prestige of supervisor}

1. Members of my group respect and admire my supervisor.

2. Members of my group always expect my supervisor to be successful.

3. Members of my group do not value my supervisor's opinion. (R)

4. My supervisor's unique talents and abilities are recognized by others in the group.

(7-point scale: $1=$ Not at All; $7=$ Very Much)

\section{Trait anger}

1. I am an even-tempered person. (R)

2. Sometimes I fly off the handle for no good reason.

3. I have trouble controlling my temper.

(5-point scale: 1 = Strongly Disagree; 5= Strongly Agree)

\section{Trait hostility}

1. Other people always seem to get the breaks.

2. I sometimes feel that people are laughing at me behind my back.

3. When people are especially nice, I wonder what they want. 
(5-point scale: $1=$ Strongly Disagree; $5=$ Strongly Agree)

\section{Need fulfillment at work}

1. I feel like I can provide a lot of input into deciding how my job gets done.

2. I really like the people I work with.

3. I do not feel very competent when I am at work. (R)

4. People at work tell me I am good at what I do.

5. I feel pressured at work. (R)

6. I get along with people at work.

(7-point scale ranging: $1=$ Strongly Disagree; $7=$ Strongly Agree)

\section{Collectivism}

1. Only those who depend on themselves get ahead in life. (R)

2. One should live one's life independent of others as much as possible. (R)

3 . Working with a group is better than working alone.

4. In society, people are born into extended families or clans who protect them in shared necessity for loyalty.

(5-point scale: 1 = Strongly Disagree; $5=$ Strongly Agree)

\section{Positive meaning in work}

1. I have found a meaningful career.

2. I understand how my work contributes to my life's meaning.

3. I have a good sense of what makes my job meaningful.

4. I have discovered work that has a satisfying purpose.

(5-point scale: $1=$ Strongly Disagree; $5=$ Strongly Agree)

\section{Work engagement}

1. At my work, I feel that I am bursting with energy.

2. I am enthusiastic about my job.

3. I am immersed in my work.

(7-point scale: $1=$ Never; $7=$ Always $)$ 


\section{Emotional exhaustion}

1. I feel burned out from my work.

2. I feel tired when I get up in the morning and have to face another day on the job.

3. Working all day is really a strain for me.

(7-point scale: 1 = Never; 7 = Always)

Note: "R" = reverse-scored items 